\title{
Site Suitability and Hazard Assessment Guide for Small Modular Reactors
}

October 2013

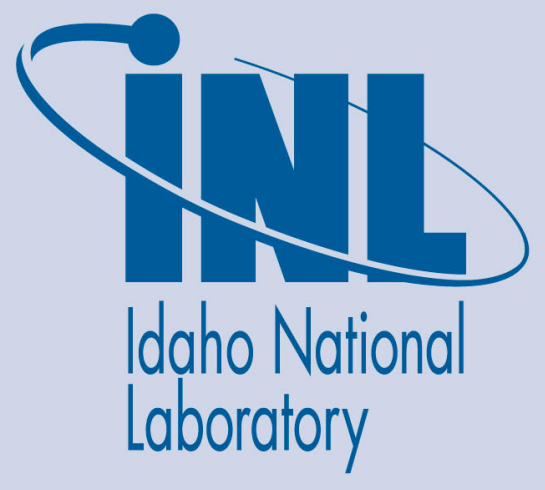

The INL is a U.S. Department of Energy National Laboratory operated by Battelle Energy Alliance 


\section{DISCLAIMER}

This information was prepared as an account of work sponsored by an agency of the U.S. Government. Neither the U.S. Government nor any agency thereof, nor any of their employees, makes any warranty, expressed or implied, or assumes any legal liability or responsibility for the accuracy, completeness, or usefulness, of any information, apparatus, product, or process disclosed, or represents that its use would not infringe privately owned rights. References herein to any specific commercial product, process, or service by trade name, trade mark, manufacturer, or otherwise, does not necessarily constitute or imply its endorsement, recommendation, or favoring by the U.S. Government or any agency thereof. The views and opinions of authors expressed herein do not necessarily state or reflect those of the U.S. Government or any agency thereof. 


\section{Site Suitability and Hazard Assessment Guide for Small Modular Reactors}

October 2013

Idaho National Laboratory Idaho Falls, Idaho 83415

http://www.inl.gov

Prepared for the

U.S. Department of Energy

Office of Nuclear Energy

Under DOE Idaho Operations Office

Contract DE-AC07-05ID14517 


\section{Site Suitability and Hazard Assessment Guide for Small Modular Reactors}

INL/EXT-13-29749

October 2013

Approved by:
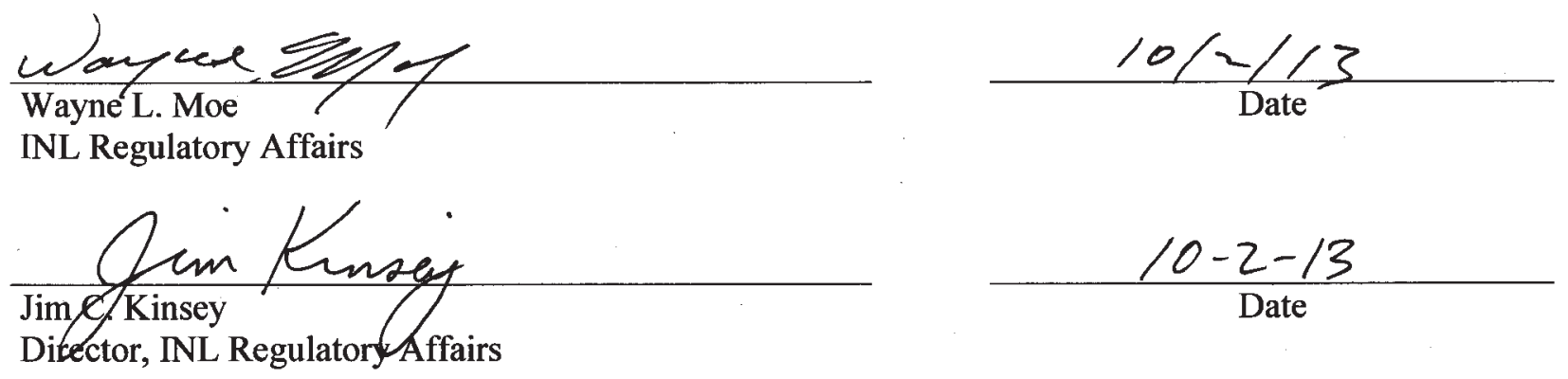


\section{FOREWORD}

This document was developed to provide readers with key background information, a listing of important reference material, and a robust methodology suited to assess field conditions and ambient hazards important in determining the suitability of specific site(s) for the possible construction and operation of a nuclear reactor in the U.S. The guidance provided by this report allows for an initial evaluation and prioritization of candidate reactor site(s) for a variety of purposes that include:

1. Comparison screenings between multiple sites to identify the most favorable candidate(s) worthy of further study while eliminating unfavorable sites from further consideration

2. Evaluation of site hazard characteristics and physical attributes according to standard regulatory requirements typically linked with nuclear facility licensing

3. A means to evaluate a site against key small modular reactor (SMR) technology design parameters to determine if the location meets minimum facility criteria

4. A technique to systematically gather and document site-specific information that can in turn be used to inform later plant design decisions and prospective SMR license applicants about site-related issues that might be encountered during subsequent SMR deployments.

The guidance for performing a nuclear site hazards and suitability assessment was compiled from existing regulations, regulatory guidance documents, and related nuclear industry studies effective in the U.S. as of 2010. Using this information, a reactor technology neutral, generally non-invasive field investigation approach was formulated for use at locations already identified as potentially viable for SMR construction and operation. The approach initially characterizes a candidate location according to whether prior development has occurred and relies on an assessment team to collect relevant existing data and perform field observations in 18 technical areas (i.e., characteristics) of regulatory concern. The methodology also provides evaluators with a means of grading the location with respect to satisfaction of each characteristic, as well as an ability to determine if the site can satisfy basic plant siting parameters (as defined for the specific reactor technology being considered for deployment at the site). Professional judgments are then made so the site can be determined to be acceptable, challenged, or unacceptable with respect to each characteristic; additional discussions can be developed concerning the likelihood of successfully mitigating site hazards that were observed during the assessment.

The guidance and recommendations contained in this document are intended for use as a tool when performing an initial feasibility assessment for nuclear facility siting. This guidance can assist users in developing site information suitable for license application submission to the Nuclear Regulatory Commission should the quality standards applicable to such a submission be met. However, by using the plant and site characteristic templates provided in the appendixes of this report and reviewing the explanations that accompany those templates, site evaluators experienced in the corresponding site characteristic subject matter will be able to efficiently assess site characteristics, identify significant hazards, grade initial site suitability, and be able to identify options for mitigating site risks that could lead to regulatory acceptance during licensing review. 


\section{CONTENTS}

FOREWORD

ACRONYMS

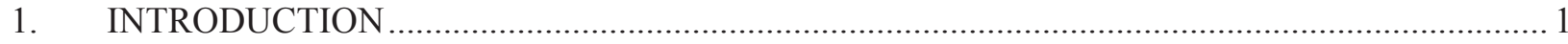

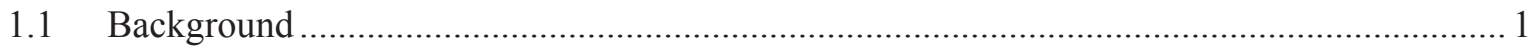

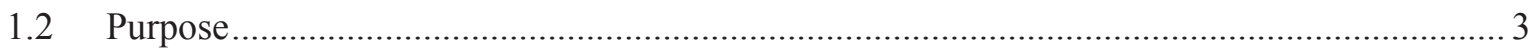

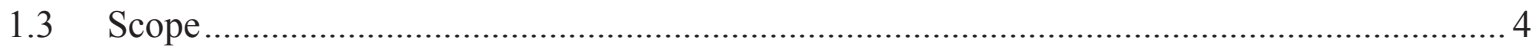

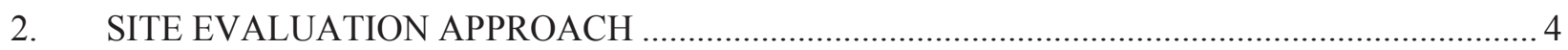

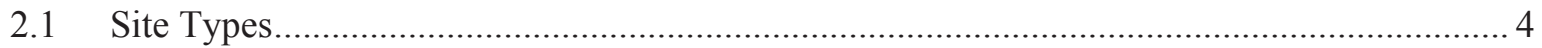

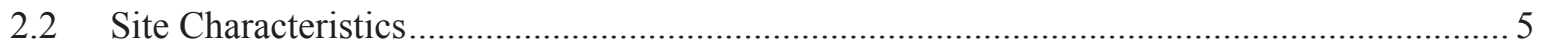

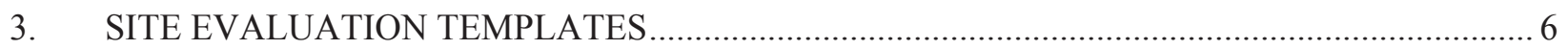

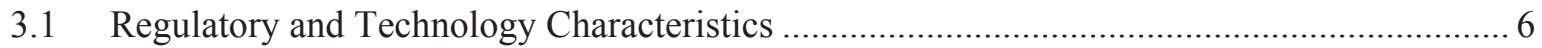

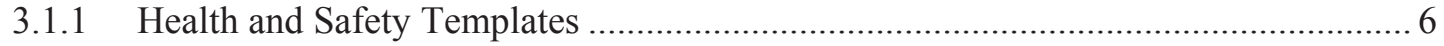

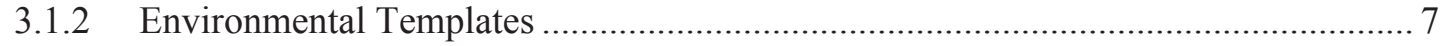

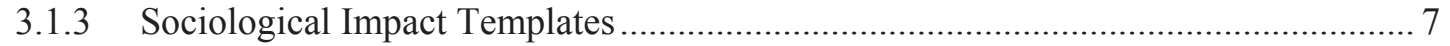

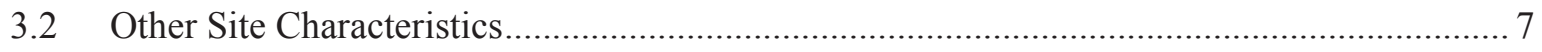

4. SITE HAZARD EVALUATION PROCESS ........................................................................ 8

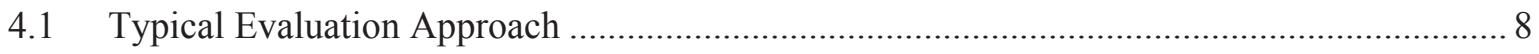

4.2 Modified Evaluation Approach................................................................................. 9

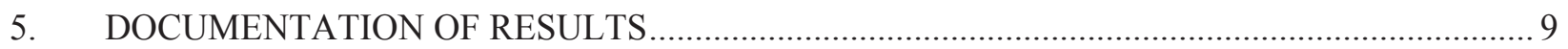

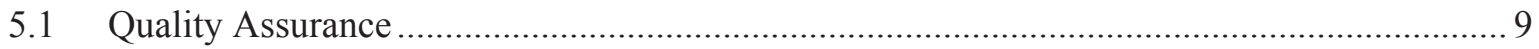

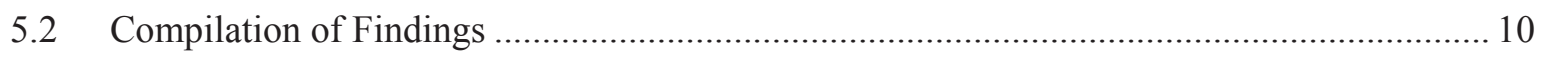

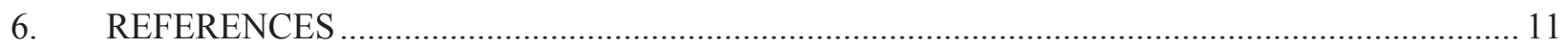

APPENDIX A PLANT PARAMETER DEFINITIONS …............................................................ A-1

APPENDIX B PLANT PARAMETER WORKSHEET .................................................................... B-1

APPENDIX C TEMPLATES FOR EVALUATING SITE CHARACTERISTICS .............................. C-1

Appendix C-1a Geology, Seismology and Geotechnical Engineering .............................................. C-5

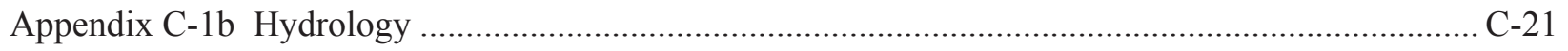

Appendix C-1c Nearby Hazardous Activities/Facilities that Could Affect Plant Safety..................... C-29

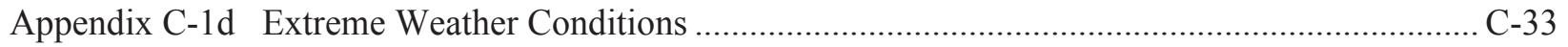

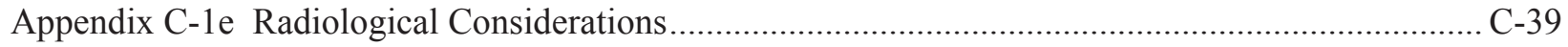

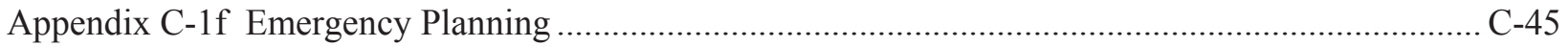




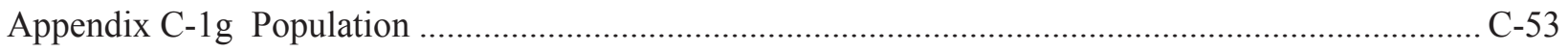

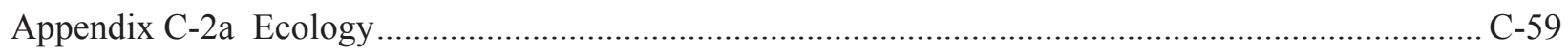

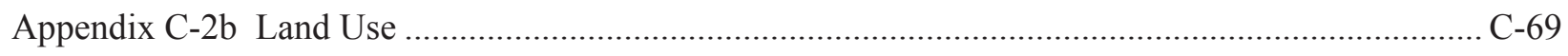

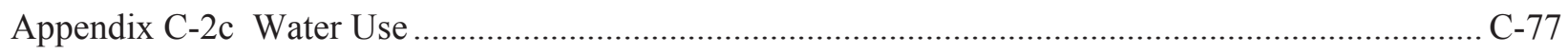

Appendix C-3 Sociological Impact Characteristics Templates ..................................................... C-83

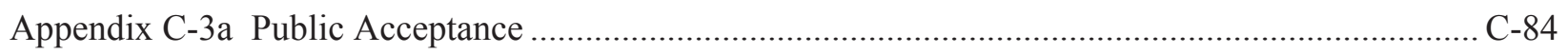

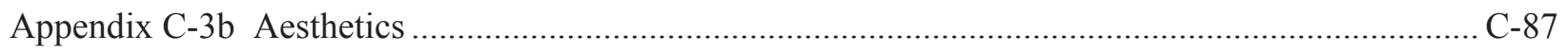

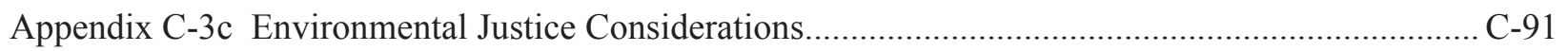

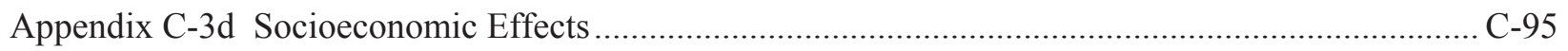

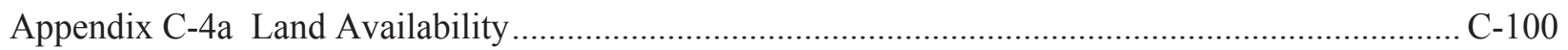

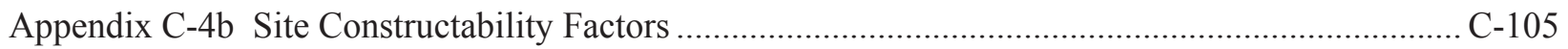

Appendix C-4c Potential for Brownfield Contamination Issues.......................................................... C-109

Appendix C-4d Features that Could Affect Development of Security Measures and Adequate

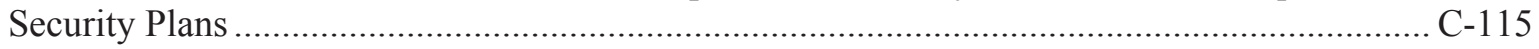

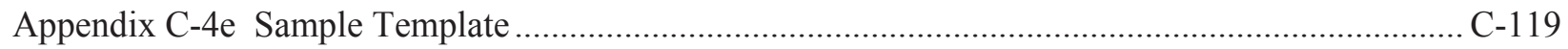

APPENDIX D EMERGENCY PLANNING TEMPLATE - ADDENDUM …................................... D-1 


\section{ACRONYMS}

CFR Code of Federal Regulation

DOE U.S. Department of Energy

EPRI Electric Power Research Institute

GIS geographic information system

HTGR high temperature gas-cooled reactor

INL Idaho National Laboratory

LWR light water reactor

NGNP Next Generation Nuclear Plant

NRC Nuclear Regulatory Commission

ORNL Oak Ridge National Laboratory

OR-SAGE Oak Ridge Siting Analysis for power Generation

PPE plant parameter envelope

R\&D research and development

SMR small modular reactor

SSEC site selection and evaluation criteria 


\section{Site Suitability and Hazard Assessment Guide for Small Modular Reactors}

\section{INTRODUCTION}

Commercial nuclear reactor projects in the U.S. have traditionally employed large light water reactors (LWR) to generate regional supplies of electricity. Although large LWRs have consistently dominated commercial nuclear markets both domestically and abroad, the concept of small modular reactors (SMRs) capable of producing between $30 \mathrm{MW}(\mathrm{t})$ and $900 \mathrm{MW}(\mathrm{t})$ to generate steam for electricity is not new. Nor is the idea of locating small nuclear reactors in close proximity to and in physical connection with industrial processes to provide a reliable, long-term source of thermal energy. Growing challenges associated with continued use of fossil fuels and enhancements in efficiency and safety due to recent advancements in reactor technology suggests that the likelihood of near-term SMR technology(s) deployment at multiple locations within the United States is growing.

Many different types of SMR technology are viable for siting in the domestic commercial energy market. The target application of a particular proprietary SMR design will vary according to the designated heat end-use application and the site upon which the facility is proposed to be located. Reactor heat applications most commonly referenced in connection with the SMR market include electric power production, district heating, desalinization, and the supply of thermal energy to various processes that require high temperature over long time periods, or a combination thereof. Indeed, the modular techniques of construction, reliability and long operational life purported to be associated with some SMR concepts now being discussed could offer flexibility and benefits no other technology can offer.

Effective siting is one of the many early challenges that face all proposals for SMR construction. Site-specific factors associated with facility construction and operations support, risks posed to the plant and the surrounding area, and the consequences subsequent to a realization of those risks must be fully identified, analyzed, and mitigated as necessary before a license will be granted to construct and operate a nuclear facility. Examples of major site-related concern include area geotechnical and geological hazard properties, local climatology and meteorology, water resource availability, the vulnerability of surrounding populations and sensitive environmental features to adverse impacts in the unlikely event of radionuclide release, the socioeconomic effects of SMR plant installation, and the effect the facility has on aesthetics. Additional concerns include proximity of the plant to energy use customers, area topography and local infrastructures that affect plant constructability and security, and the issues related to transportation, installation, operation, and decommissioning of major plant components.

While comprehensive local and regional characterizations of these and other factors, as well as an associated risk and consequence analysis will be required of all SMR siting action as part of the licensing process, an ability to quickly and reliably identify, screen, and initially quantify site attributes at potentially viable locations is an important early step in any SMR project. Indeed, establishing a suite of promising locations and efficiently comparing them to determine the optimal site(s) with respect to the needs of a particular SMR deployment is important not only to manage project risk, but could be instrumental in determining the overall feasibility of a planned SMR project.

\subsection{Background}

Beginning in late 2008, the U.S. Department of Energy's (DOE) Oak Ridge National Laboratory (ORNL) initiated development of the Oak Ridge Siting Analysis for power Generation Expansion (OR-SAGE) computer tool. The nominal objective of OR-SAGE is to employ standard industry-accepted approaches and appropriate selection criteria during a "first step" identification and screening of suitable plant locations, and apply an array of geographic information systems (GIS) data sources to identify viable candidate sites for various power generation technology applications. 
Development of OR-SAGE required exclusionary, avoidance, and suitability criteria to be established relevant to evaluating physical locations for a given siting application such as those which would be associated with SMR construction. For a specific reactor technology application it is also necessary to develop appropriate site selection and evaluation criteria (SSEC) that encompass multiple key attributes of the technology. These attributes must then be overlaid on overall site environmental conditions and characterizations pertinent to the requirements of that siting application. These SSEC include a variety of attributes important to nuclear facility siting such as population density, seismic activity, available water resources, proximity to documented hazardous industrial activities, avoidance of protected lands and flood plains, susceptibility to landslides, and factors that impact constructability and operations at a particular location.

As a dynamic visualization database, the SSEC are fields in OR-SAGE and the GIS data for a given variable represent the values against which a search can be performed. The evaluation process divides the contiguous United States into $100 \mathrm{~m} \times 100 \mathrm{~m}$ (1 hectare) squares (cells); if a cell meets the requirement of a SMR siting criterion as described in the database, the cell is included as a candidate and integrated into a larger set of cells to denote a site which merits further consideration. Some SSEC parameters may preclude a cell from further consideration due to the indicated presence of significant environmental, regulatory, or land-use constraints. Other SSEC may suggest a less favorable, yet still potentially viable parcel that might result from being in close proximity to industrial activities. All OR-SAGE SSECs tend to recommend against a site where a challenge to defined siting criteria are observed to be present.

A set of sample locations were subjected to OR-SAGE analysis to identify possible issues with those sites and demonstrate the determinative capabilities of the tool. Results of these analysis can be found in ORNL/TM-2013/109, "Evaluation of Suitability of Selected Set of Coal Plant Sites for Repowering with Small Modular Reactors," and ORNL/TM-2013/118, "Evaluation of Suitability of Selected Set of Department of Defense Military Bases and Department of Energy Facilities for Siting a Small Modular Reactor." 2

In a parallel effort, the Next Generation Nuclear Plant (NGNP) project was established at DOE's Idaho National Laboratory (INL) pursuant to provisions of the Energy Policy Act of 2005. ${ }^{3}$ NGNP was created to advance research and development (R\&D) in support of the DOE Generation IV Nuclear Energy Systems Initiative with the principal objective of supporting commercialization of high temperature, gas-cooled reactor (HTGR) technology. The HTGR is an advanced reactor that uses helium to remove heat from a modular graphite-moderated reactor core and is capable of operating at temperatures much higher than conventional LWRs.

A large number of pre-licensing actions were conducted in support of NGNP, including one important activity concerned the performance of siting hazard assessments. This was done to identify, evaluate, and catalogue the hazards, environmental characteristics, and constraints that must be considered relative to designing, constructing, and operating the first commercial HTGR facility in the U.S. Detailed site data was collected for multiple sites at two different locations believed to be representative of the initial NGNP deployment. These data were then analyzed and catalogued so that future HTGR design decisions and prospective commercial licensees might be informed concerning the circumstances and challenges that may be found at sites such as these. The studies emphasized the identification of complex hazard types in and around highly industrialized areas and considered the reciprocal risks posed both by and to the nuclear facility relative to adjacent industrial complex(s).

Two NGNP-typical sites were located in a coastal region of the United States and proximal to very large non-nuclear petrochemical facilities that served as example end-users for nuclear reactor heat. One site was also located near a large LWR power plant. Systematic record searches were done for both sites and field reconnaissance inspections were performed at one location using an INL procedure developed specifically for NGNP. ${ }^{4}$ Results of the NGNP assessments were documented in INL reports 
NGNP-LIC-ETR-RPT-004, "NGNP Site 1 Hazards Assessment," and INL/EXT-11-23178, "NGNP Site 2 Hazards Assessment."

\subsection{Purpose}

The OR-SAGE computer tool was designed to assist users in identifying and preliminary evaluating certain site factors important to installation of an energy facility such as SMRs. It does this using standard industry criteria and data gathered to form a supporting GIS. However, as is the case with all computational evaluation tools, OR-SAGE is inherently limited by the types and accuracy of information incorporated into the resource database upon which it relies to perform screening functions. Because such data typically represents "snapshots in time," some of this information may become non-representative over time (i.e., the prior accuracy and precision of site characterization information incorporated into the GIS may change as site characteristics and attributes are altered over time due to natural phenomena and/or human intervention).

Examples of informational drift include changes in local population distributions, the initiation of new infrastructure projects, alterations in surface water or land features, and transient activities that support local industry and transportation initiatives. Similarly, not all criteria applicable to licensing SMRs are addressed by OR-SAGE; this includes characterization of local meteorology, accessibility to water use rights, local zoning requirements, archeological and cultural resources, or issues related to environmental justice.

It is necessary that sites preliminarily identified as favorable using tools such as OR-SAGE undergo a deeper, field-oriented follow-up assessment to both confirm initial site suitability findings and acquire additional information on uncharacterized site features and challenges that can inform and support later project decisions. This guide was created for use as a companion to the OR-SAGE site evaluation tool to support such a follow-up assessment and can also be employed in a stand-alone capacity to assess the suitability of any site targeted for a possible SMR deployment. Thus, users of OR-SAGE are offered a methodology to systematically gather additional detail about promising sites and comparatively gauge those locations against each other in order to determine which might merit further investigation and which are challenged to an extent that they no longer merit further consideration.

Because NGNP performed systematic site hazard assessments in the context of preparatory planning for the first commercial modular HTGR facility, the procedure used by NGNP to perform site assessments has been modified and adapted for use as a generic SMR technology site evaluation guide. The guide provides users a set of detailed instructions that relate directly to siting conditions and hazards important to contemporary nuclear reactor licensing. It sets forth an approach to compare individual or multiple sites using characteristics and parameters that must be addressed in a license application submitted to the U.S. Nuclear Regulatory Commission (NRC) for review and approval. The guide can also be used to acquire site-related data that informs subsequent SMR design decisions and future license applicants as to the challenges and variables that may be encountered when deploying a reactor technology to atypical locations and settings.

This guidance was gathered from a variety of existing sources and includes relevant regulations, regulatory guidance documents and related industrial studies. ${ }^{7,8,9,10,11,12}$ The guide is not intended to be a replacement to or alternative for applicable regulatory requirements or related guidance that has been endorsed by the NRC. Nor is it to be used as a replacement for applicable state and/or local requirements. However, by using the appropriate site characteristic-specific templates provided in the appendixes and reading the corresponding explanations, site evaluators experienced in the related subject matter will be able to effectively assess and semi-quantitatively grade a site technical area (i.e., characteristics) in terms of both anticipated regulatory acceptance and degree of satisfaction for reactor technology/facility requirements. 


\subsection{Scope}

This guidance emphasizes site characteristics commonly understood to be important to successfully licensing and safely operating a nuclear facility. Background information is provided to assist site evaluators in better understanding the basis for making a characteristic suitability determination and to establish a foundation for identifying siting risks which can, in turn, support development of recommendations on possible methods for mitigating recognized hazards.

Efforts have been made to make template methodologies and guidance as reactor technology neutral as possible; thus, this guide is not limited in application to any particular SMR design type or site condition. However, because a variety of different reactor designs are being proposed that may mandate unique requirements or a specific siting criteria, the nuclear facility parameters identified in Appendix A and $\mathrm{B}$ of this document may require revision to accommodate the goals of a particular site assessment with respect to certain reactor design case.

Site assessments are approached in the context of three typical site categories (i.e., "Greenfield" sites), "Brownfield" sites, and existing nuclear power stations (see Section 2.1 for more information on the site types). Once the site type is determined, individual site characteristics are assessed so that each characteristic can be classified as either "Acceptable Site," "Challenges Site Requiring Further Evaluation," or "Site Not Suitable" with respect to licensing and the SMR technology being considered.

The process enables site evaluators to develop a supportable basis for determining whether a site is unacceptable and should be rejected from further consideration. However, a determination that a site is acceptable or challenged in some way will require additional evaluation as part of a more detailed site investigation process. The detailed follow-on site investigation can be directly related to development of a NRC license application; in this respect, assessments resulting from the guidance provided by this document will identify major risks and potential cost adders that should be considered when planning subsequent site evaluations.

\section{SITE EVALUATION APPROACH}

Informational templates are to be used to assist personnel in gathering and evaluating site characteristics. Key site factors are specifically identified in the guidance templates, which are then compared against both the site characteristic observed and applicable plant requirements. A template is provided for each characteristic (or group of characteristics, where appropriate) to guide data acquisition and subsequent analysis for that site characteristic (or group of characteristics, as appropriate). Templates also contain background information relative to the characteristic(s) being examined and provide recommendations concerning how to make a final suitability determination.

The three general site types that support the evaluation are discussed in Section 2.1. Requirements related to determining site characteristic acceptability relative to a particular SMR technology are discussed in Section 2.2. Site characteristic templates that support the evaluation process are discussed in Section 3.

The assessment protocol divides various site characteristics into regulatory considerations (i.e., health and safety, environmental, sociological) and other considerations (i.e., land availability, constructability, contamination hazards, and features affecting security). Each characteristic and/or group of characteristics are described in terms of expected importance and associated risk according to project site evaluation criteria and the guidance nominally used by the NRC while reviewing a license application. Supplemental commentaries may be added by assessors as necessary concerning each site characteristic evaluation.

\subsection{Site Types}

The three types of site descriptor envelopes used are: (1) existing nuclear power plant sites; (2) Brownfield sites, where industrial or urban activities are or have been located; and (3) Greenfield 
sites, where no known history of industrial development has occurred. The basis for using these site descriptors is discussed below.

\section{Existing Nuclear Power Plant Sites}

Locations adjacent to or which previously hosted an operational nuclear power plant have the advantage of prior analyses of most, if not all, site characteristics important to an SMR project. Access to comprehensive characterization data and the prior analysis connected to an existing nuclear facility would generally be expected to exhibit high levels of accuracy and precision. If available, this information can greatly assist a SMR site suitability evaluation and dramatically accelerate subsequent site assessments.

\section{Brownfield Sites}

Brownfield infers a site of real property where expansion, redevelopment, or reuse of the land may be complicated by the presence or migration potential of a hazardous substance, pollutant, or contaminant from prior activities. Brownfield sites typically consist of former commercial and/or industrial land parcels that may have already undergone decommissioning, been abandoned, or is otherwise being sparingly utilized. Examples of a Brownfield site includes legacy nuclear operational areas at DOE sites that handled or processed nuclear material, locations associated with past or current fossil fuel-fired power plant operations, former metal fabrication or equipment manufacturing facilities, and locations where solid and/or hazardous wastes were managed. Brownfield sites have a potential advantage of prior development and could indicate compatible zoning and land use potential. However, they may also be subject varying levels of risk associated with nearby industrial facilities that may or may not be operating. It should be noted that environmental contaminants like asbestos, organic solvents, and heavy metals may be present at Brownfield locations. The historical and/or analytical information necessary to perform a competent site hazards assessment at such a site may not be available to evaluators or of questionable quality, unrepresentative, and subject to future legal action should remediation and cleanup be ordered.

\section{Greenfield Sites}

Greenfield sites comprise locations beyond urban and industrial areas such as agricultural and forest land or other land surfaces not previously developed and/or known to be polluted. Development of a Greenfield site can be undertaken with relatively little concern about prior activities. However, there may be relatively little site-specific data available to support a thorough initial site suitability evaluation. Determining whether a Greenfield site is a viable SMR location may involve greater levels of uncertainty due to risks posed to pristine environments and protected indigenous species.

\subsection{Site Characteristics}

Minimum acceptable site conditions will differ somewhat based on the underlying requirements of the reactor technology and the associated plant parameter criteria. An advanced non-water reactor may require substantially different combinations of site acceptance attributes than a LWR. Appendix A defines many of the key reactor technology attributes important to consider when evaluating site suitability. Appendix B provides a list of typical reactor technology design parameters that site assessors can use to determine if the site is amenable to the technology under consideration; these values must be obtained from the reactor vendor. If a specific value cannot be assigned, a plant perimeter envelope (PPE) value should be defined by the reactor vendor to bound necessary inputs.

It should be noted that not all of the parameters specified in Appendixes A and B are necessary for developing a license application. However, all identified parameters support significant aspects of safety, environmental, and project evaluations that may be necessary beyond those directly related to securing a plant license. Since many advanced reactor designs are still maturing, it is possible that some design parameters (or their bounding PPE) will be unknown at the time a site feasibility assessment is performed. In those cases the evaluator is expected to characterize the features of the site related to the parameter, but may be unable to draw any conclusions regarding site acceptability. 


\section{SITE EVALUATION TEMPLATES}

The site characteristic evaluation templates used during the assessment are provided in Appendix C. These templates address key site attributes according to the following categories: health and safety, environmental, and sociological impacts and other site considerations.

Each site characteristic is evaluated with a separate template which has been formatted to capture the following key information:

- Describe of characteristic being evaluated

- Discuss of the importance of the site characteristic

- List criteria to be satisfied for the site to be considered acceptable, challenged, or unsuitable

- Identify site type

- Identify reactor technology

- Discuss risks associated with not satisfying the associated criteria

- Provide risk mitigation recommendations (if any)

- Provide regulatory and other references.

Each site characteristic should be evaluated using the guidance template and professional judgments made concerning suitability according to the discussion contained in Section 4. Site evaluators must exercise prudence when interpreting and applying LWR-oriented regulations and guidance such as this to alternative non-LWR technologies.

Modifications to the guidance templates provided in this document may be necessary to accommodate new or additional federal, state, or local requirements and regulations, or when additional regulatory guidance becomes available for the reactor technology being considered for siting.

\subsection{Regulatory and Technology Characteristics}

Appendix $\mathrm{C}$ site characteristic templates are grouped according to health and safety, environmental and sociological impacts. Each of these categories are then progressively divided into sub-categories until a detailed site characteristic is identified for evaluation according to the provided methodology.

\subsubsection{Health and Safety Templates}

Health and safety characteristic templates address issues related to site geotechnical properties, susceptibility of surface deformation through capable faults, available water supply, flood potential, area land use hazards, weather extremes, and radiological considerations. Also included are supplemental considerations that involve populated areas, site security, and emergency planning that might challenge development of facility contingency measures. Templates are organized as:

- Geology, Seismology, and Geotechnical Engineering

- $\quad$ Seismic ground motions

- Global geohazards

- Site geotechnical

- Hydrology

- Water availability

- Flooding

- Nearby hazardous activities/facilities that could affect plant safety 
- Extreme weather considerations

- Radiological considerations

- Atmospheric dispersion-accident conditions

- Emergency planning

- Population

- Population density

- Population centers.

\subsubsection{Environmental Templates}

Environmental characteristic templates address local ecological concerns (including threatened and endangered species), wetlands and other fragile habitats, land and water use, and historic resource affects. Templates area organized as:

- Ecology

- Terrestrial ecology

- Aquatic ecology

- $\quad$ Land Use

- Transmission corridors and transportation routes

- Historic/archeological/cultural resource issues

- Water Use

- Hydrologic impacts.

\subsubsection{Sociological Impact Templates}

Sociological impact templates address issues related to public acceptance, environmental justice, and socioeconomic impacts upon surrounding communities and the region. Templates are arranged as:

- Public acceptance

- Aesthetics

- Environmental justice considerations

- Socioeconomic effects.

\subsection{Other Site Characteristics}

Additional consideration must be given to site characteristics related to land availability, cost, factors affecting site constructability and the need for decontamination and cleanup. Templates provided consist of:

- Land availability

- Site constructability factors

- Potential for brownfield contamination issues

- Features that could affect development of security measures and adequate security plans

- Sample template (with instructions).

A sample (blank) template is provided at the end of Appendix $\mathrm{C}$ for instances where requirements for unique parameters must be considered during the evaluation that are not otherwise addressed by standard templates. 


\section{SITE HAZARD EVALUATION PROCESS}

\subsection{Typical Evaluation Approach}

The first step in conducting a site hazard suitability evaluation is to determine the goals of the project, customer, and owner/operator as well as investigative limitations. Potential goals and constraints derived from this determination include identification of the intended SRM technology to be used, the intended outputs of the plant (electricity, steam, process heat, etc.), limitations related to physical plant design, size and location, non-nuclear regulations and legal agreements that will be incumbent at a site, and goals related to facility emergency preparedness. This information should be documented in the final site evaluation report and incorporated into individual templates as necessary to ensure site characteristic are appropriately evaluated. Initial plant design assumptions should concur with the design parameters gathered during the next step of the evaluation process.

The second step in the evaluation process is to complete the Design Parameter Worksheet provided in Appendix B. This should be done using vendor-supplied information for the specific reactor technology being considered for the site. Reactor specific design information will be the basis for establishing acceptable bounding values that are then used in the Appendix $\mathrm{C}$ site characteristic template evaluations. (NOTE: If bounding or actual reactor design parameters are unavailable, refer to Section 4.2 for additional instruction.)

Once the Design Parameter Worksheet is completed, evaluators should review the templates associated with the characteristics they are to evaluate. The information, references, and methods provided by each template will assist evaluators in assessing the site characteristic and in arriving at a plausible judgment of site acceptability.

The primary goal of evaluation templates is to provide a framework upon which a documented site hazards and suitability analysis can be performed. To use the templates most effectively, evaluators should be made aware of and become familiar with key NRC licensing guidance and requirements documents. $^{7,8,9,11,13,14}$

If project-specific limitations and priorities are incorporated into the site characteristic templates to address a particular project need, subject matter experts for these new issues of interest should direct those revisions. If additional site characteristics are identified as necessary to support a specific evaluation, the sample template form provided at the end of Appendix $C$ should be used for this purpose.

Normally, it is expected that templates will be completed using existing available information; however, invasive field investigations like deep soil borings or analytical laboratory testing of materials collected in the field may be necessary if existing sources of data cannot support a conclusion. Computer modeling analyses for an issue like atmospheric dispersion may also be necessary if there is reason to believe an unusually high risk is present, in which case a focused characterization analysis might be justified for purposes of initial assessment. Potential situations where this may be justified are discussed in individual site characteristic assessment templates.

The templates are not intended to restrict evaluators to a specific evaluation method or particular source of data. However, the evaluations should not be inconsistent with regulatory guidance applicable to the subject matter. Qualitative judgments should be documented and adequately supported to justify the conclusion. Consideration should be given to the applicability of 10 CFR 50 Appendix B quality assurance requirements if it is possible that the template evaluations will be relied as input for a future NRC license application (see Section 5). 
After site characteristic information is collected and evaluated, judgments will be made concerning site acceptability for the targeted reactor technology with respect to that specific characteristic. Hazards and risks involved in designating a site as acceptable, challenged and requiring further evaluation, or not suitable, should be specifically identified. Final determinations are defined as:

- Acceptable Site: The site fully satisfies the acceptance criteria specified in the template and no undue hazards were identified.

- Challenged Site Requiring Further Evaluation: Hazards were identified, but the characteristic could not be adequately evaluated or the acceptance criteria were not fully satisfied; compensatory factors or other forms of mitigation may be required.

- Site Not Suitable: Hazards were identified for which no feasible compensatory action was recognized or the site failed to satisfy the key characteristic criteria being evaluated; no reasonable (or cost-effective) alternatives were identified, which would make the site acceptable.

Evaluators should document the evaluation approach that was used and the level of detail to which a methodology was employed for the analysis, as well as the path by which a judgment of site suitability was derived. It is important that the discussion include a characterization of the process used to make the determination so that subsequent analysis can be supported should the site be carried forward for additional study. All references employed during the evaluation are to be documented.

\subsection{Modified Evaluation Approach}

Template configurations assume that plant design and facility requirements are defined adequately to support an evaluation of individual site characteristics. However, if facility design is still in an early stage of development (e.g., conceptual or preliminary) and prerequisite facility requirements are undefined or uncertain, site information may still be collected, which could, in turn, be used to support design element decisions. Such an instance will require site evaluators to characterize plant design features according to a broad PPE and relate site attributes to those bounding parameters. This means evaluators will be unable to draw a firm conclusion regarding site acceptability. However, the evaluator would still be able to identify key site features as well as potential risks and constraints for future consideration.

Using this modified approach means some aspects of the Section 4.1 evaluation must be changed. For instance, during the first process step the informational needs of reactor designers should be clearly established and incorporated into the templates to the level necessary to inform design decisions. For assessment areas where design information is unknown, assessment results should be documented in a summary observation format rather than follow an "acceptable - challenged - not acceptable" pattern.

\section{DOCUMENTATION OF RESULTS}

\subsection{Quality Assurance}

Because this guidance presumes existing site data will be used for most (if not all) site suitability analysis, this process would not normally be subjected to the requirements associated with nuclear facility licensing and the requirements specified in 10 CFR 50 Appendix B, "Quality Assurance." However, should gathered information be considered for eventual use in a formal license application submission (e.g., an Environmental Report) to the NRC, appropriate quality elements must be incorporated into the site evaluation. One way to ensure the accuracy and reliability of collected information will support a subsequent licensing review is to develop and implement a site assessment quality plan to accompany the initial site assessment. If this option is chosen, requirements are described in 10 CFR 50 Appendix B, 10 CFR 52.17(a)(1)(xi) and 10 CFR 52.79(a)(25). 


\subsection{Compilation of Findings}

Site evaluation results should be compiled into a final report that documents individual characteristic findings and an overall conclusion concerning site suitability and hazards. These conclusions should be directly related to the reactor technology being considered for placement at the site. If the assessment will be used to support a future licensing action, the appropriate quality measures as discussed in Section 5.1 should also be described in the report. At a minimum, the quality measures to be used in support of future licensing actions would address validation of the investigative methodologies and inputs that are used and a documented review of assessment study results by qualified subject matter experts.

The assessment report resulting from the guidance provided in this document would typically contain the following elements:

Executive Summary

Report Body

- Table of Contents

- Summary Description of Assessment Process

- Summary Description of Assessment Results

- Assessment Conclusions.

Attachments

- Project requirements and site owner requirements

- General drawings/pictures of the evaluated site that display key site features (e.g., proposed plant location, property lines, existing infrastructure features)

- Summary table of site characteristic evaluation results (NOTE: For areas where design information is unavailable, the table should summarize observed conditions rather than provide a determination of acceptability.)

- Site characteristic evaluation worksheets

- List of persons/organizations contacted and sources of information

- List of persons performing assessment including area(s) of expertise

- Completed Plant Parameter Worksheet. 


\section{REFERENCES}

1. Belles, R. J, Copinger, D. A, et al., 2013, "Evaluation of Suitability of Selected Set of Coal Plant Sites for Repowering with Small Modular Reactors," ORNL/TM-2013/109, Oak Ridge National Laboratory, March 2013.

2. Poore, W. P, Belles, R. J., et al., 2013, "Evaluation of Suitability of Selected Set of Department of Defense Military Bases and Department of Energy Facilities for Siting a Small Modular Reactor," ORNL/TM-2013/118, Oak Ridge National Laboratory, March 2013.

3. "Energy Policy Act of 2005,” 2005, Pub. L. 109-58, Energy Efficiency and Renewable Energy (EERE), Federal Energy Management Program, July 29, 2005.

4. Entergy, 2009, "Procedure for Site Hazards Evaluation and Impact Assessment," Rev. 1, NGNP-LIC-ETR-RPT-001, September, 2009.

5. Entergy, 2011, "NGNP Site 1 Hazards Assessment,” NGNP-LIC-ETR-RPT-004, March 2011 [restricted distribution].

6. INL, 2011, "NGNP Site 2 Hazards Assessment," INL/EXT-11-23178, Rev. 0, Idaho National Laboratory, October 2011.

7. EPRI, "Siting Guide: Site Selection and Evaluation Criteria for an Early Site Permit Application," Final Report No. 1006878, Electric Power Research Institute, March 2002.

8. NRC, "Standard Review Plan,” NUREG-0800, U.S. Nuclear Regulatory Commission, March 2007.

9. NRC, "Standard Review Plans for Environmental Reviews for Nuclear Power Plants," NUREG-1555 (Draft Rev. 1), July 2007.

10. 10 CFR Part 100, Subpart B, "Evaluation Factors for Stationary Power Reactor Site Applications on or after January 10, 1997."

11. NRC, Regulatory Guide 4.7, "General Site Suitability Criteria for Nuclear Power Stations," U.S. Nuclear Regulatory Commission, April 1998.

12. NRC, Draft Regulatory Guide DG-4015, Proposed Rev 1 of Regulatory Guide 4.2, Supplement 1, dated September 2000, "Preparation of Environmental Reports for Nuclear Power Plant License Renewal Applications," U.S. Nuclear Regulatory Commission, September 2000.

13. NRC, Regulatory Guide 1.206, "Combined License Applications for Nuclear Power Plants (LWR Edition),” U.S. Nuclear Regulatory Commission, June 2007.

14. NRC, Regulatory Guide 4.2, "Preparation of Environmental Reports for Nuclear Power Stations," U.S. Nuclear Regulatory Commission, July 1976. 


\section{APPENDIX A \\ PLANT PARAMETER DEFINITIONS}




$$
\text { A-2 }
$$




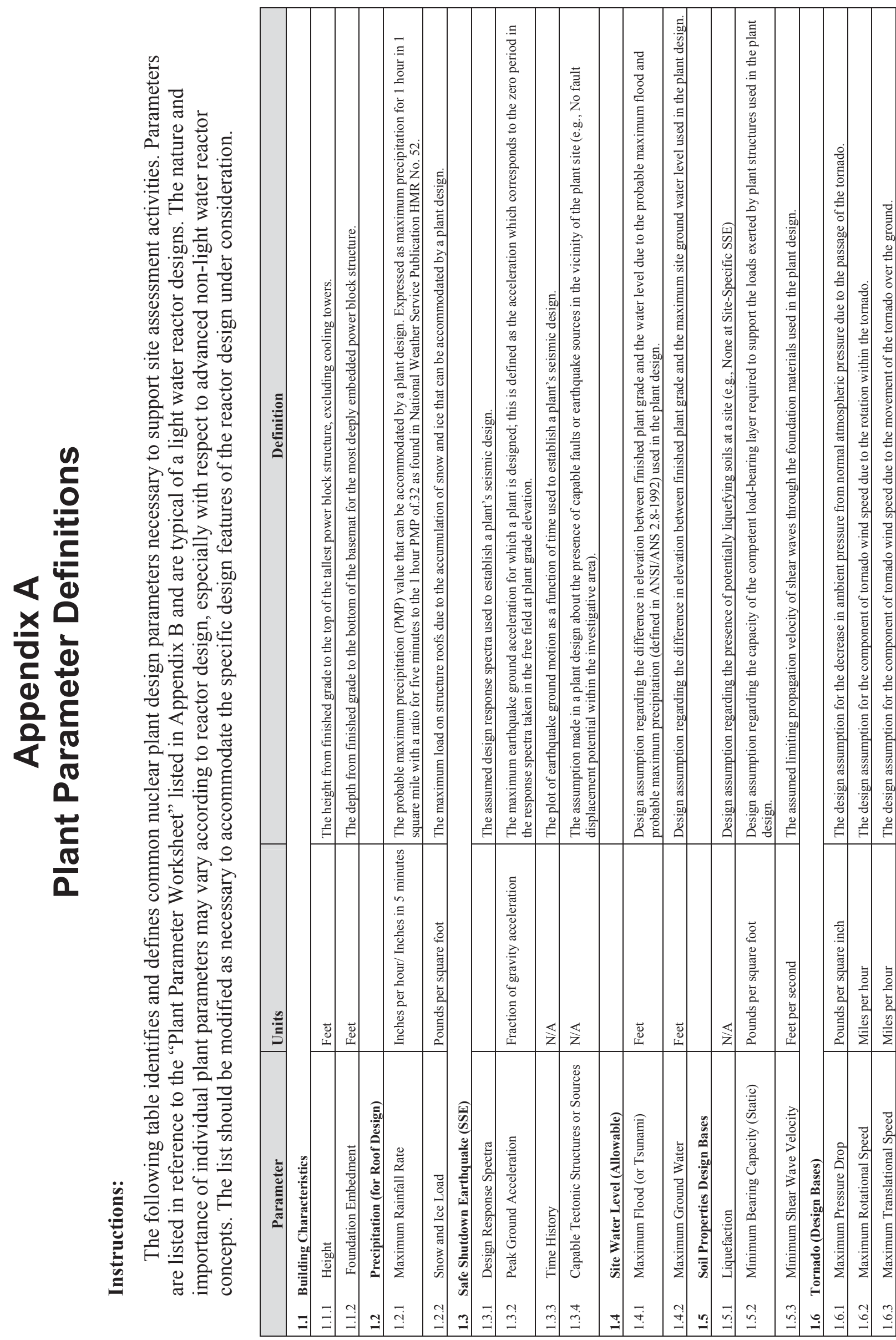




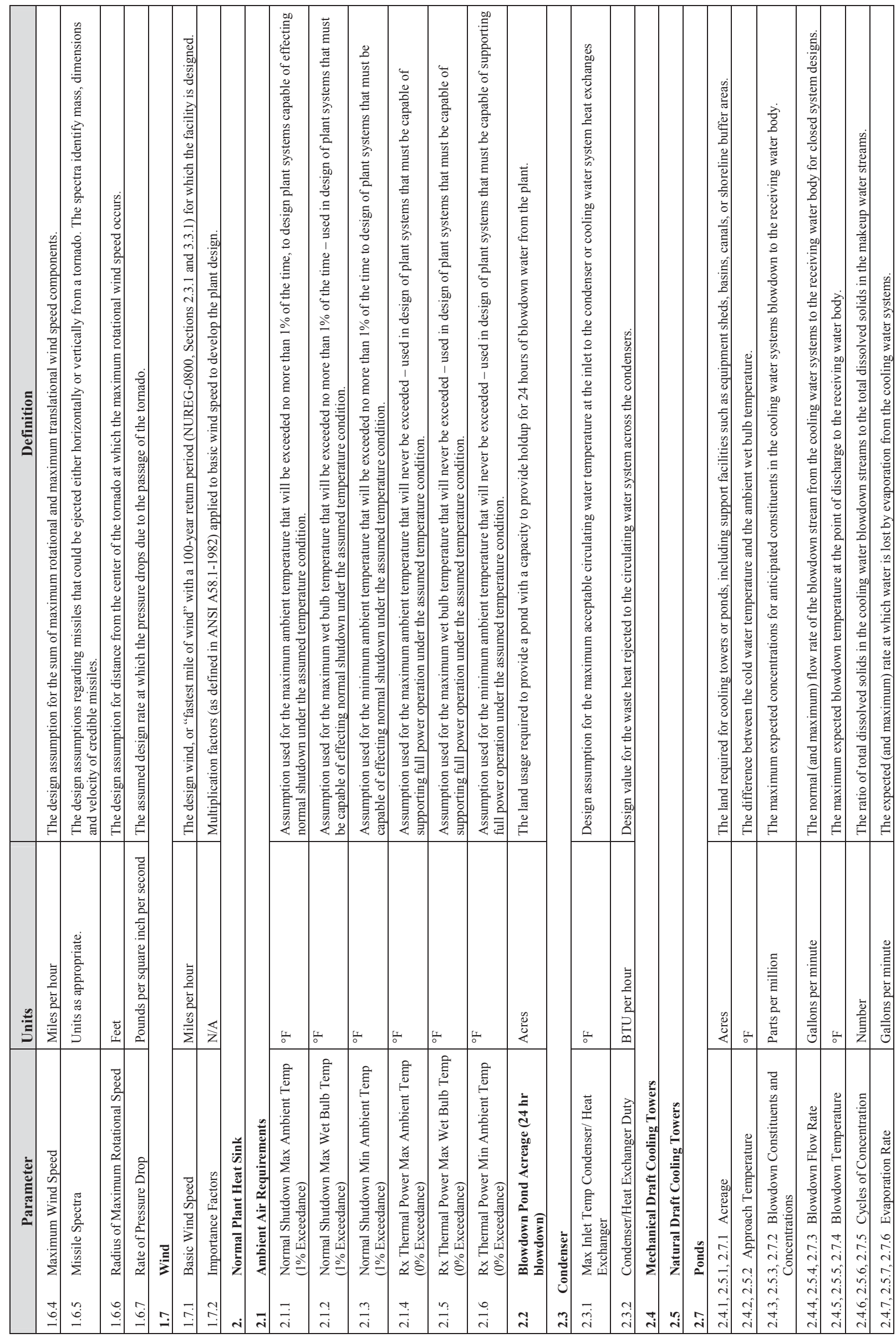




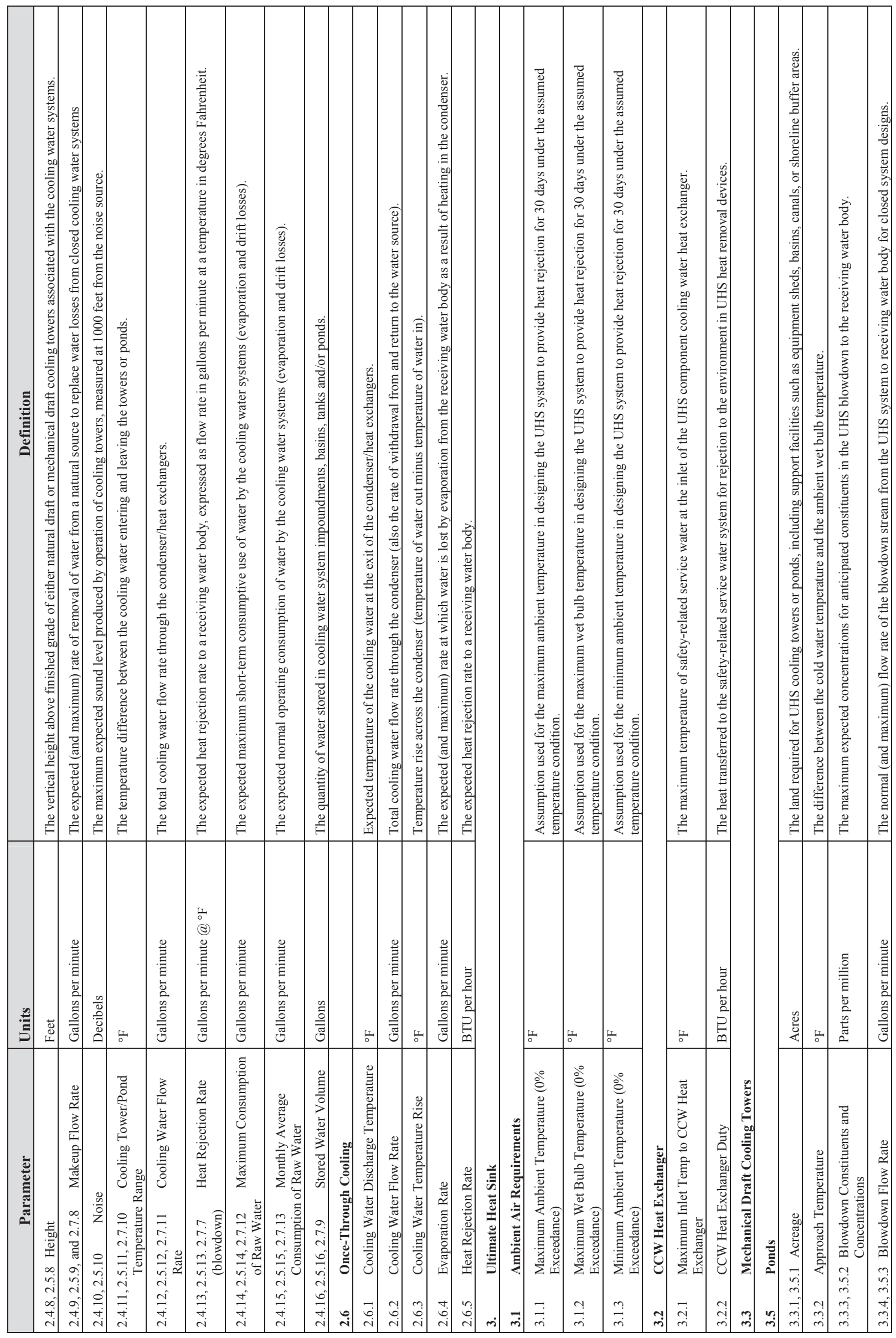




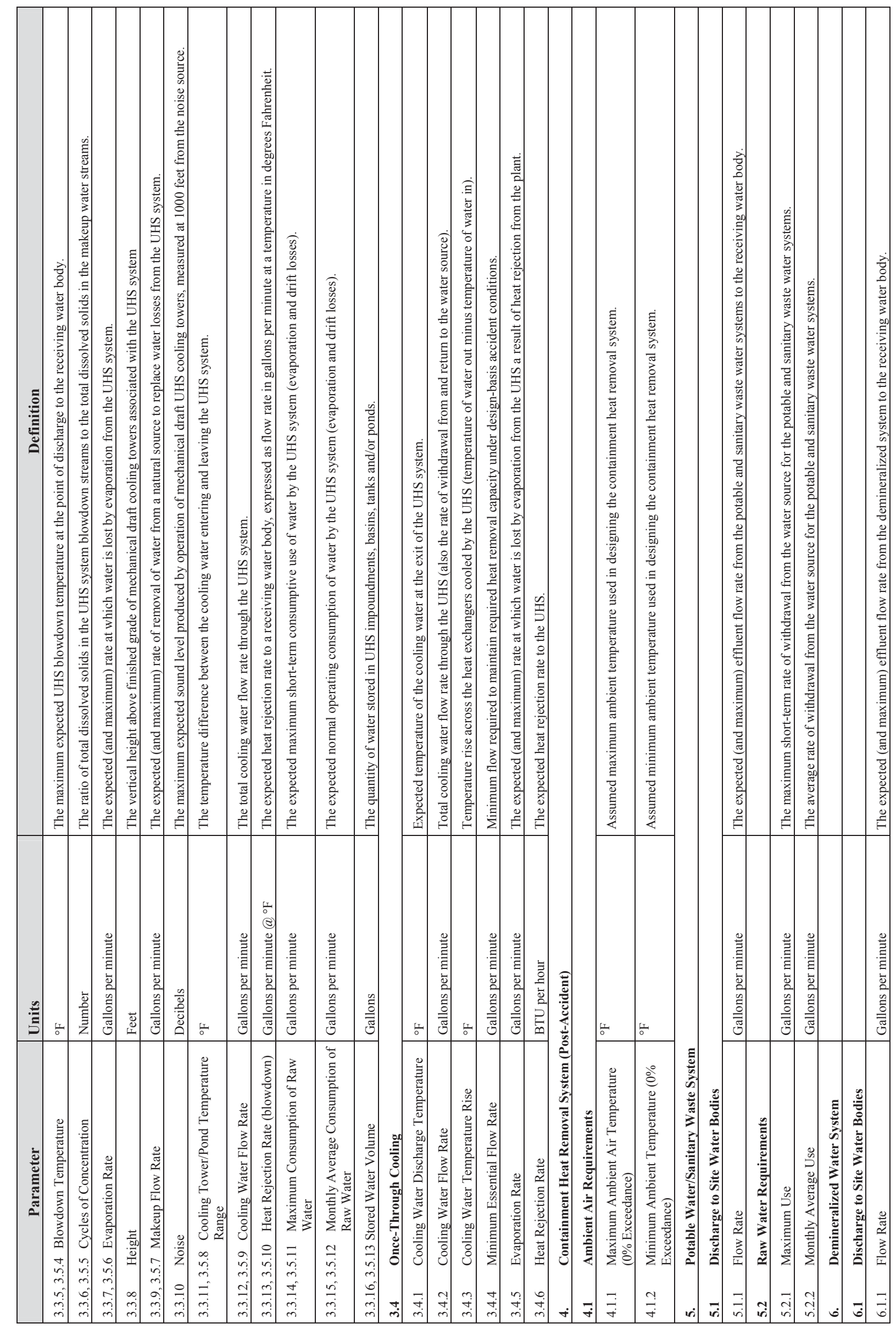




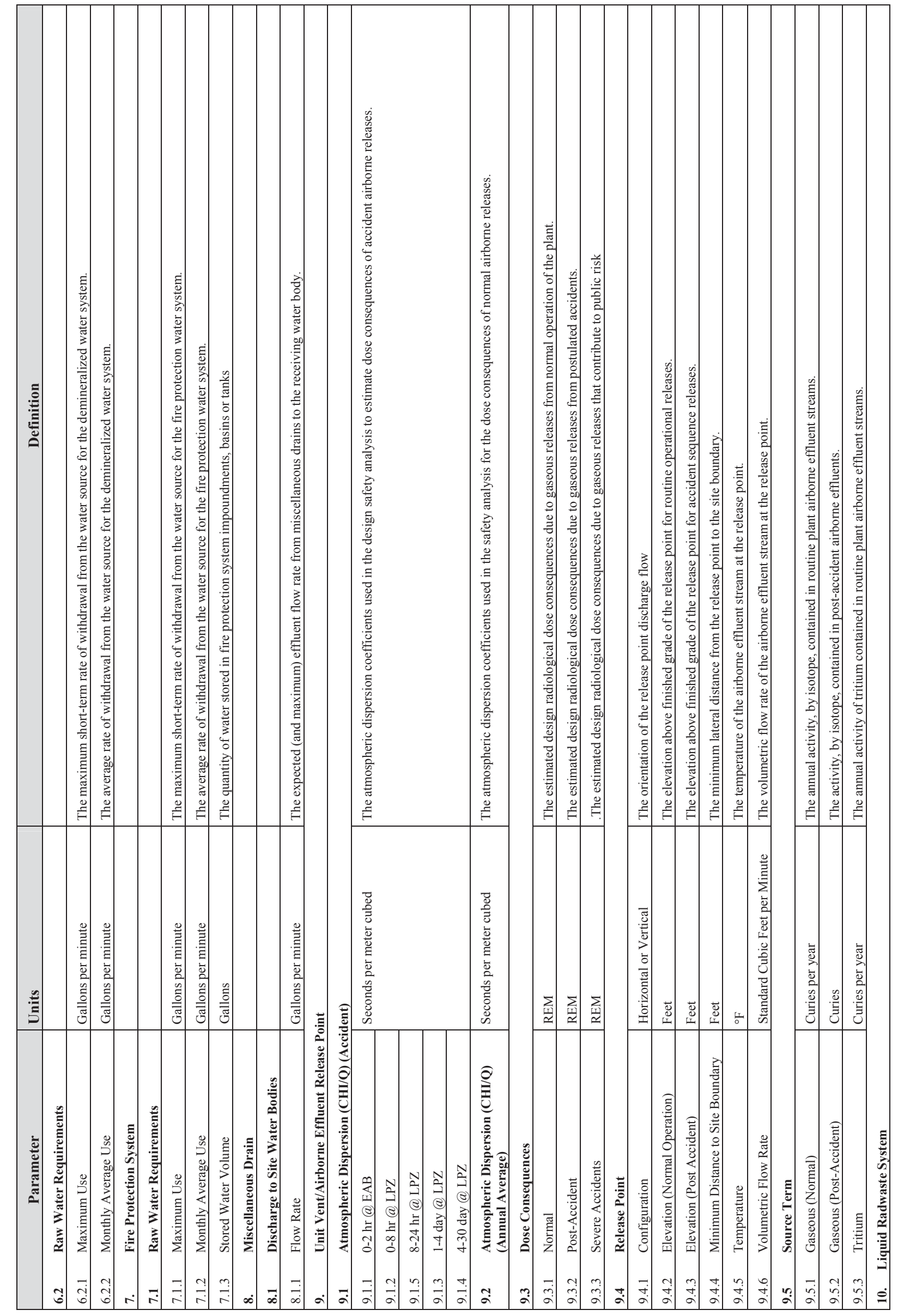




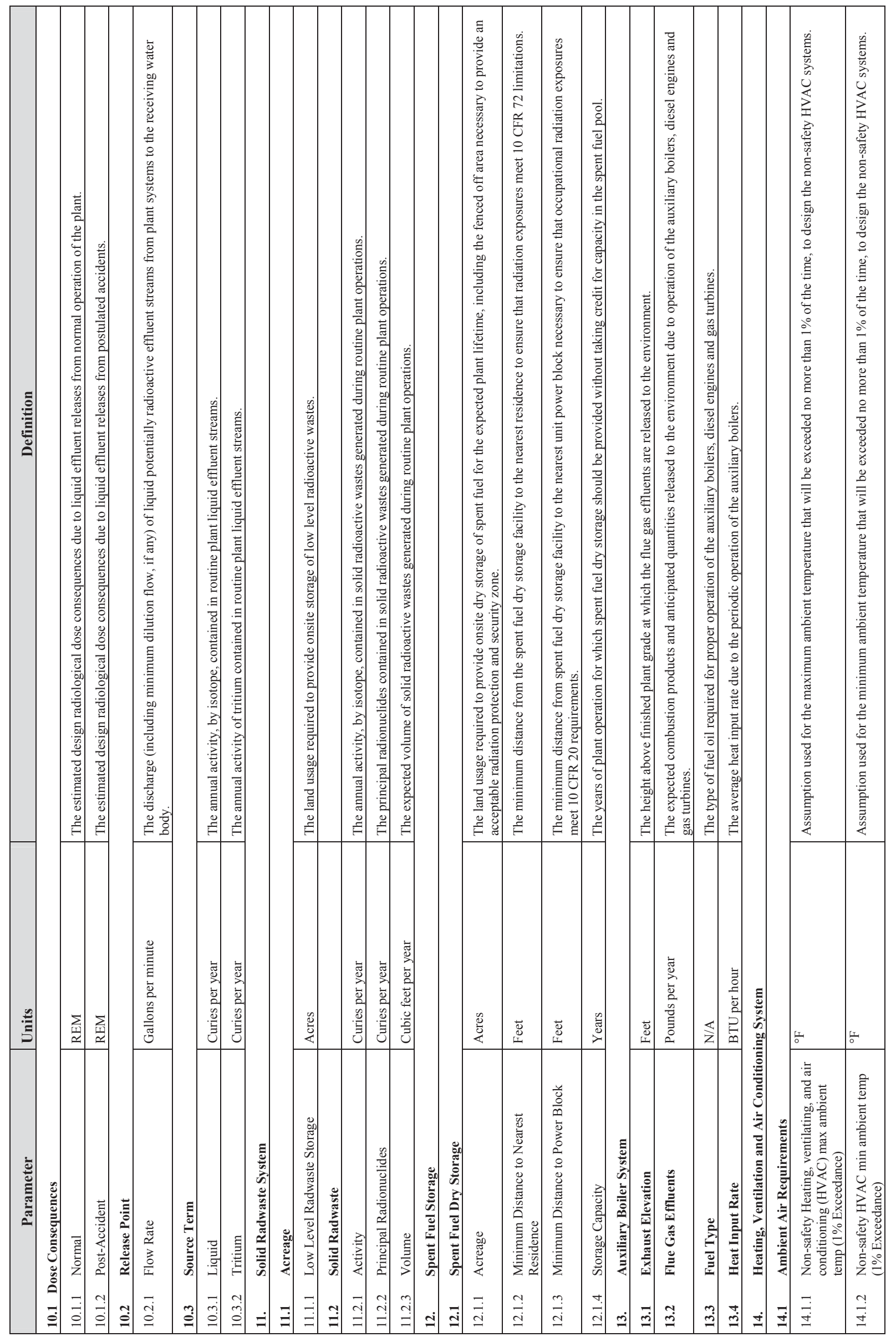




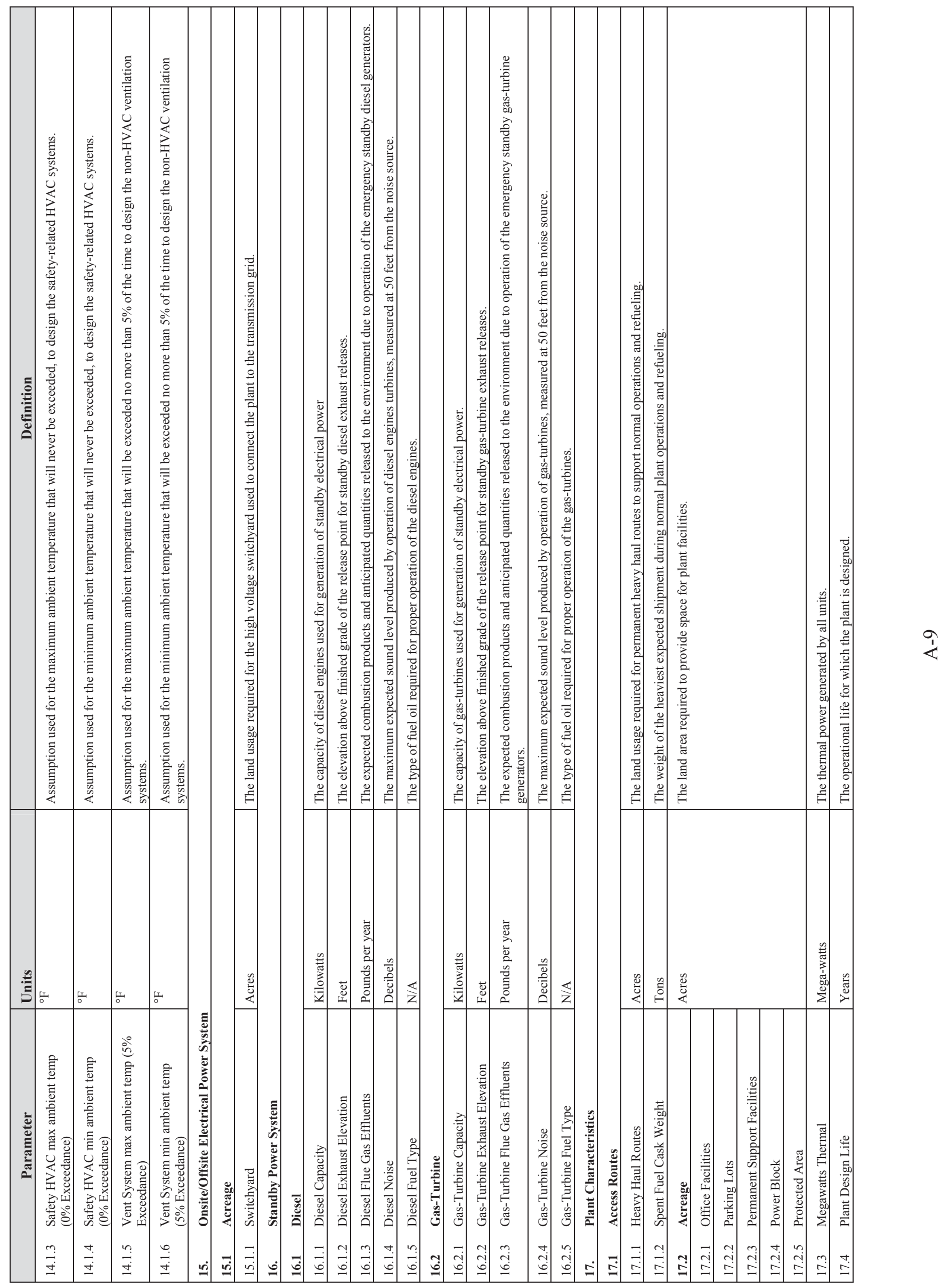




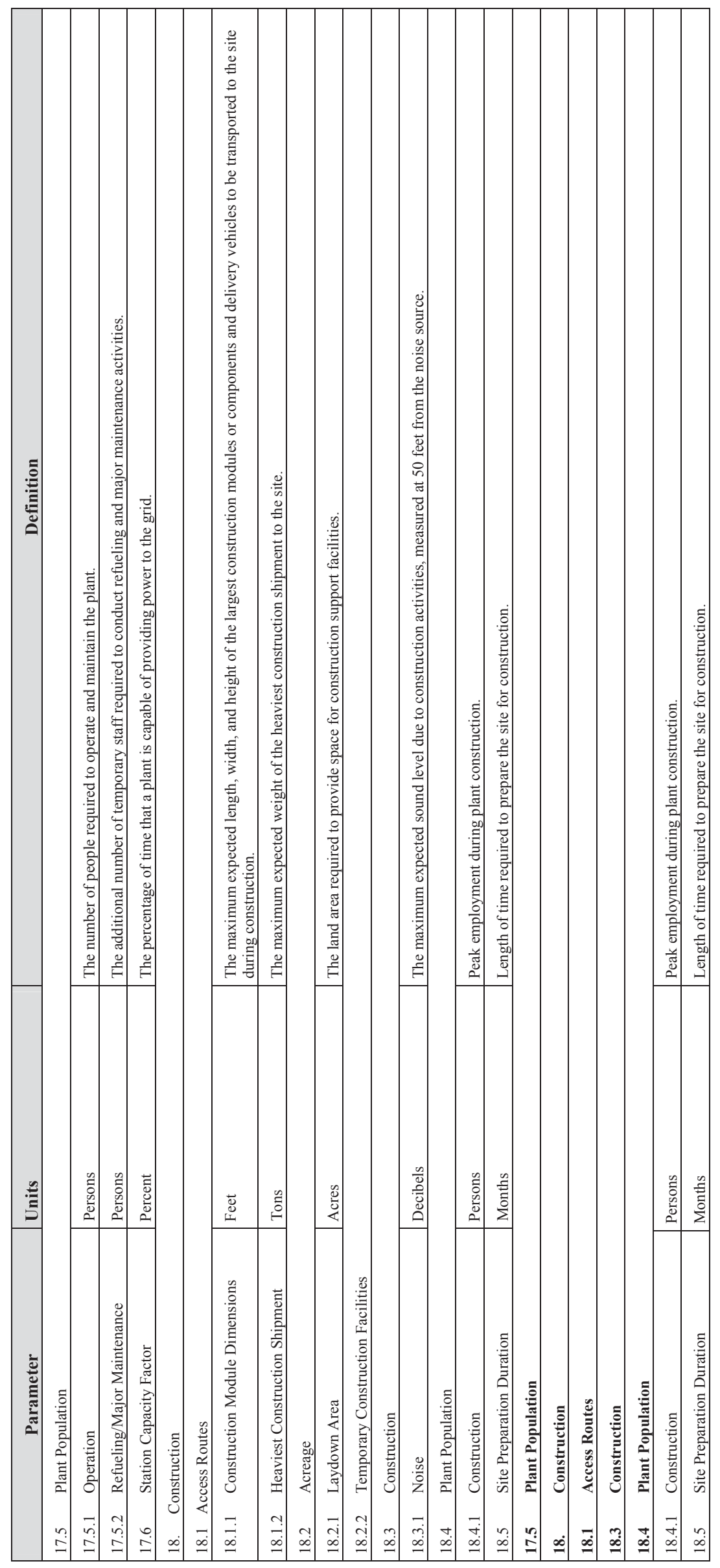

$\frac{0}{4}$ 


\section{APPENDIX B PLANT PARAMETER WORKSHEET}


Appendix B - Plant Parameter Worksheets 


\section{Appendix B Plant Parameter Worksheet}

\section{Instructions:}

The following plant design parameters are believed relevant to most SMRs being considered for "near term" deployment (i.e., within the next decade). However, given that the nature and importance of the individual plant design parameters may be function specific to a particular proprietary design, the Plant Parameter Worksheet entries should be modified to correct or incorporate unique facility specifications.

Using the definitions provided in Appendix A, fill in values for each reactor design parameter as they are to be applied to considerations of site suitability. If a parameter is not applicable or unimportant to the facility design, enter "N/A" in the data field. If a bounding number is entered to represent a design specification envelope, identify as such. If explanation is required to clarify or caveat an assigned value, include that explanation in the "value" entry field. For modular plants, clearly state whether the value is per modular unit or for some combination of modular units. If the value is contingent on some other value or an assumption (e.g., "contingent on megawatt"), then please state as such.

There are key components of many SMR concepts that may still reside in a conceptual or preliminary phase of design. Hence, certain plant parameters important to site selection may not be known at the time of assessment. In those cases the evaluator is expected to characterize the features of the site as they relate to the design parameter. In the absence of a firm facility siting criteria, the evaluator will be unable to draw a conclusion regarding site acceptability but should be able to assess and document specific site attributes and risks that should be utilized during planning of the project. 
Appendix B - Plant Parameter Worksheets

REACTOR TECHNOLOGY:

\begin{tabular}{|c|c|c|c|c|}
\hline \multicolumn{3}{|r|}{ Parameter } & Units & \multirow[t]{2}{*}{ VALUE } \\
\hline \multicolumn{3}{|c|}{ 1. Structures } & & \\
\hline \multirow[t]{2}{*}{1.1} & \multicolumn{2}{|c|}{ Building Characteristics } & & \\
\hline & 1.1 .1 & Height & Feet & \\
\hline & 1.1 .2 & Foundation Embedment & Feet & \\
\hline \multirow[t]{3}{*}{1.2} & \multicolumn{2}{|c|}{ Precipitation (for Roof Design) } & & \\
\hline & 1.2 .1 & Maximum Rainfall Rate & $\begin{array}{l}\text { Inches per } \\
\text { hour/ inches in } \\
5 \text { minutes }\end{array}$ & \\
\hline & 1.2 .2 & Snow and Ice Load & $\begin{array}{l}\text { Pounds per } \\
\text { square foot }\end{array}$ & \\
\hline \multirow[t]{5}{*}{1.3} & \multicolumn{2}{|c|}{ Safe Shutdown Earthquake (SSE) } & & \\
\hline & \multicolumn{2}{|c|}{ 1.3.1 Design Response Spectra } & & \\
\hline & 1.3 .2 & Peak Ground Acceleration & $\begin{array}{l}\text { Fraction of } \\
\text { gravity } \\
\text { acceleration }\end{array}$ & \\
\hline & 1.3 .3 & Time History & $\mathrm{N} / \mathrm{A}$ & \\
\hline & 1.3 .4 & $\begin{array}{l}\text { Capable Tectonic Structures } \\
\text { or Sources }\end{array}$ & N/A & \\
\hline \multirow[t]{3}{*}{1.4} & \multicolumn{2}{|c|}{ Site Water Level (Allowable) } & & \\
\hline & 1.4 .1 & $\begin{array}{l}\text { Maximum Flood (or } \\
\text { Tsunami) }\end{array}$ & Feet & \\
\hline & 1.4 .2 & Maximum Ground Water & Feet & \\
\hline \multirow[t]{4}{*}{1.5} & \multicolumn{2}{|c|}{ Soil Properties Design Bases } & & \\
\hline & 1.5 .1 & Liquefaction & N/A & \\
\hline & 1.5 .2 & $\begin{array}{l}\text { Minimum Bearing Capacity } \\
\text { (Static) }\end{array}$ & $\begin{array}{l}\text { Pounds per } \\
\text { square foot }\end{array}$ & \\
\hline & 1.5 .3 & $\begin{array}{l}\text { Minimum Shear Wave } \\
\text { Velocity }\end{array}$ & $\begin{array}{c}\text { Feet per } \\
\text { second }\end{array}$ & \\
\hline \multirow[t]{2}{*}{1.6} & \multicolumn{2}{|c|}{ Tornado (Design Bases) } & & \\
\hline & 1.6 .1 & Maximum Pressure Drop & $\begin{array}{l}\text { Pounds per } \\
\text { square inch }\end{array}$ & \\
\hline & 1.6 .2 & Maximum Rotational Speed & Miles per hour & \\
\hline & 1.6 .3 & $\begin{array}{l}\text { Maximum Translational } \\
\text { Speed }\end{array}$ & Miles per hour & \\
\hline & 1.6 .4 & Maximum Wind Speed & Miles per hour & \\
\hline & 1.6 .5 & Missile Spectra & $\begin{array}{c}\text { Units as } \\
\text { appropriate. }\end{array}$ & \\
\hline & 1.6 .6 & $\begin{array}{l}\text { Radius of Maximum } \\
\text { Rotational Speed }\end{array}$ & Feet & \\
\hline & 1.6 .7 & Rate of Pressure Drop & $\begin{array}{l}\text { Pounds per } \\
\text { square inch } \\
\text { per second }\end{array}$ & \\
\hline
\end{tabular}


Appendix B - Plant Parameter Worksheets

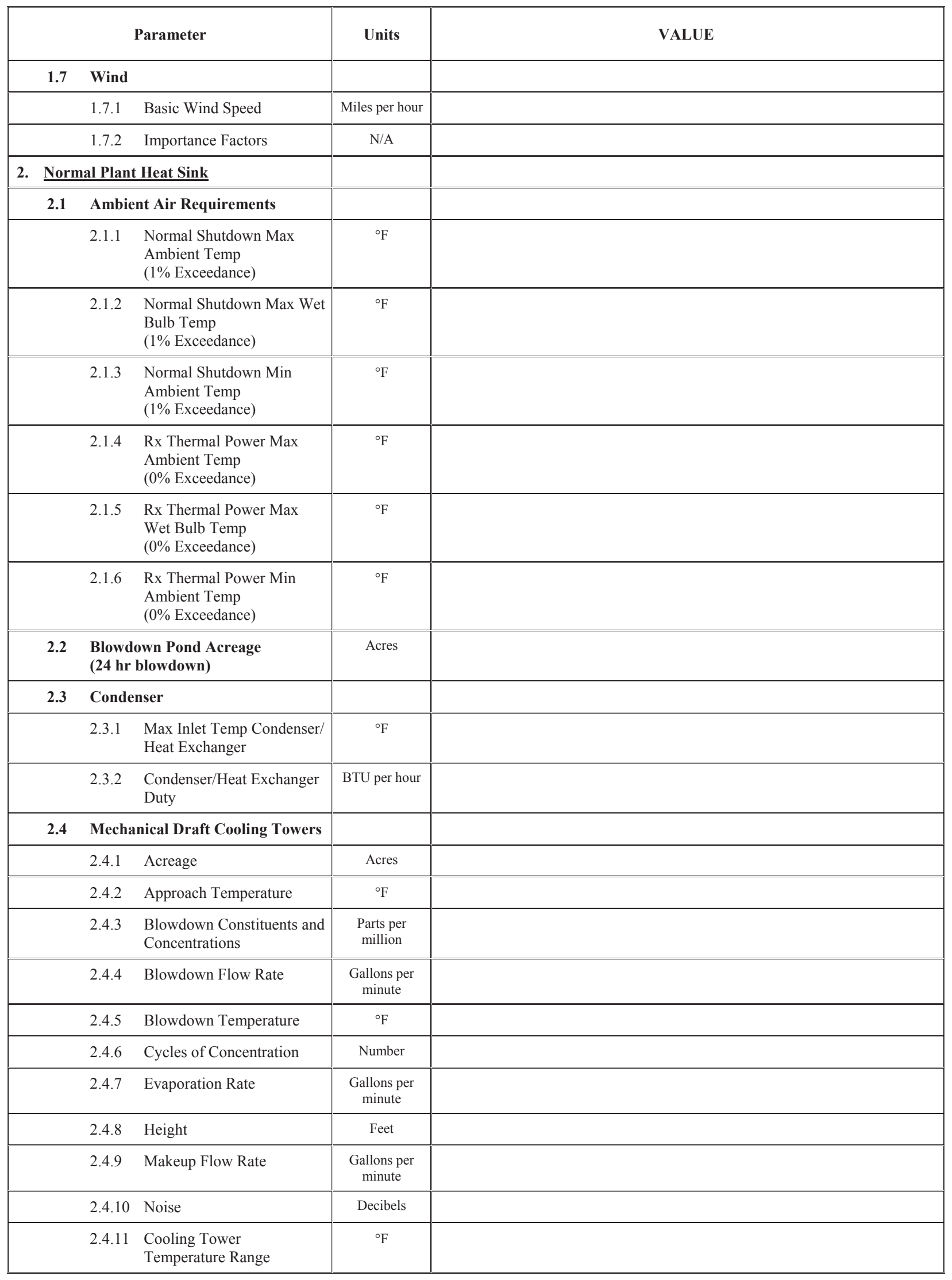


Appendix B - Plant Parameter Worksheets

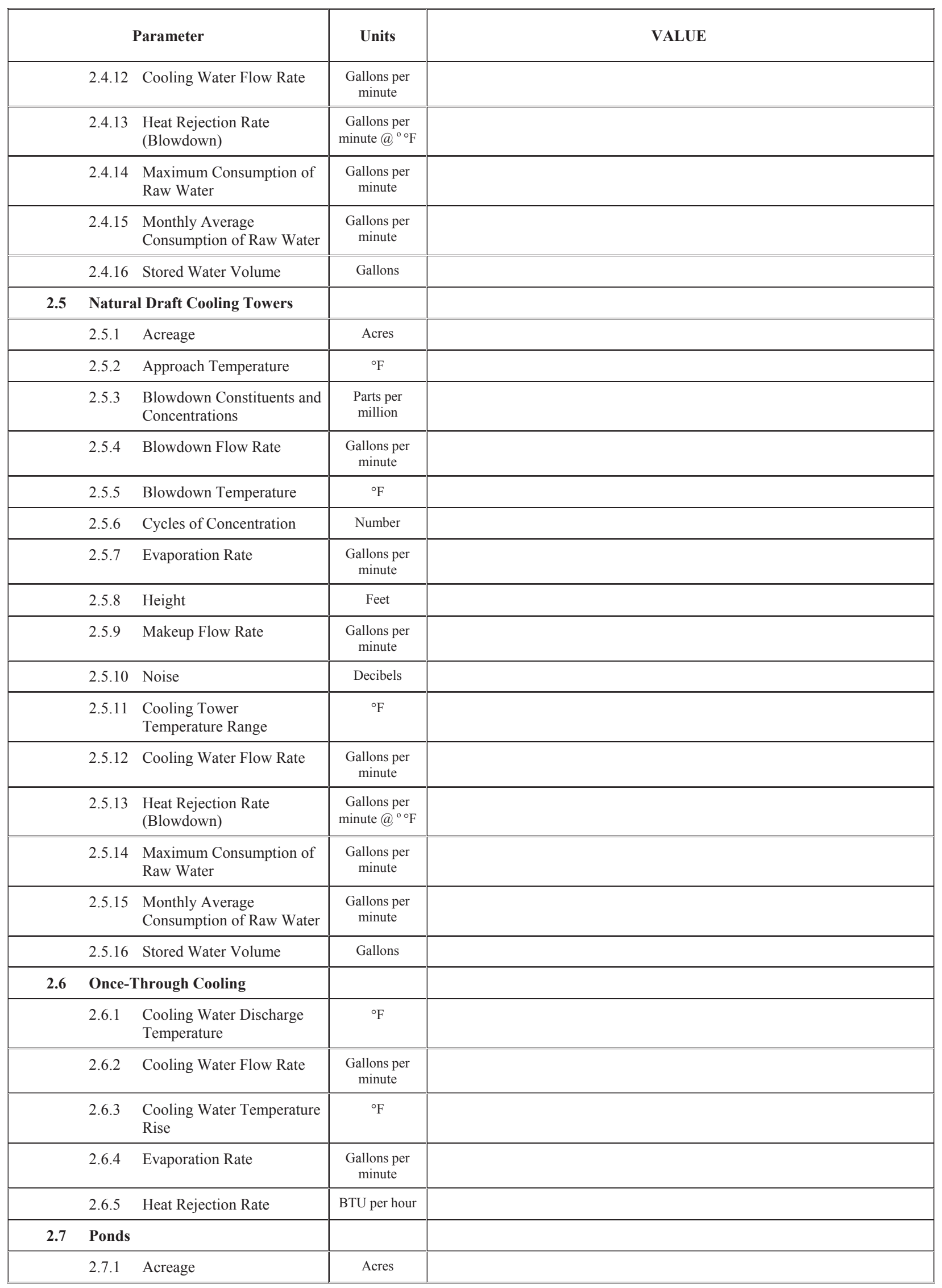


Appendix B - Plant Parameter Worksheets

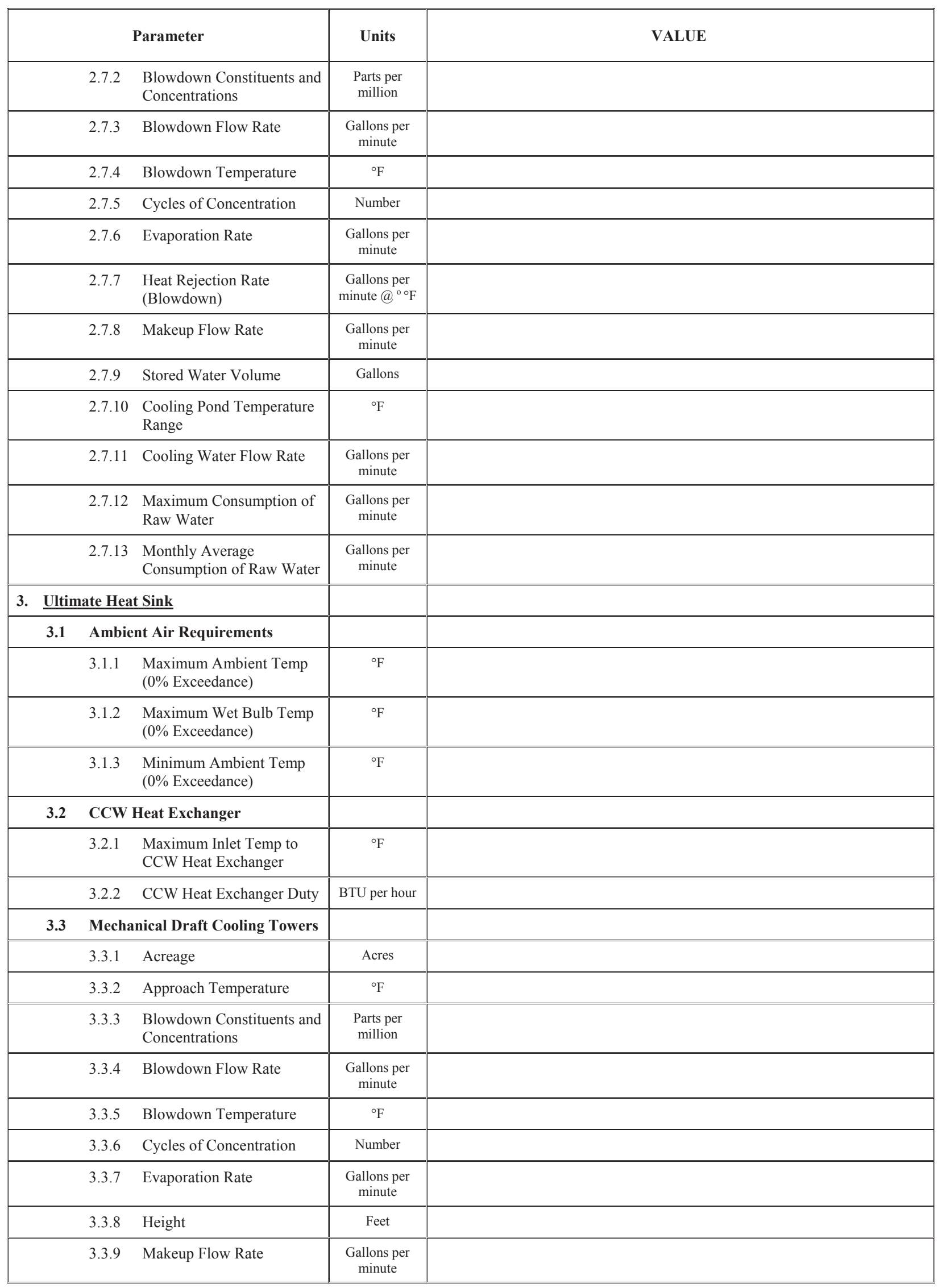


Appendix B - Plant Parameter Worksheets

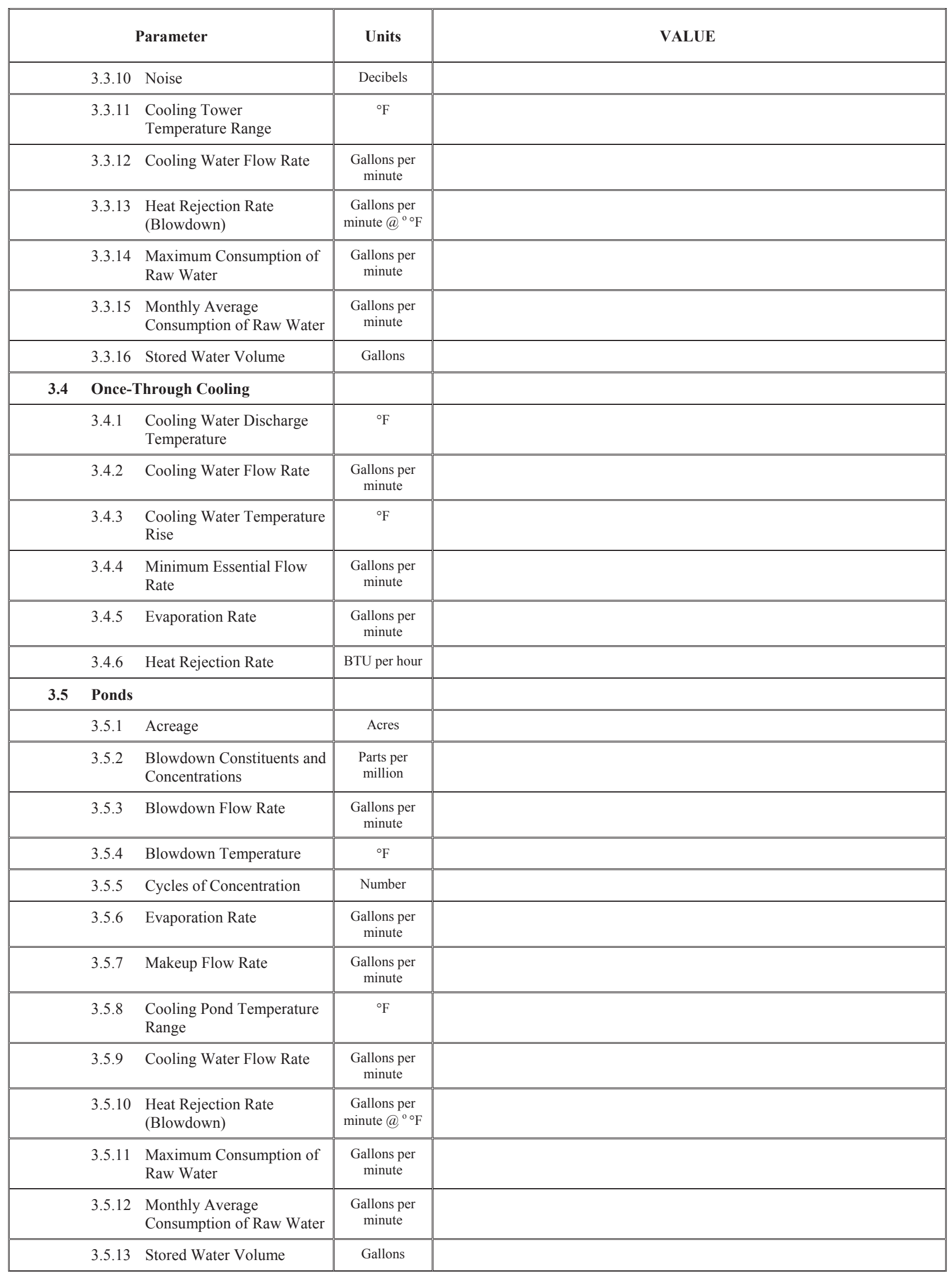




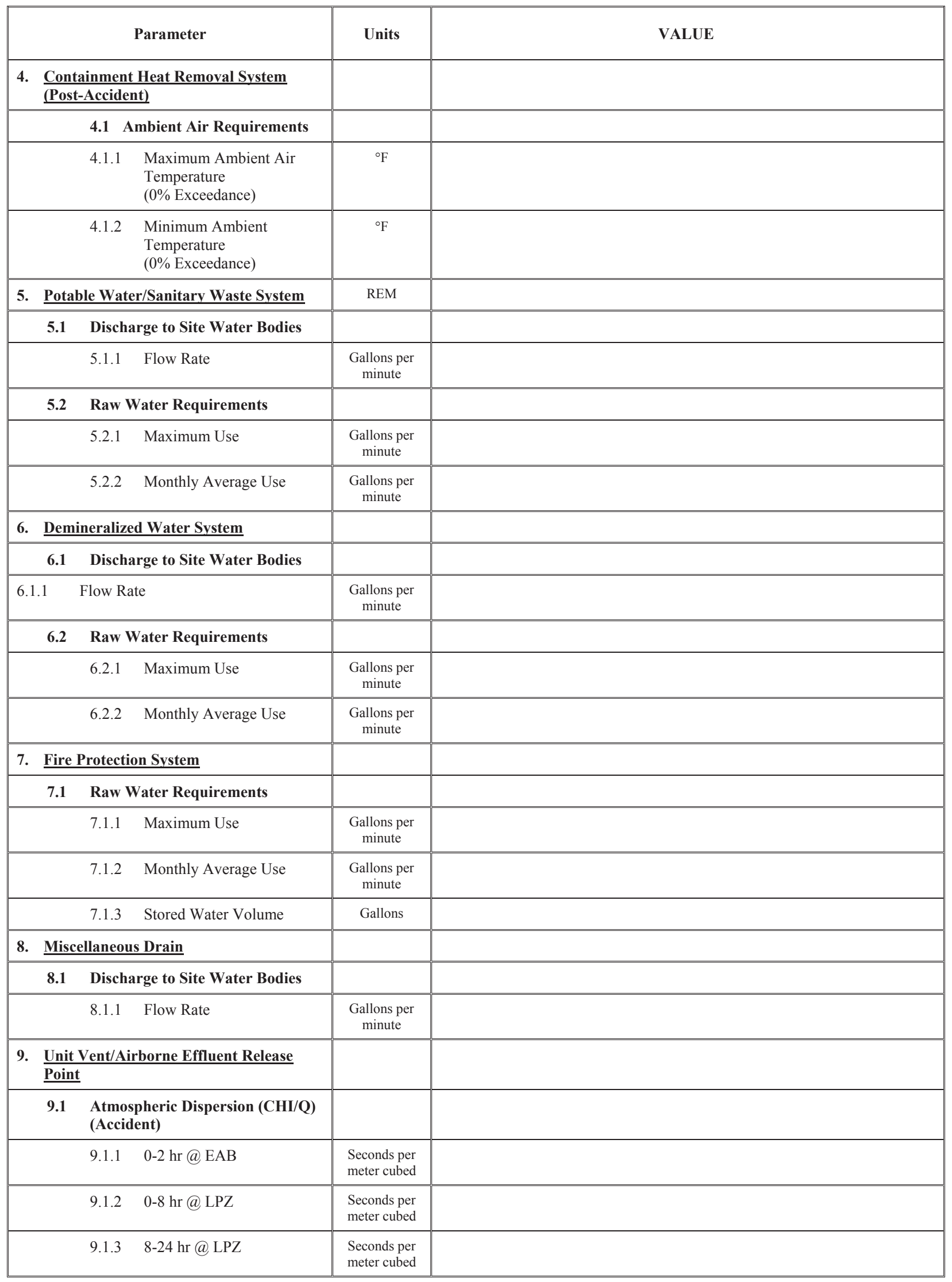


Appendix B - Plant Parameter Worksheets

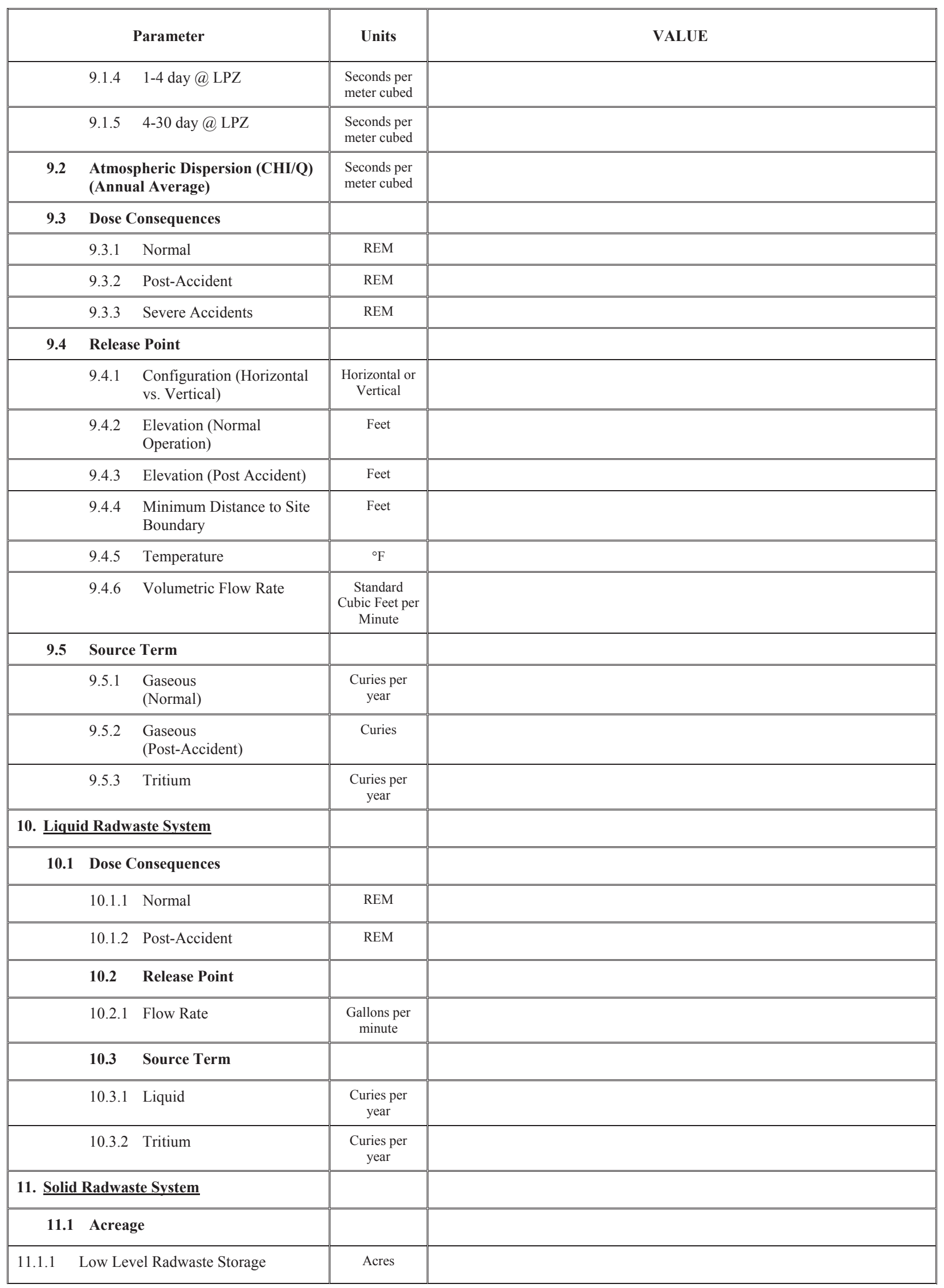


Appendix B - Plant Parameter Worksheets

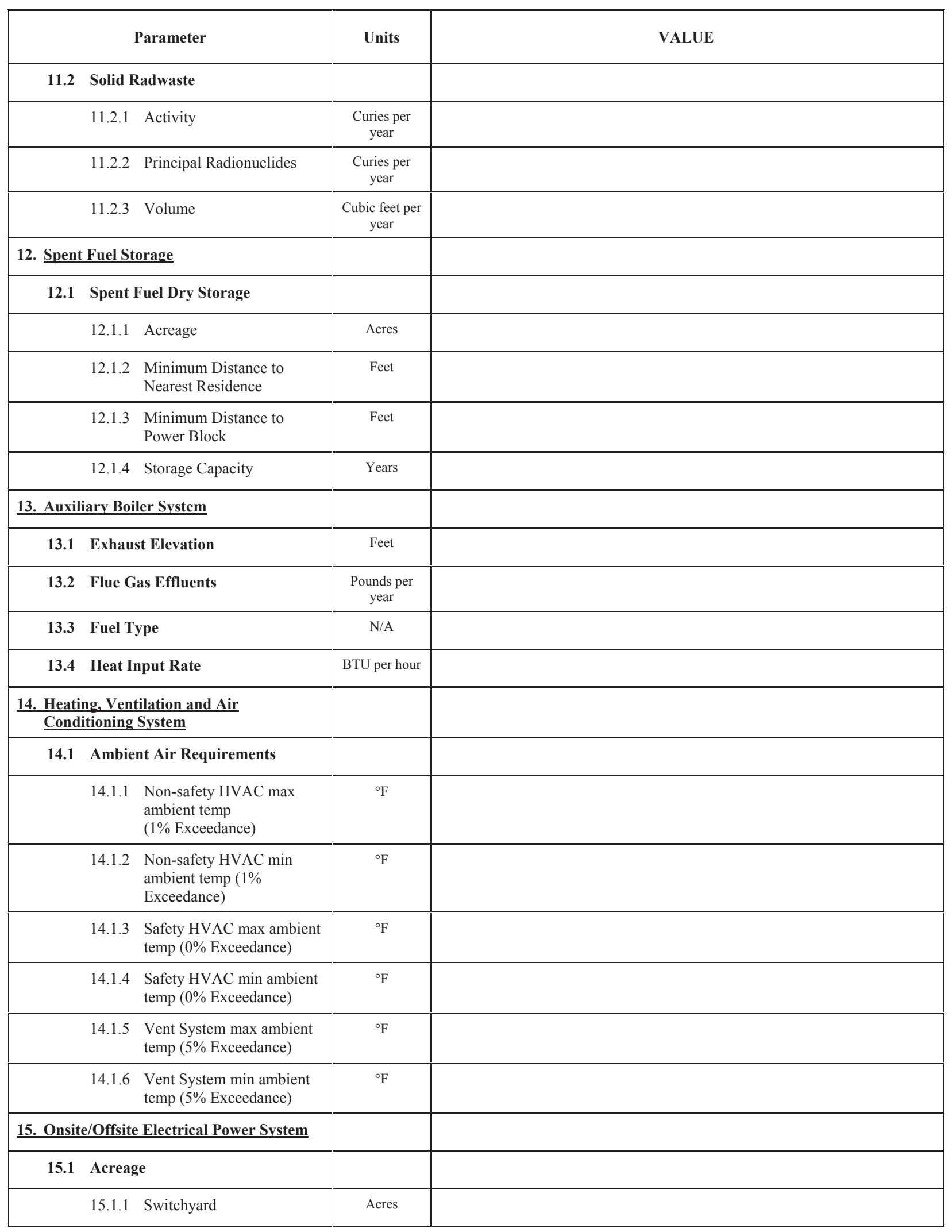


Appendix B - Plant Parameter Worksheets

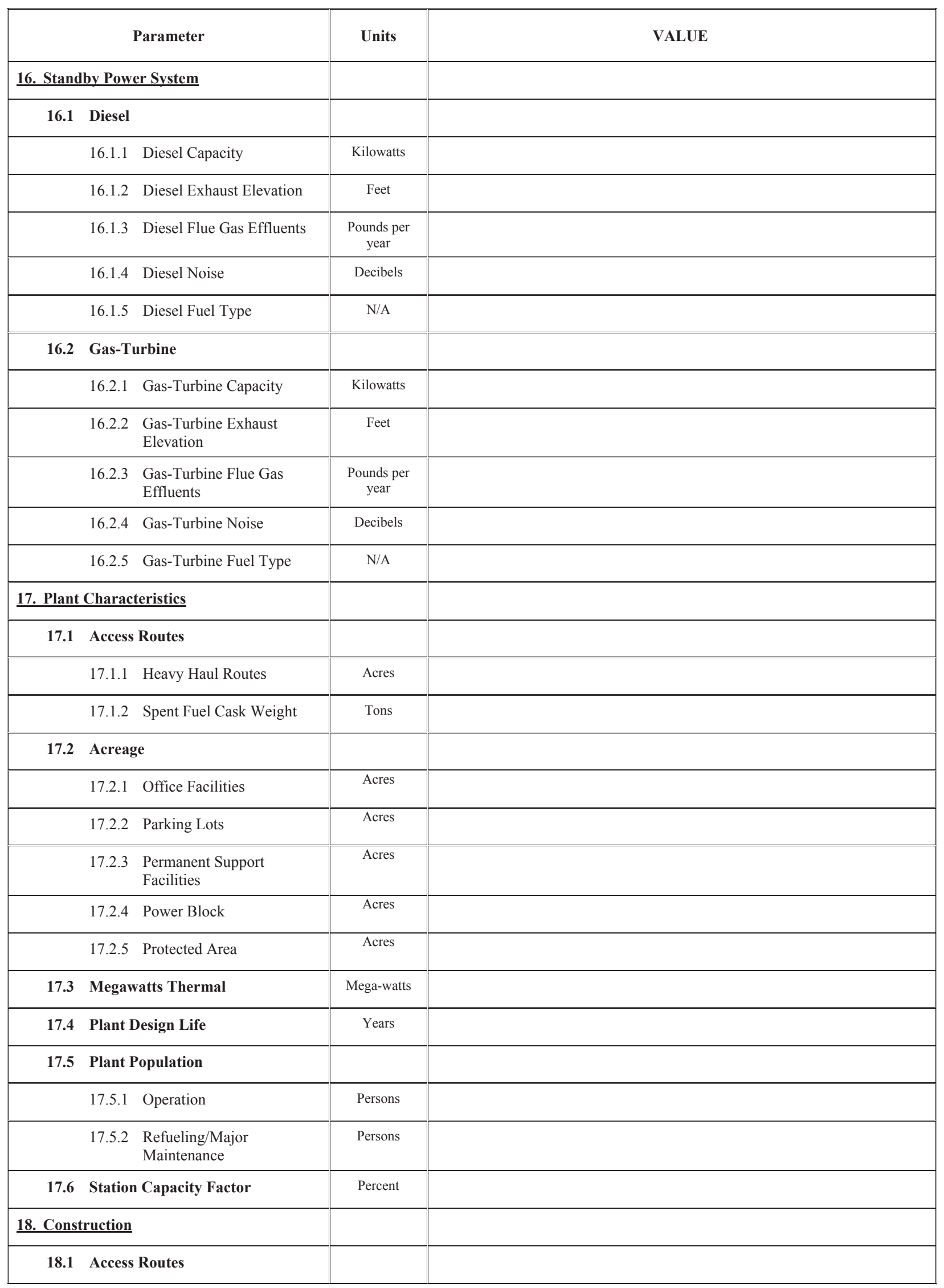


Appendix B - Plant Parameter Worksheets

\begin{tabular}{|c|c|c|c|}
\hline \multicolumn{2}{|r|}{ Parameter } & \multirow{2}{*}{$\frac{\text { Units }}{\text { Feet }}$} & \multirow[t]{2}{*}{ VALUE } \\
\hline & $\begin{array}{l}\text { 18.1.1 Construction Module } \\
\text { Dimensions }\end{array}$ & & \\
\hline & $\begin{array}{ll}\text { 18.1.2 } & \begin{array}{l}\text { Heaviest Construction } \\
\text { Shipment }\end{array}\end{array}$ & Tons & \\
\hline \multicolumn{4}{|c|}{ 18.2 Acreage } \\
\hline & 18.2.1 Laydown Area & Acres & \\
\hline & $\begin{array}{ll}\text { 18.2.2 } & \text { Temporary Construction } \\
& \text { Facilities }\end{array}$ & Acres & \\
\hline \multicolumn{4}{|c|}{ 18.3 Construction } \\
\hline & 18.3.1 Noise & Decibels & \\
\hline \multicolumn{4}{|c|}{ 18.4 Plant Population } \\
\hline & 18.4.1 Construction & Persons & \\
\hline 18.5 & Site Preparation Duration & Months & \\
\hline $\begin{array}{l}\text { 19. Other } \\
\text { characteri } \\
\text { anticipate } \\
\text { site can ac } \\
\text { acreage } n c \\
\text { by/transp }\end{array}$ & $\begin{array}{l}\text { - Identify any other site } \\
\text { istic assumptions embedded in the } \\
\text { d design which must be verified the } \\
\text { commodate }- \text { e.g., storage tanks, } \\
\text { eeds, chemicals to be used } \\
\text { orted to/from facility }\end{array}$ & & \\
\hline
\end{tabular}

COMPLETED BY:

DATE: 
Appendix B - Plant Parameter Worksheets

B-14 


\section{APPENDIX C TEMPLATES FOR EVALUATING SITE CHARACTERISTICS}


Appendix C - Templates for Evaluating Site Characteristics 


\section{Appendix C Templates for Evaluating Site Characteristics}

TABLE OF CONTENTS

Health and Safety Characteristics Templates

- Geology, Seismology and Geotechnical Engineering

- $\quad$ Seismic Ground Motions

- Global Geohazards

- Site Geotechnical

- Hydrology

- Water Availability

- Flooding

- Nearby Hazardous Activities/Facilities that Could Affect Plant Safety

- Extreme Weather Conditions

- Radiological Considerations

- Atmospheric Dispersion - Accident Conditions

- Emergency Planning

- Population

- Population Density

- Population Centers

Environmental Characteristics Templates

- Ecology

- Terrestrial Ecology

- Aquatic Ecology

- $\quad$ Land Use

- Transmission Corridors and Transportation Routes

- Historic/Archeological/Cultural Resource Issues

- Water Use

- Hydrologic Impacts

\section{Sociological Impact Characteristics Templates}

- Public Acceptance

- Aesthetics

- Environmental Justice Considerations

- Socioeconomic Effects

Other Site Characteristics Templates

- Land Availability

- Site Constructability Factors

- Potential for Brownfield Contamination Issues

- Features that Could Affect Development of Security Measures and Adequate Security Plans

- Sample Template (with instructions). 
Appendix C - Templates for Evaluating Site Characteristics 


\section{Appendix C-1a Geology, Seismology and Geotechnical Engineering \\ Seismic Ground Motions \\ Global Geohazards \\ Site Geotechnical}


Appendix C - Templates for Evaluating Site Characteristics

\section{Site Characteristic: Health ANd SAfETy/Geology, SEISMology and Geotechnical ENGINEERING/SEISMIC GROUND MOTIONS}

\section{DESCRIPTION:}

Seismic ground motion assessments involve evaluation of the level of earthquake-induced vibratory shaking based on analyses of regional and local faults, tectonic stress conditions and structures, historic and instrumental seismicity (past earthquake record), paleoseismic features (prehistoric, geologic evidence of past earthquakes), and site geologic/stratigraphic conditions (e.g., shear wave velocity profile). The level of seismic ground shaking at the site is estimated for a specific probability (hazard) level, defined by applicable regulatory criteria (e.g., annual probability of exceedance of $\left.1 \times 10^{-4}\right)$. Site-specific seismic ground shaking is typically summarized by a seismic design response spectrum that plots ground acceleration versus frequency of vibration. This response spectrum is compared against the Certified Seismic Design Response Spectrum (CSDRS) used for design of the power plant to ensure that site-specific earthquake ground motions are below the design level for safety-related structures, systems, and components (SSCs).

\section{IMPORTANCE:}

General Design Criterion 2, "Design Bases for Protection Against Natural Phenomena," of Appendix A, "General Design Criteria for Nuclear Power Plants," to 10 CFR Part 50, "Licensing of Production and Utilization Facilities," requires that SSCs important to safety be designed to withstand the effects of natural phenomena such as earthquakes and geologic hazards, without loss of capability to perform their expected safety functions. Strong vibratory ground shaking, or possible ground failure triggered by seismic shaking, may pose an unacceptable risk to the continued operability of safety related (SR) SSCs. 10 CFR Part 100, Section 100.23, "Geologic and Seismic Siting Criteria" defines criteria for evaluating the suitability of a proposed site based on consideration of geologic, geotechnical, geophysical, and seismic characteristics. A Safe Shutdown Earthquake (SSE) is defined for evaluation of the possible level of ground shaking based on evaluation of potential earthquake sources, past documented earthquakes, and site characteristics. The SSCs must be able to remain functional under the site-specific SSE level of earthquake ground shaking.

Guidelines for SSE development are defined in RG1.165, "Identification and Characterization of Seismic Sources and Determination of Safe Shutdown Earthquake Ground Motion." However, current industry practice and updated NRC RGs have migrated away from the SSE approach defined in RG 1.165, and instead adopt a probabilistic, performance-based approach defined in RG 1.208, "A Performance-Based Approach to Define Site-Specific Earthquake Ground Motion," for qualifying a SSE for a site. For application of the performance-based approach, a site-specific ground motion estimate defined as the "Ground Motion Response Spectrum" (GMRS) is determined, using essentially the same basic geologic, tectonic, seismicity, and site characteristics input that are used to develop the SSE as outlined in RG 1.165. The Standard Review Plan (NUREG-0800) provides further insight as to areas of review by the NRC Staff and indicates either RGs 1.165 or 1.208 approaches to developing the SSE are suitable.

For site screening purposes, potential ground shaking levels are developed in an approach generally consistent with the SSE/GMRS methodology, with the level of consistency increasing with the more-focused later phases of screening. For an initial screening, however, a single estimate of site ground motion can be utilized (e.g., peak ground acceleration, peak ground acceleration [PGA]), and for preferred sites at the final screening stages a ground acceleration response spectrum can be used. The resulting PGA and response spectrum are then compared against the seismic design basis, or CSDRS, of the plant to demonstrate that the site-specific ground motion is enveloped by the plant design seismic levels. 


\section{Risk:}

During a license application review, the NRC Staff will review the site-specific SSE/GMRS and the technical basis used (e.g., seismic source model and site characteristics) to determine the ability of the safety related SSCs to withstand the predicted levels of seismic shaking. The predicted site ground motions will also be evaluated to assess the likelihood of seismically-induced ground failure, as is further discussed in the "Geologic Hazard" and "Site Geotechnical" templates.

RG 1.60, "Design Response Spectra for Seismic Design of Nuclear Power Plants" defines a smooth response spectrum that is generally used as the basis for many of the current CSDRS's accepted or under consideration by the NRC. For example, current standard nuclear plant designs for the Central and Eastern United States (CEUS) generally adopt the RG 1.60 spectrum anchored at a maximum PGA of $0.3 \mathrm{~g}$, with some modifications (especially in the high frequency range of the spectrum) to the base-line spectra by individual vendors. Available CSDRS's, either developed generically or for specific sites, may accommodate greater seismic design levels, but higher design motions may be accompanied by a greater level of regulatory scrutiny, higher licensing risk and duration, greater design costs, and greater construction costs. Therefore, the RG 1.60 spectral shape anchored at $0.3 \mathrm{~g}$ PGA is not strictly an exclusionary criteria. However, areas with ground motions that result in an exceedance of the RG 1.60 spectrum and PGA of $0.3 \mathrm{~g}$ are best initially avoided or down-ranked in an initial screening study. The likelihood of an exceedance of the RG 1.60 spectrum, and $0.3 \mathrm{~g}$ PGA, increases dramatically for highly seismic areas, and areas near potentially active geologic/tectonic structures.

The recommended siting approach is to initially avoid areas where regional hazard mapping shows PGA exceeding $0.30 \mathrm{~g}$ at an annual probability of exceedance of $1 \times 10^{-4}$. This probability of exceedance, roughly correlative with a seismic event with recurrence intervals of about 10,000 years, enables screening to be performed using reasonably available resources such as the 2008 U.S. Geological Survey National Seismic Hazard Maps (Peterson et al. 2008) and the U.S. Geological Survey Quaternary Fault and Fold database (Machette et. al., 2004).

\section{EVALUATION:}

\section{Acceptable Site}

\section{Challenged Site Requiring Further Evaluation}

\section{Site Not Suitable}

\section{DISCUSSION:}

Plant safety related SSCs must be capable of withstanding the site-specific SSE/GMRS ground motions. If an existing probabilistic seismic hazard analysis (PSHA) model is being used in the screening, the technical basis and justification of the model must be evaluated; if a new PSHA is being developed, a technical basis for that model must be developed. The evaluation is commonly conducted by a team of geologists and seismologists experienced in all aspects of PSHA models (e.g., source characterization, ground motion attenuation, site response). This evaluation typically involves review of the regional and local geologic setting, tectonic setting, and known seismic sources as reported within publicly available information (e.g., journal articles, government publications) and as discovered through interviews with the professional community (e.g., university researchers, U.S. Geological Survey researchers, consultant experts).

For existing PSHA models (e.g., the 2008 U.S. Geological Survey Seismic Hazard Maps), potential earthquake sources that are not included in the existing model (e.g., updated source information, newly-identified faults, etc.) need to be accounted for within the analysis of sites. For new PSHA models being developed, all potential earthquake sources capable of impacting the site need to be included following the guidance of RG 1.208. These PSHA models are then used to calculate the screening level site ground motions (e.g., PGA or response spectrum), and the ground motion levels 
for alternate sites are compared against the evaluation criteria listed above and the plant CSDRS to establish a relative ranking.

Unfavorable sites are dismissed or downgraded, with a brief summary of the basis for the initial ranking. Favorable sites are then described and verified by further more-detailed ground motion analyses in compliance with RG 1.165 or 1.208 procedures, and as described below.

Site Type - The evaluation should identify the type of site being evaluated, i.e., a "Greenfield," "Brownfield " or existing nuclear power plant site, in addition to site characteristics such as deep soil, dense shallow soil, or bedrock conditions. The evaluation should identify the unique applicability of site type-related differences, if any, for the treatment of this issue. For example, bedrock sites may be preferable to adjacent deep soil sites (that can amplify ground motions) for areas where controlling earthquakes are from distant and major sources with potentially large earthquakes. In contrast, some dense soil or soft rock sites may be preferable to hard rock sites in areas where controlling ground motions are related to nearby sources of small to moderate size earthquakes that can produce substantial high frequency motions. In addition, the evaluation should take into consideration existing data and analyses that might be available, for example, in the case of an existing nuclear site or, perhaps, a "Brownfield site." In these cases the additional ground motion analysis may not be needed and the overall confidence level in the analysis results may be very high compared to a "Greenfield site."

Evaluation Criteria - A site is classified as "Acceptable Site" if site-specific ground motions are $<90 \%$ of RG 1.60 spectra.

A site is classified as "Challenged Site Requiring Further Evaluation" if site-specific ground motions are $=90$ to $110 \%$ of RG 1.60 spectra.

A site is classified as "Site Not Suitable" if site-specific ground motions are $>110 \%$ of RG 1.60 spectra.

The Standard Review Plan (NUREG-0800) describes types of ground motion analyses acceptable to the NRC staff for safety related SSCs. It should be used in conjunction with the following acceptability guidance to determine final site acceptability. The site verification ground motion analysis should be performed for a probability of exceedance equivalent to $1 \times 10^{-4}$ (roughly 10,000 year return period) to develop correlative site-specific SSE/GMRS ground motions correlative to the RG 1.60 spectrum. This requires collection of regional and site data and includes development of a documented seismic source model, site-specific PSHA, and where warranted, a site response analyses that incorporates geotechnical subsurface exploration and geophysical (e.g., shear wave velocity profiles) and laboratory test data (e.g., dynamic soil testing). The results from the site-specific verification analyses are again classified according to the Evaluation Criteria listed above. Those sites exhibiting site-specific ground motions $90 \%$ or less of the RG 1.60 spectrum anchored at $0.3 \mathrm{~g}$ are deemed to be fully acceptable. Those sites with site-specific ground motions between 90 and $110 \%$ of the RG 1.60 spectrum anchored at $0.3 \mathrm{~g}$ are considered challenged and downranked. Any sites exhibiting site-specific ground motions in excess of $110 \%$ of the RG 1.60 spectrum anchored at $0.3 \mathrm{~g}$ should be further downranked, and/or considered to be unfavorable/potentially not suitable. More-detailed ground motion analyses are required to further evaluate/verify the suitability of sites classified as challenged or potentially not suitable.

Risk - A primary technical risk associated with site seismic evaluation is insufficient knowledge of potential earthquake sources and/or site conditions that could potentially cause under prediction of actual seismic ground motion levels for site screening. If site screening suggests seismic ground motions are acceptable, yet later detailed studies demonstrate that they are higher and exceed plant design criteria, a late-stage site rejection or potential forced plant seismic re-evaluation may be required. Potential regulatory risks associated with the seismic evaluation include extensive Requests for Additional Information (RAIs) and protracted review process if seismic sources and site conditions are not adequately investigated and documented. The degree of risk becomes lower as 
more information about possible earthquake sources and site conditions become available, or are directly developed. The degree of risk also is lower for sites that are not within, or near, known areas of active geologic processes such as active faults, volcanic centers, crustal plate margins, zones of enhanced historic seismicity, etc.

Risk Mitigation - The risk associated with under prediction and/or poor characterization of seismic conditions can be reduced by: (1) integration of experienced seismic experts in the site selection team; (2) collection and documentation of a robust data base of existing information and querying of topical and regional seismic experts; (3) use of conservative assumptions for initial ground motion modeling/analyses; (4) geologic aerial and field reconnaissance in the site region and location; (5) obtain site-specific geologic, geophysical, and geotechnical information to evaluate seismic site response, dynamic properties, and ground failure potential; and, (6) early NRC interaction.

\section{REFERENCES:}

1. U.S. Nuclear Regulatory Commission, Regulatory Guide 1.60, "Design Response Spectra for Seismic Design of Nuclear Power Plants."

2. U.S. Nuclear Regulatory Commission, Regulatory Guide 1.165, "Identification and Characterization of Seismic Sources and Determination of Safe Shutdown Earthquake Ground Motion."

3. U.S. Nuclear Regulatory Commission, Regulatory Guide 1.208, "A Performance-Based Approach to Define Site-Specific Earthquake Ground Motion."

4. U. S. Nuclear Regulatory Commission, NUREG-0800, SRP 2.4.4, "Potential Dam Failures."

5. 2008 U.S. Geological Survey National Seismic Hazard Maps (Peterson et al., 2008).

6. U.S. Geological Survey Quaternary Fault and Fold database (Machette et. al., 2004). 
Appendix C - Templates for Evaluating Site Characteristics

\section{Site Characteristic: Health and SafeTy/Geology, Seismology and Geotechnical ENGINEERING/GLOBAL GEOHAZARDS}

\section{DESCRIPTION:}

Global Geohazard (including "Surface Deformation" as commonly referenced in NRC RGs) assessment involves evaluation of the potential for surface deformation at, or through, the plant site as the result of active geologic processes. These processes include fault displacement, tectonic deformation, subsidence (typically induced by groundwater withdrawal or mining), karst/dissolution, mechanically weakened zones (shear zones), liquefaction, irregular weathering, slope failure (landslides), unstable geologic deposits, and volcanism. The geohazard potential is assessed by compilation and review of existing geoscience data and remote imagery, followed by geologic reconnaissance (ground and aerial) and site subsurface exploration. Typically, the risk and hazard assessment associated with geohazards is performed on a qualitative basis in the initial siting phase, with possible quantitative evaluation of identified geohazards during later "fatal flaw" site verification. With regards to geologic processes, those structures or phenomena that show evidence of activity within the Quaternary geologic period (past 1.8 million years) are considered to be potentially active structures that require additional investigation. The NRC formally defines capable structures as those with evidence of activity once in the past 50,000 years or with evidence of recurring activity within the past 500,000 years (RG 1.208). The typical approach with regards to geohazards is avoidance, rather than mitigation. Avoidance is preferred because many geohazards cannot be reasonably mitigated (e.g., active fault displacement), would require prohibitive characterization/mitigation costs, and pose a major licensing risk due to extended review schedules and the potential for license rejection.

Appendix D to RG 1.165 (D.2.1) states that: (1) in general, any tectonic surface deformation within 25 miles $(40-\mathrm{km})$ of a site will require detailed investigation to determine its significance,

(2) engineering solutions may not be adequate to mitigate the effects of ground surface deformation or displacement, and (3) it is prudent to select an alternative site when a potential for permanent ground displacement exists at a proposed site. Therefore, site locations that are within 25 miles(40$\mathrm{km}$ ) of a tectonic structure that has exhibited, or has the potential to exhibit, surface displacement or deformation should be avoided, if possible, or downranked in comparison to other sites. If such a site is to be considered, it must be determined through detailed investigations whether the structure is capable. If the investigations demonstrate that the structure is not capable, then additional considerations relative to surface displacement or deformation would not be required. Section D.2.1 also indicates that more extensive investigation will be needed for any faults or other tectonic structures located within 5 miles $(8-\mathrm{km})$ of a site to determine if they are capable tectonic sources. Accordingly, sites without such structures are more favorable.

\section{IMPORTANCE:}

General Design Criterion 2, "Design Bases for Protection Against Natural Phenomena," of Appendix A, "General Design Criteria for Nuclear Power Plants," to 10 CFR Part 50, "Licensing of Production and Utilization Facilities," requires that SSCs important to safety be designed to withstand the effects of natural phenomena such as earthquakes and geologic hazards, without loss of capability to perform their safety functions. Geohazard-related surface deformation or movements can pose an unacceptable risk to the continued operability of safety related SSCs. 10 CFR Part 100, Section 100.23, "Geologic and Seismic Siting Criteria" defines criteria for evaluating the suitability of a proposed site based on consideration of geologic, geotechnical, geophysical, and seismic characteristics of a proposed site. The presence of geohazards or Quaternary-active geologic structures, are identified and compiled on regional and local maps typically in a Geographic Information System (GIS) database. Particular focus is given to any geohazards or Quaternary structures within each of three areas defined by circles drawn around the site using radii of 25 miles (40-km), 5 miles $(8-\mathrm{km})$, and 0.6 miles $(1-\mathrm{km})$. 
Appendix C - Templates for Evaluating Site Characteristics

Guidelines for evaluation of geohazards (surface deformation) are presented in RGs 1.165, "Identification and Characterization of Seismic Sources and Determination of Safe Shutdown Earthquake Ground Motion," and 1.208 "A Performance-Based Approach to Define Site-Specific Earthquake Ground Motion." Some additional guidance related to characterization of geohazards and potential adverse site conditions is provided in RGs 1.132 "Site Investigations for Foundations of Nuclear Power Plants," 1.198 "Procedures and Criteria for Assessing Seismic Soil Liquefaction at Nuclear Power Plant Sites," and 4.7 "General Site Suitability Criteria for Nuclear Power Stations."

The Standard Review Plan (NUREG-0800) provides insight as to areas of review by the NRC Staff, and references the above-listed RGs as guiding criteria. The Standard Review Plan specifies compliance with requirements of 10 CFR 100.23 with respect to evaluation of geohazards (surface deformation).

For site screening purposes, potential geohazards are identified and compiled on regional and local maps in a consistent approach as specified in RGs 1.165 and 1.208, including, as appropriate, GIS-based maps of the 25 miles $(40-\mathrm{km}), 5$ miles $(8-\mathrm{km})$, and 0.6 miles $(1-\mathrm{km})$ radii around the site. The geohazard map compilation is performed in a consistent manner for all considered sites to permit relative evaluation and ranking of sites. For identified and mapped geohazards, brief descriptive narratives are developed that summarize the hazard/feature, define it's characteristics and potential hazard, and describe potential additional work for further characterization, if needed, during later "fatal flaw" verification studies.

\section{RISK:}

The NRC Staff will review applications for the possible presence of geohazards (surface deformation), as described above, to determine the potential risk for the safe function of the safety related SSCs. Regulatory documents do not define exclusionary criteria for geohazards/surface deformation, but rather suggest avoidance and detailed characterization of potential geohazards and Quaternary geologic structures. Nuclear plant Design Control Documents (DCD) provide performance criteria with respect to plant foundation stability and settlement that can be used to compare against estimated magnitudes of surface deformation associated with a geohazard. However, characterization of potential magnitudes of surface deformation associated with a geohazard typically has substantial uncertainty, and/or requires very extensive, expensive, and long-duration field and office studies. Additionally, regulatory review schedules may be significantly extended if geohazard characterization and mitigation is required, and final regulatory acceptance of the site may be jeopardized. For example, it is stated in the Standard Review Plan that "It is important to note that no commercial nuclear power plant has ever been constructed on a known capable tectonic deformation feature, and it is questionable whether it may be feasible to design for surface or near-surface tectonic displacements with any degree of confidence that safety-related plant features would remain intact and functional if displacements were to occur. Consequently, it is NRC policy to recommend that any site determined, based on results of detailed fault investigations, to lie on a surface or near-surface tectonic structure capable of displacement be prudently re-located to an alternate site by the applicant."

Therefore, the recommended siting approach is to avoid areas where regional and local mapping show the presence of geohazards and Quaternary geologic structures. For initial screening, consistent setback distances from various types of possible geohazard or Quaternary geologic structures (e.g., active faults, volcanic centers, areas of subsidence, etc.) are established and used to develop derivative hazard maps defining hazard avoidance zones. A ranking matrix is developed that includes relative hazard for various identified or mapped geohazards (i.e., some geohazards are more adverse than others), setback distance, and activity. Various published maps and databases, such as the 2004 Quaternary Fault and Fold database (Machette et. al. 2004), provide consistent and appropriately detailed information for regional screening purposes of large areas 25 mile (40-km) radius), and for identification of major Quaternary geologic/tectonic structures. State geological surveys and federal agencies typically publish maps at various levels of detail and scales (e.g., 25- to 5 miles ([40- to 
Appendix C - Templates for Evaluating Site Characteristics

8-km] radii) that are useful to define general geologic setting and stratigraphy, mining and natural resources, hazards (e.g., landslide maps, volcanic hazard maps), and soil types (e.g., Soil Conservation Service) that help identify and define potential geohazards or sources of surface deformation. Local agencies (e.g., Regional Water Quality Control Boards, County Building Departments) typically compile maps and databases at local and detailed scales that are useful for evaluation of conditions and features within the 5 miles $(8-\mathrm{km})$ and 0.6 miles $(1-\mathrm{km})$ site radii. These local maps and databases are especially useful to evaluate potential hazards related to man-induced subsidence related to groundwater withdrawal, mining, or oil and gas production. The various maps, augmented with remote imagery interpretation (e.g., satellite, air photographs), and discussions with local geosciences researchers, provide initial information for site-specific screening. Any data from previous geologic, geophysical, groundwater, and geotechnical studies performed at the site(s) greatly assist site-specific evaluation of potential geohazards (surface deformation), and should be collected, if available. Existing nuclear plant sites typically have the greatest amount of high quality, site-specific data, followed (perhaps) by Brownfield sites that have had previous large structures or facilities. If existing site-specific and subsurface data is not available (e.g., "Greenfield" site), then limited "fatal flaw" site investigations may be required for final verification of siting alternatives.

\section{EVALUATION:}

\section{Acceptable Site}

\section{Challenged Site Requiring Further Evaluation}

\section{Site Not Suitable}

\section{DISCUSSION:}

The plant safety related SSCs must be capable of withstanding potential surface deformations at the site related to geohazards. The evaluator is expected to identify any potential geohazards or causes of surface deformation, and assess the potential hazard/risk associated with identified features. Initial screening is performed using existing geosciences databases, as described above, and regional reconnaissance by plane and or driving surveys. Initial screening of alternative sites is performed using the distance-based Evaluation Criteria listed above.

Unfavorable sites are downranked, or dismissed (if other clearly more-favorable sites are identified), with a brief summary of the basis for this initial ranking. Favorable and challenged sites are then ranked and described. Those sites found to be most-favorable are verified by further more-detailed evaluation in compliance with RG 1.165 or 1.208 procedures, and as described below.

For initially favorable, and possibly challenged, sites an additional level of screening is performed to refine a relative ranking scheme that incorporates criterion such as distances to geohazards, activity of features, and potential magnitude or style of deformation. The additional screening incorporates more detailed, and larger scale, map data from state and local agencies, review of satellite and aerial photograph imagery, site reconnaissance visits, and compilation/review of any available site-specific geologic, geophysical, geotechnical, and groundwater data and investigations. This information is compiled within a GIS database and analyzed in conformance with guidelines presented in RGs 1.165 and 1.208. The additional information is used to develop, or refine, recommended setback distances from identified geohazards and Quaternary geologic features, and to estimate relative activity and surface deformation hazard.

Those sites that are advanced as preferred sites are verified by site-specific "fatal flaw" investigations that may include geologic mapping, subsurface exploration, geophysical and laboratory testing, as well as geologic and geotechnical engineering analyses. These site-specific investigations should be performed in compliance with guidelines presented in RGs 1.165, 1.208, 1.132, and 1.138.

The results from the final ranking and/or fatal flaw verification studies are used to document an absence of potential geohazards/surface deformation at the site(s), or provide convincing initial 
investigative and quantitative data and analyses to demonstrate that potential surface deformations are less than the plant DCD and/or performance criteria.

Site Type - The evaluation should identify the type of site being evaluated, i.e., a "Greenfield," "Brownfield "or existing nuclear power plant site. The evaluation should identify the unique applicability of site type-related differences, if any, for the treatment of this issue. In addition, the evaluation should take into consideration existing data and analyses that might be available, for example, in the case of an existing nuclear site or, perhaps, a "Brownfield site." In these cases the "fatal flaw" site investigations may not be needed and the overall confidence level in the analysis results may be very high compared to a "Greenfield site."

Evaluation Criteria - A site is classified as "Acceptable" if no identified or suspected geohazards are located within 25 miles $(40-\mathrm{km})$ of the site. A site is classified as "Challenged Site Requiring Further Evaluation" if there are identified or suspected geohazards between 5 and 25 miles (8 and 40$\mathrm{km}$ ) from the site. A site is classified as "Site Not Suitable" if any geohazards are identified onsite or within a 5 mile $(8-\mathrm{km})$ radius of the site.

The Standard Review Plan (NUREG-0800) describes the expected data sources and level of investigation and evaluation for screening of geohazards that are acceptable to the NRC staff for SR SSCs. As described previously, NRC indicates a preference for avoidance of geohazards/surface deformation rather than mitigation. A significant licensing risk is accepted for any sites that are potentially impacted by geohazards/surface deformation, even if detailed investigations and analyses demonstrate that potential magnitudes of deformation are within allowable tolerances specified in the plant DCD. The NRC references procedures and approaches presented in RGs 1.165, 1.208, 1.132, and 1.138 to determine final site acceptability.

Those sites with no identified or suspected geohazards or surface deformation sources within 25 miles $(40-\mathrm{km})$ are deemed to be fully acceptable. Those sites with identified or suspected geohazards or deformation sources at distances of between 5 and 25 miles ( 8 and 40-km) of site should be downranked. Sites with geohazards or surface deformation sources identified on, or within a 5 mile $(8-\mathrm{km})$ radius of site should be further downranked, and/or considered to be unfavorable/potentially not suitable. More-detailed site studies are required to further evaluate/verify the suitability of sites classified as challenged or potentially not suitable.

Risk - A primary technical risk associated with site global geohazard evaluation is insufficient knowledge of potential geohazard and surface deformation sources that could potentially exist at, or near, the site(s). Insufficient knowledge could result in non-identification, misrepresentation of geohazards feature/structure activity, under prediction of potential surface deformation magnitude, etc. If site screening suggests that no significant geohazards or surface deformation sources exist or represent potential hazard, yet later detailed studies show that a hazard exists, a late-stage site rejection or potential major mitigation and investigative delays may be incurred. Potential regulatory risks associated with geohazard evaluation include extensive Requests for Additional Information (RAIs) and expectations for comprehensive site and regional geologic/geotechnical study, and associated protracted review process or possible non-acceptance by NRC. The degree of risk becomes lower as more information about possible earthquake sources and site conditions become available, or are directly developed. The degree of risk also is lower for sites that are not within, or near, known areas of active geologic processes such as active faults, volcanic centers, crustal plate margins, zones of enhanced historic seismicity, etc.

Risk Mitigation - The risk associated with under prediction and/or poor characterization of geohazards and surface deformation can be reduced by: (1) integration of experienced geologic experts in the site selection team; (2) collection and documentation of a robust data base of existing information and querying of topical and regional experts; (3) use of conservative assumptions regarding activity and consequences for initial evaluations of potential geohazard/surface deformation sources; (4) geologic aerial and field reconnaissance in the site region and location; (5) obtain 
site-specific geologic, geophysical, and geotechnical information to evaluate site geologic conditions and subsurface conditions; and; (6) early NRC interaction.

\section{REFERENCES:}

1. U.S. Nuclear Regulatory Commission, Regulatory Guide 1.165, "Identification and Characterization of Seismic Sources and Determination of Safe Shutdown Earthquake Ground Motion."

2. U.S. Nuclear Regulatory Commission, Regulatory Guide 1.208, “A Performance-Based Approach to Define Site-Specific Earthquake Ground Motion.”

3. U.S. Nuclear Regulatory Commission, Regulatory Guide 1.132, "Site Investigations for Foundations of Nuclear Power Plants."

4. U.S. Nuclear Regulatory Commission, Regulatory Guide 1.138, "Laboratory Investigations of Soils and Rocks for Engineering Analysis and Design of Nuclear Power Plants."

5. U.S. Nuclear Regulatory Commission, Regulatory Guide 1.198, "Procedures and Criteria for Assessing Seismic Soil Liquefaction at Nuclear Power Plant Sites."

6. U.S. Nuclear Regulatory Commission, NUREG-0800, SRP 2.4.4, "Potential Dam Failures."

7. U.S. Geological Survey Quaternary Fault and Fold database (Machette et. al., 2004). 
Appendix C - Templates for Evaluating Site Characteristics

\section{Site CHARACTERISTIC:}

\section{HEALTH AND SAFETY/GEOLOGY, SEISMOLOGY AND GEOTECHNICAL ENGINEERING/SITE GEOTECHNICAL}

\section{DESCRIPTION:}

Site geotechnical (stability of subsurface conditions and foundations) assessment involves evaluation of the potential for site-specific geologic and geotechnical hazards or issues that could affect plant safety or function, or present unusual difficulty or cost for construction of a plant at the site. Specific issues/conditions that fall under this category, as defined in the Standard Review Plan (SRP, NUREG-0800) include subsidence, karst/dissolution, uplift/heave (stress relief), collapse/settlement, localized altered or weak zones, irregular weathering profiles, weak bedrock structures or shear zones, unstable mineralogy, seismically-induced ground failure (e.g., liquefaction, lateral spreading), soil amplification of seismic ground motions, and high or unusual groundwater conditions. Evaluation of these issues requires characterization of the site-specific geologic and soil stratigraphy and composition, geologic structure and stress history (e.g., past glacial loading, erosional stress relief, tectonic stress), subsurface material engineering properties (e.g., shear strength, density, compressibility, stress-relief or saturation-induced weakening), groundwater conditions, and impacts of site construction activities (e.g., fill and foundation surcharge loading, excavation-induced stress relief).

Initial evaluation of site geotechnical conditions is performed by compilation and review of existing geoscience data and remote imagery to understand the geologic setting and depositional/stress history, followed by geologic reconnaissance (ground and aerial) and site subsurface exploration and material testing. Typically, assessment of the risks and hazards associated with site geotechnical conditions is performed on a qualitative basis in the initial siting phase, with follow-on quantitative evaluation during "fatal flaw" site verification. The quantitative evaluation is initially performed using any available existing data compiled from local agencies and the applicant (e.g., existing nuclear plant Safety Analysis Report or Brownfield site geotechnical studies), and limited field reconnaissance mapping and inspection. Fatal flaw verification investigations typically are required for most sites, even those with existing site-specific investigation data, in order to obtain consistent information for each site to enable final suitability ranking and site selection. The site geotechnical assessment is performed concurrently with the geohazards/surface deformation evaluation to ensure consistent hazard evaluations between different site parameters. Site geotechnical evaluation typically is a focal point for NRC review and insufficient characterization of site conditions and related potential issues at the siting stage can lead to delays in the NRC acceptance of a site.

The typical approach with regards to adverse site geotechnical issues is avoidance, where possible. However, as opposed to other geologic and seismologic hazards (e.g., vibratory ground motions and permanent ground deformation), many geotechnical issues can be mitigated using industry standard approaches to site preparation, ground improvement, and foundation design. Typical mitigation approaches include: ground improvement through grouting or other techniques (e.g., for mitigation of shallow liquefaction or weak soils), deepening of foundations, groundwater pumping or control, and grading over excavation (removal of weak or unsuitable surface soils or weathered zones). Therefore, geotechnical issues typically are not considered exclusionary criteria, but rather are considered as avoidance or preference criteria when comparing alternative sites. Mitigation measures, if proposed, must consider the specific foundation performance criteria for the plant defined in the DCD and increased investigative and cost impacts in comparison to less-challenged sites. This is accomplished by developing a consistent ranking matrix that factors the potential impacts of mitigation.

\section{IMPORTANCE:}

General Design Criterion 2, "Design Bases for Protection Against Natural Phenomena," of Appendix A, "General Design Criteria for Nuclear Power Plants," to 10 CFR Part 50, "Licensing of Production and Utilization Facilities," requires that structures, systems, and components important to safety be designed to withstand the effects of natural phenomena such as earthquakes and geologic 
hazards (including adverse site subsurface or geotechnical conditions), without loss of capability to perform their safety functions. Unstable soil/rock, or adverse geologic/geotechnical/groundwater conditions may pose an unacceptable risk to the continued operability of SR SSCs. 10 CFR Part 100, Section 100.23, "Geologic and Seismic Siting Criteria" defines criteria for evaluating the suitability of a proposed site based on consideration of geologic, geotechnical, geophysical, and seismic characteristics of the proposed site. Section 2.5.4 of NUREG-0800 presents the NRC's Standard Review Plan (SRP) for the evaluation of site investigations used to determine soil and rock properties and characteristics needed in the analysis and design of foundations and earthworks for proposed nuclear power plants. Required investigations include dynamic and static analyses to evaluate the subsurface material's responses to seismic loading, interactions between soils and structures, as well as foundation and facility stability.

Guidelines for the evaluation of site geotechnical conditions to ensure meeting the SRP and the requirements of 10 CFR Part 50 and 10 CFR Part 100, Section 100.23 are presented in RGs 1.132 "Site Investigations for Foundations of Nuclear Power Plants," 1.138 "Laboratory Investigations of Soils for Engineering Analysis and Design of Nuclear Power Plants," 1.198 "Procedures and Criteria for Assessing Seismic Soil Liquefaction at Nuclear Power Plant Sites," and 4.7 "General Site Suitability Criteria for Nuclear Power Stations."

As outlined in these RGs, characterization of site geotechnical conditions and subsurface variability for design-level studies requires extensive subsurface investigations and testing. This level of effort is not feasible for initial siting studies. Therefore, for site screening purposes, potential site geotechnical hazards are initially assessed based on review of existing regional and local maps in a consistent approach as specified in RGs 1.165 and 1.208, including, as appropriate, GIS-based maps of the 25 miles $(40-\mathrm{km}), 5$ miles $(8-\mathrm{km})$, and 0.6 miles $(1-\mathrm{km})$ radii around the site. These maps are used to identify the general geologic setting, geologic formations and stratigraphy, stress history, and possible global geohazards (e.g., large-scale landsliding, young Quaternary geologic deposits potentially susceptible to liquefaction, active tectonic zones, evidence for past glaciation, etc.). Large-scale state or local geologic and geotechnical hazard maps, if available, can also provide useful information to evaluate potential major geotechnical hazards or issues. In additional to utilizing existing mapping, remote sensing techniques (e.g., analysis of Google Earth imagery and aerial photographs), coupled with direct aerial and/or ground reconnaissance, provide the primary means during initial screening studies to identify potential geotechnical hazards or issues. For identified geotechnical hazards or issues, brief descriptive narratives are developed that summarize the hazard/issue, define its potential impacts, and describe potential additional work for further characterization, if needed, during later "fatal flaw" verification studies.

\section{RISK:}

The NRC Staff will review the possible presence of adverse geotechnical conditions to determine the potential risk they present to the safe functioning of SSCs. Regulatory documents do not define exclusionary criteria for geotechnical issues but rather suggest avoidance coupled with detailed characterization of site geotechnical conditions, subsurface material properties, and their variability. The site characteristics and material properties are compared against the nuclear plant DCD performance criteria for site characteristics to verify site suitability with respect to plant performance, such as foundation stability and tolerable settlements. The site geotechnical conditions also are assessed to verify that construction of the plant can be reasonably performed, and to define general mitigation approaches to address any geotechnical issues that cannot be reasonably avoided. The detailed site characterizations are needed either as evidence against the presence of adverse geotechnical conditions that require mitigation or as evidence supporting the techniques proposed to mitigate adverse geotechnical conditions.

In order to facilitate consistent factoring of geotechnical conditions between sites, a ranking matrix is developed that defines key potential geotechnical hazards (e.g., liquefaction susceptibility, landslide/slope failure susceptibility, karst/dissolution, subsidence) and primary geotechnical 
conditions that impact foundation design or site construction (e.g., soil type and thickness, depth to bedrock, shear wave velocity, groundwater conditions) that could have the greatest impact on construction schedule and cost for a site.

Any data from previous geologic, geophysical, groundwater, and geotechnical studies performed at the site(s) greatly assist site-specific evaluation of these potential hazards, and should be compiled, if available. Existing nuclear plant sites typically have the greatest amount of high quality, site-specific data, followed (perhaps) by Brownfield sites that have had previous large structures or facilities. If existing site-specific and subsurface data is not available (e.g., Greenfield site), then focused "fatal flaw" site investigations may be required for final verification of alternative sites.

\section{EVALUATION:}

\section{Acceptable Site}

\section{Challenged Site Requiring Further Evaluation}

\section{Site Not Suitable}

\section{DISCUSSION:}

The plant SSCs must be capable of withstanding potential site geotechnical hazards and conditions without impact on safe function. This may be achieved by avoidance, or reasonable mitigation. The evaluator is expected to identify any potential geotechnical hazards, and provide a general characterization of primary geotechnical and subsurface conditions, to assess the potential hazard/risk and required mitigation efforts.

A first level of screening is performed using existing geoscience databases, as described above, and site reconnaissance by aerial and/or ground reconnaissance. Initial screening of alternative sites is performed using the distance-based Evaluation Criteria listed above. Unsuitable sites are dismissed, with a brief summary of the basis for dismissal. Favorable sites are described and verified by further more-detailed evaluation in compliance with RGs 1.132, and 1.138, and 1.198 procedures, and as described below.

The remaining sites undergo a secondary screening to define a relative ranking scheme that incorporates criterion such as distances to geohazards, activity of features, and potential magnitude or style of deformation. The secondary screening utilizes more detailed mapping from state and local agencies, more detailed reviews of satellite and aerial photograph imagery, additional site reconnaissance, and compilation/review of any available site-specific geologic, geophysical, geotechnical, and groundwater data from previous investigations. This information is compiled and analyzed in conformance with guidelines presented in RGs 1.165 and 1.208, and compiled in a GIS database. Guidance within RGs 1.132, 1.138, and 1.198 is used assess the general quality and suitability of the available existing site-specific data. Combined, the results of these efforts are used to develop the comparative geotechnical hazard ranking matrix.

The geotechnical characteristics of those sites advanced as preferred sites by the site selection team are verified by site-specific "fatal flaw" investigations that may include geologic mapping, subsurface exploration, geophysical/laboratory testing, as well as geologic and geotechnical engineering analyses. These site-specific investigations should be performed in compliance with guidelines presented in RGs 1.165, 1.208, 1.132, and 1.138.

The results from these studies will be used to either: (a) document the absence of primary geotechnical hazards at the site(s), (b) provide evidence demonstrating that geotechnical conditions at the site are within the plant DCD performance or can be reasonably mitigated for plant foundation design and site construction, or (c) result in a revision of the initial classification of a site as unsuitable. Based on these results a refined ranking for the site(s) can be developed. 
Site Type - The evaluation should identify the type of site being evaluated, i.e., a "Greenfield," "Brownfield "or existing nuclear power plant site. The evaluation should identify the unique applicability of site type-related differences, if any, for the treatment of this issue. In addition, the evaluation should take into consideration existing data and analyses that might be available, for example, in the case of an existing nuclear site or, perhaps, a "Brownfield site." In these cases the "fatal flaw" site investigations may not be needed and the overall confidence level in the analysis results may be very high compared to a "Greenfield site."

Evaluation Criteria - A site is classified as "Acceptable" if there are generally favorable site conditions and no identified major geotechnical hazards.

A site is classified as "Challenged Site Requiring Further Evaluation" if potential geotechnical hazards exist that can be reasonably mitigated and/or if some site improvement or special foundation approaches might be required.

A site is classified as "Site Not Suitable" if major or multiple geotechnical hazards exist or if highly adverse site conditions exist.

The Standard Review Plan (NUREG-0800)_describes the expected data sources and level of investigation and evaluation for screening of site geotechnical conditions that are acceptable to the NRC staff for safety related SSCs. As described previously, NRC guidance indicates a preference towards avoidance of geotechnical issues rather than mitigation and there are specific requirements and expectations regarding approaches and level of site investigation and testing needed to characterize geotechnical conditions and variability. A significant licensing risk is accepted for any site that is potentially impacted by major geotechnical hazards or that has multiple geotechnical issues requiring substantial mitigation. The NRC references procedures and approaches presented in RGs $1.165,1.208,1.132$, and 1.138 to determine final site acceptability.

Those sites with no identified or suspected major geotechnical hazards and generally favorable site conditions are deemed to be fully acceptable. Those sites with potential geotechnical hazards that can be reasonably mitigated and/or some site improvement or special foundation approaches possibly required should be classified as challenged and initially downranked. Sites with major or multiple geotechnical hazards, or highly adverse site conditions should be classified as unfavorable/potentially unsuitable and further downranked or dismissed. Sites that are classified as challenged or unfavorable/potentially not suitable, yet are still carried forward as a candidate site, require further evaluation/verification to confirm suitability and reasonableness of required mitigation measures.

Risk - A primary technical risk associated with site geotechnical characterization is insufficient knowledge of potential geotechnical issues and hazards that could potentially exist at the site(s) and impact site foundation and grading design, or require extensive mitigation. Insufficient knowledge could result in non-identification or under prediction of potential severity of geotechnical issues. If site screening suggests no significant geotechnical issues exist, yet later detailed studies reveal major geotechnical issues, late-stage redesign or major mitigation and investigative delays may be incurred. Potential regulatory risks associated with geotechnical site characterization include extensive Requests for Additional Information (RAIs) and expectations for comprehensive site and regional geologic/geotechnical study, and associated protracted review process or possible non-acceptance by NRC. The degree of risk becomes lower as more information about specific site conditions become available, or are developed. The degree of risk also is lower for sites that are not within known areas of geotechnical problems, have high site uniformity, and have existing subsurface and geotechnical information.

Risk Mitigation - The risk associated with geotechnical characterization can be reduced by: (1) integration of experienced geologic/geotechnical experts in the site selection team; (2) collection and documentation of a robust data base of existing information and querying of topical and regional experts; (3) use of conservative assumptions regarding site conditions, uniformity, and material 
properties; (4) geologic aerial and field reconnaissance in the site region and location; (5) site-specific geologic, geophysical, and geotechnical information; (6) review and incorporation of "lessons learned" from past nuclear project siting and evaluation studies and existing license applications; and; (6) early NRC interaction.

\section{REFERENCES:}

1. U.S. Nuclear Regulatory Commission, Regulatory Guide 1.165, "Identification and Characterization of Seismic Sources and Determination of Safe Shutdown Earthquake Ground Motion."

2. U.S. Nuclear Regulatory Commission, Regulatory Guide 1.208, “A Performance-Based Approach to Define Site-Specific Earthquake Ground Motion.”

3. U.S. Nuclear Regulatory Commission, Regulatory Guide 1.132, "Site Investigations for Foundations of Nuclear Power Plants."

4. U.S. Nuclear Regulatory Commission, Regulatory Guide 1.138, "Laboratory Investigations of Soils and Rocks for Engineering Analysis and Design of Nuclear Power Plants."

5. U.S. Nuclear Regulatory Commission, Regulatory Guide 1.198, "Procedures and Criteria for Assessing Seismic Soil Liquefaction at Nuclear Power Plant Sites."

6. U.S. Nuclear Regulatory Commission, NUREG-0800, SRP 2.4.4, "Potential Dam Failures."

7. U.S. Geological Survey Quaternary Fault and Fold database (Machette et. al., 2004). 
Appendix C - Templates for Evaluating Site Characteristics 
Appendix C - Templates for Evaluating Site Characteristics

\section{Appendix C-1b Hydrology}

\section{Water Availability}

Flooding 


\section{Site Characteristic: Health AND Safety/Hydrology/Water AVAILABILITy}

\section{DESCRIPTION:}

Water requirements for nuclear power plants are that sufficient water be available for cooling during plant operation and normal shutdown, for the ultimate heat sink, and for fire protection. The limitations imposed by existing laws, water use plans of cognizant water resource planning agencies, and other statutory requirements and policies govern the use and consumption of water at potential sites for normal operation.

\section{IMPORTANCE:}

Depending on overall plant design, nuclear power plants may require reliable water sources for heat exchanger circulation and steam generation, emergency cooling, fire protection, potable water, and other functions.

\section{RISK:}

During a license application review, the NRC Staff will compare the site water supply characteristics during times of low-flow and corrected for other use allocations as projected into the period of facility operations with the design basis facility water consumption rate. Plant water use and consumption must be compatible with existing water use plans. In the absence of an existing water use plan, the effect of plant water usage on other water users is evaluated and considers flow or volume reduction and the resultant ability of all users to obtain adequate supply and to meet applicable water quality standards. The risk of insufficient quality or quantity of data may result in the rejection of the site for the nuclear power plant license.

\section{EVALUATION:}

\section{Acceptable Site}

\section{Challenged Site Requiring Further Evaluation}

\section{Site Not Suitable}

\section{DISCUSSION:}

Site Type - The analysis of water availability is relatively independent of site type (Greenfield, Brownfield, or existing nuclear power plant). Potential sites located in "Greenfields" may require more investigation to characterize water sources while existing power plant sites and Brownfields may possess extensive data. The intensity of each assessment will vary depending upon the quantity and quality of readily available data from existing plant sources and publicly available sources.

Evaluation Criteria - An "Acceptable Site" for purposes of the feasibility study is one that has adequate water resources to meet or exceed plant usage expectations during low-flow conditions and based on conservative assumptions without exceeding existing water withdrawal restrictions or affecting the ability of other water users to meet their water needs.

A "Challenged Site Requiring Further Evaluation" is one in which alternative water use strategies or mitigation measures would be necessary to meet water availability requirements for all users.

A "Site Not Suitable" evaluation occurs when the capacity of available water resources is exceeded and it is not reasonable to mitigate impacts.

Water Availability during Low-Flow Conditions:

The high-level water availability analysis requires comparison between the low-flow site conditions or low water levels with the maximum rate of raw water use. The availability of essential water during periods of low-flow or low water level is an important initial consideration for identifying potential sites on rivers, small shallow lakes, or along coastlines. The frequency and duration of low-flow or low level periods should be determined by inspecting available historical records. 
The limiting facility parameter requirements should be compared with candidate site water supply characteristics during low-flow conditions and projected use allocations over the life of the proposed plant (which may be 65 years or more). For water supplies from rivers and streams, states typically disallow withdrawals exceeding 10 percent of the dependable flow to be withdrawn for consumptive use. The U.S. Geological Survey (USGS) provides data on the 7-day average low-flow for a recurrence interval of 10 years (7Q10) for streams and rivers throughout the United States. Both the frequency and duration of low-flow or low-level periods should be determined from the historical record and, if the cooling water is to be drawn from impoundments, from projected operating practices.

A site is unsuitable when rivers and stream segments indicate a minimum flow of record of less than the total of the facility consumption rate and the future non-facility consumption rate. The site is also not suitable when segments of streams or rivers that meet the criteria are located beyond realistic pumping distances that exceed engineering and cost criteria.

For lakes, the supply capacity would be evaluated considering the lake capacity and lake levels, as well as historic low levels (droughts) and refill (inflow) rates, together with the potential for conflict with lake usage, such as recreation.

It is assumed that an adequate water supply can be provided at estuarine and ocean sites with similar pumping distance constraints.

Groundwater supply sources can be included in the evaluation as independent sources or as supplemental sources to the surface water supply using the same conservative approach applied for projections of non-facility consumptive use. The groundwater supply can be estimated based on the aquifer yield characteristics and bounded by the aquifer areal distribution plus reasonable pumping distances.

The water supply, whether the source is surface water, groundwater, or a combination of both, must meet the facility consumption rate combined with the projected future non-facility consumptive uses for the site to be considered acceptable.

Local, state, or regional water policies may also apply to the consumption of water. A demonstration of a request for certification of the rights to withdraw or consume water in a manner consistent with existing programs and policies may be included as part of the NRC construction permit application or operating license application. Regulatory agencies should be consulted to determine applicable policies and avoid potential conflicts.

Impacts of Plant Water Usage:

Consumptive use of water should be restricted such that the supply to other users is not impaired and that applicable surface water quality standards can be met, assuming normal station operational discharges and extreme low-flow conditions defined by generally accepted engineering practices. The allowance for non-facility future allocations (i.e., other users) should be based on conservative assumptions developed in consultation with state water supply planning.

For multipurpose impounded lakes and reservoirs, consumptive use should be restricted such that the magnitude and frequency of drawdown will not result in unacceptable damage to important habitats (see Aquatic Ecology template) or be inconsistent with the management goals for the water body. Similarly, plant withdrawals from multi-purpose rivers and streams may be restricted after assessing impacts to the flow of the river, important habitats, and the management goals for the water body.

The site evaluation relates to the degree with which the supply at low-flow conditions, based on 7Q10 and historical drought stages or water surface elevations, exceeds the design basis consumption rate and the projected future use requirements. Plant water usage may have a greater impact on water quality at sites with more limited water availability. The potential effects of cooling water withdrawals on water quality will be evaluated on the basis of the likelihood of conflicts, based on 
minimum flow availability, in areas with existing or expected wastewater discharges or other potentially significant water quality constraints.

Risk - Specific information about the site being evaluated may not be available, but high quality data from publicly available local, state, and federal sources may be used to initially assess the site. Insufficient quality or quantity of data may result in increased investments of time and money to generate the data or in the rejection of the site for the nuclear power plant license application.

Risk Mitigation - Alternative water use strategies may be necessary to supplement available water sources to reduce the effect of low-flow conditions or low water levels on plant operation. Where water resource availability is low, construction of ponds and/or impoundments may be feasible.

\section{REFERENCES:}

1. 10 CFR Part 50, Appendix A, General Design Criterion 2, "Design Bases for Protection Against Natural Phenomena."

2. 10 CFR Part 100, "Reactor Site Criteria."

3. U.S. Nuclear Regulatory Commission, "Design Basis Floods for Nuclear Power Plants Regulatory Guide 1.59, Revision 2, August 1977. ${ }^{1}$

4. U.S. Nuclear Regulatory Commission, "Ultimate Heat Sink for Nuclear Power Plants," Regulatory Guide 1.27, Revision 2, January 1976.

5. U.S. Nuclear Regulatory Commission, "Standard Format and Content of Safety Analysis Reports for Nuclear Power Plants, Regulatory Guide 1.70," Revision 3, November 1978.

6. U.S. Nuclear Regulatory Commission, Regulatory Guide 4.7, "General Site Suitability Criteria for Nuclear Power Stations," Revision 2, April 1998. 


\section{Site CharaCteristic: Health ANd SAFETy/Hydrology/Flooding}

\section{DESCRIPTION:}

Safety-related structures, systems, and components (SSC) for a new nuclear power plant must be designed to withstand the worst flooding caused by an appropriate combination of several hypothetical events. The Nuclear Regulatory Commission (NRC) requires the license applicant to apply for a license that includes evaluation of hypothetical worst case flooding scenarios. The hypothetical events include but are not limited to probable maximum flood (PMF), coincident wind-generated waves, probable maximum hurricanes, probable maximum tsunamis, surge, seiche, seismic failure of upstream and downstream dams, and ice jams etc. The potential for flooding at the proposed facility may involve any or all of the hypothetical events, or any various combinations of these events, such that the surface water level rises to or above the grade elevation of facility safety related SSCs.

\section{IMPORTANCE:}

Nuclear power plants are to be designed to prevent the loss of capability for cold shutdown and maintenance resulting from the most severe flood conditions that may occur at a site due to hydrometeorological and seismic activities. General Design Criterion 2, "Design Bases for Protection Against Natural Phenomena," of Appendix A, "General Design Criteria for Nuclear Power Plants," to 10 CFR Part 50, "Licensing of Production and Utilization Facilities," states that the SSCs important to safety be designed to withstand the effects of flooding due to combination of several hypothetical events discussed above without loss of capability to perform their safety functions. Flooding of the facility may pose an unacceptable risk to the continued operability of safety related structures.

\section{RISK:}

During license application reviews, the NRC Staff will evaluate the site elevation, plant layout and design, data, analyses and all flood-related factors (including those listed above) to determine the ability of the facility to withstand the worst-case flooding scenarios and combinations thereof. An inability to clearly demonstrate sufficient flooding protection may result in rejection of the facility for the nuclear plant license.

\section{EVALUATION:}

\section{Acceptable Site}

\section{Challenged Site Requiring Further Evaluation}

\section{Site Not Suitable}

\section{DISCUSSION:}

The facility must be capable of withstanding the worst-case flooding either by showing that the site is a "Dry Site" (e.g., either as a result of natural terrain or by an engineered fill construction, i.e., "plant island") or through the use of external or incorporated barriers. The evaluator shall consider each of the subject causes for flooding at the site and determine which ones have realistic and important considerations for purposes of the assessment. Those causes that are not of high importance should be qualitatively dismissed and a brief justification provided for the dismissal. The remaining evaluated worst case flooding scenarios should be detailed and discussed in the subsequent flooding analysis.

Site Type - The evaluation should identify the type of the site being analyzed, i.e., a "Greenfield," "Brownfield," or "an existing nuclear power plant site." The evaluation should identify unique site type-related differences, if any, for the treatment of flooding hazards. In addition, the evaluation should take into consideration existing data and analyses that is available.

Evaluation Criteria - The site should not be located in 100-year or 500-year flood zone. Federal Emergency Management Agency (FEMA) Flood Hazard Maps may be used to determine whether the site is in a FEMA flood zone. 
A flooding analysis should be performed to estimate the preliminary PMF water surface elevation along with an appropriate safety factor.

The site should be classified as "Acceptable Site" if the analysis indicates that the location is a "Dry Site," i.e., the flood level elevation does not reach the ground level elevation in the area where the plant is likely to be located (e.g., is at least 5-10 ft. below proposed facility grade elevation).

The site should be classified as "Challenged Site Requiring Further Evaluation" if the flooding level elevation is at or slightly below ground level elevation in the area where the plant is likely to be located (e.g., is $0-5 \mathrm{ft}$. below the proposed facility grade elevation).

The site should be classified as "Site Not Suitable" if the flood level elevation is expected to be above the plant ground surface elevation, and mitigation measures are deemed impractical.

RG 1.102 describes acceptable flood protection measures. It should be used in conjunction with the following guidance to determine final site acceptability.

\section{Flooding Analysis:}

A preliminary PMF estimate at the site may be quickly estimated using RG 1.59. RG 1.59 describes methods for estimating the PMF for plants located on streams, along lakeshores, coastlines, and estuaries. Although the methods contained in RG 1.59 are based on superseded materials, the simplified alternative method using isoline maps requires only the drainage area as input and may be used as a basis for a preliminary PMF estimate. The drainage area may be estimated using United States Geological Services (USGS) stream gauge information, quadrangle topographic maps, or other topographic sources. A cross section at or near the site may be estimated using USGS quadrangles. The estimated PMF may then be translated to a water surface elevation using models such as FlowMaster or hand calculations.

RG 1.59 states that "Analyses of only the most severe flood conditions may not indicate potential threats to safety related structures; however a combination of less and most severe flood conditions pose threat to safety related structures." Therefore, a reasonable combination of less-severe flood conditions should also be considered, to include dam failure permutations and coincident wind wave activity as appropriate. Because RG 1.59 is based on previous probable maximum precipitation (PMP) information prior to most or all of the Hydrometeorological Reports (HMRs) currently in use, it may be prudent to use an increased safety factor when estimating the PMF from the RG 1.59 isoline maps. It is recommended to increase the preliminary PMF result by $25-50$ percent for allowance of this safety factor. It is recommended to use a higher safety factor for Greenfield sites (i.e., 50 percent) compared to existing nuclear power plants (i.e., 25 percent). The safety factor accounts for unknowns such as antecedent conditions, nonlinear basin response, current HMRs, more detailed hydraulic modeling, dam failures, wind wave, etc. that may not have been incorporated in the RG 1.59 preliminary PMF estimate.

Generally the PMF provides the design basis flood for plants sited along rivers and streams. For sites along lakes or seashores, the design basis flood may be produced by the most severe combination of hydrometeorological parameters, such as PMP, probable maximum seiche or probable maximum hurricane. In the case of sites located on estuaries the probable maximum river flood, probable maximum surge or probable maximum seiche or a reasonable combination may produce the design basis flood.

For sites along or near open coastal areas of the Gulf of Mexico and the Atlantic Coast, RG 1.59 may be used to estimate the probable maximum surge based on the probable maximum hurricane. The probable maximum surge data along the Atlantic coast and the Gulf of Mexico are shown in tables and figures in RG 1.59, Appendix C. RG 1.59 suggest interpolating between these values depending upon the location. As stated earlier, the methods contained in RG 1.59 are based on superseded materials; it is recommended to increase the estimated surge result by 25 percent for allowance of safety factor to account for coincident wind wave activity and superseded data. 
For locations along the Pacific coast, ANSI/ANS-2.8-1992 points out tsunamis may generate higher floods. The historical tsunami data may be referenced along with the PMF to determine the water surface elevation at the site along the Pacific coast. Although ANSI/ANS-2.8-1992 has been withdrawn, as of August 2010 a replacement standard has not been issued by the American Nuclear Society. The NRC NUREG-0800, March 2007 includes ANSI/ANS-2.8-1992 as a historical technical reference. The historical tsunami may not result in the probable maximum tsunami as described in RG 1.206. Therefore, it is recommended to increase the historical tsunami elevation by at least 25 percent to allow a safety factor for probable maximum tsunami.

Risk - Discussions of each risk factor should include the relevance of the proposed site to the level of risk. Some typical risk factors for flooding include, but are not limited to, the following:

- Proximity and size of upstream and downstream reservoirs

- Site Topography

- Seismic activity levels at the site

- Probability of severe weather (e.g., tornadoes, hurricanes, etc.).

Additionally, if plant safety related SSCs are at or below the design basis flood elevation, the plant may be elevated by fill. However, if the fill required to prevent the facility from flooding is significant, its effect on other aspects of the plant such as ecological, groundwater etc. should be taken into consideration.

Risk Mitigation - A site considered "Challenged Site Requiring Further Evaluation" suggests the flood protection measures suggested in RG 1.02 may be considered. Also the plant may be elevated enough to be meet the criteria of an "Acceptable Site." Risk can also be mitigated by proper and through data collection such as that relating topographic information, etc.

\section{REFERENCES:}

1. U.S. Nuclear Regulatory Commission, Regulatory Guide 1.102, Revision 1, "Flood Protection for Nuclear Power Plants", September 1976.

2. U.S. Nuclear Regulatory Commission, Regulatory Guide 1.206, “Combined License Applications for Nuclear Power Plants," June 2007.

3. U.S. Nuclear Regulatory Commission, Regulatory Guide 1.59, Revision 2, "Design Basis Floods for Nuclear Power Plants," August 1977.

4. U.S. Nuclear Regulatory Commission, Regulatory Guide 4.7, Revision 2, "General Site Suitability Criteria for Nuclear Power Plants,” April 1998.

5. U.S. Nuclear Regulatory Commission, NUREG-0800, "Standard Review Plan," May 2007.

6. ANSI/ANS-2.8-1992, "Determining Design Basis Flooding at Power Reactor Sites," July 28, 1992. 
Appendix C - Templates for Evaluating Site Characteristics

C-28 


\section{Appendix C-1c Nearby Hazardous Activities/Facilities that Could Affect Plant Safety \\ Nearby Hazardous Activities}




\section{Site Characteristic: $\quad$ Health ANd SAFETy/Nearby HaZardous ACTIVITIES}

\section{DESCRIPTION:}

The identification of nearby hazardous activities located in association with potential candidate sites may require analysis of a number of factors, including transportation facilities and routes such as airports, airways, roadways, railways, pipelines, and navigable water bodies. Hazardous activities could also be associated with nearby industrial facilities and military complexes. In addition, the presence of on-site storage facilities would be subject to identification and analysis as potentially hazardous to nuclear plant operations.

\section{IMPORTANCE:}

Federal regulations including 10 CFR 100.20(b) requires that "The nature and proximity of man-related hazards (e.g., airports, dams, transportation routes, military and chemical facilities must be evaluated to establish site parameters for use in determining whether a plant design can accommodate commonly occurring hazards, and whether the risk of other hazards is very low." 10 CFR 100.21(b)(e) further states that upon evaluation and the subsequent establishment of site parameters, the applicant would demonstrate that "potential hazards from such routes and facilities will pose no undue risk to the type of facility proposed to be located at the site." The identified parameters are factors applied to the analysis undertaken for NUREG-0800 Standard Review Plan (SRP) 2.2.3 to determine potential accidents regarded as design-basis events. The details of activities associated with nearby transportation routes, military and industrial facilities would also be used in analysis for SRP 6.4 in establishing the parameters for control room habitability following the accidental release of toxic gases or vapors.

\section{RISK:}

The NRC Staff will review the nature and extent of activities involving potentially hazardous materials or activities that are conducted at nearby industrial, military, and transportation facilities, etc., to identify any such activities that have the potential for adversely affecting plant safety-related structures. According to SRP 2.2.1-2.2.2, collection and analysis of data pertaining to the identified parameters support the determination of whether design-basis events could have "potential consequences sufficiently serious to affect the safety of the plant to the extent that 10 CFR Part 100 guidelines could be exceeded." The inability to demonstrate sufficient design contingencies or provide assurance that the plant has adequate protection and can operate with an acceptable degree of safety in the event of an offsite accident involving hazardous materials, could result in the rejection of the license and/or the candidate site.

\section{EVALUATION:}

\section{Acceptable Site}

\section{Challenged Site Requiring Further Evaluation}

\section{Site Not Suitable}

\section{DISCUSSION:}

The identification of potential hazards within 5 and 10 miles ( 8 and 16-km) of a candidate site, including the nature and extent of activities associated with transportation routing, industrial, and military facilities, is necessary in establishing the degree of risk these parameters could potentially pose to the safety of a proposed facility. Once nearby potential hazards are identified, these become the basis for evaluating the risk potential, as described in NRC RG 4.7. Ultimately, the hazards analysis presented in various candidate site application documents are also dependent on knowledge of design characteristics unique to the type of plant technology designated for use at the site and the incorporation of appropriate engineering safeguards designed to withstand potential accidents.

Site Type - The evaluation should identify the type of site being evaluated, i.e., a "Greenfield," "Brownfield," or "existing nuclear power plant" site. If a candidate site is a Brownfield site and 
experienced previous industrial use, or is associated with an existing nuclear power plant, data and previous analysis may be available to help identify nearby potential hazards. However, because hazards analysis is unique to each site and somewhat dependent on the type of reactor technology being utilized, an in-depth analysis would still be necessary to adequately identify the risks posed by hazards in the area. The same strategy would be necessary in hazards analysis associated with a Greenfield site although less existing characterization information may be available.

Evaluation Criteria - The site should be classified as "Acceptable Site" when no hazardous sites are identified within 10 miles $(16-\mathrm{km})$ of the proposed facility.

The site should be classified as "Challenged Site Requiring Further Evaluation" when hazardous sites and activities are identified within 10 miles $(16-\mathrm{km})$ of the proposed facility.

A "Site Not Suitable" evaluation cannot be made at this level of evaluation. All identified nearby hazardous activities will require additional evaluation according to SRP guidance. If the probability and accident analyses exceed the defined thresholds, mitigation may be possible.

Data Collection:

For each of the analysis parameters, evaluation criteria for identifying nearby sites with potential hazards are based on the Safety Analysis Standard Review Plan (NUREG-0800). The detail of information gathered should include:

- Data that adequately describes the locations and distances from the candidate plant site to nearby industrial, military, and transportation facilities

- Descriptions of the nature and extent of activities conducted at the candidate plant site and in its vicinity, including the products and materials likely to be processed, stored, used, or transported, are adequate to permit identification of the possible hazards

- Sufficient statistical data with respect to hazardous materials are provided to establish a basis for evaluating the potential hazards to the candidate plant.

Establishing the location of nearby hazards is based on identification of the presence of industrial, military, and transportation facilities and routes within 5 miles $(8-\mathrm{km})$, and according to RG 4.7, 10 miles $(16-\mathrm{km})$ for major airports and airways. Facilities and activities located at a distance greater than 5 miles $(8-\mathrm{km})$ should be evaluated if they have the potential for affecting plant safety-related features. Along with verifying distance and the nature and extent of activities, details should include verification of potentially hazardous materials used, stored, or transported, and determination of the quantity and frequency of shipment. Bulk storage on the plant site of potentially hazardous materials should also be taken into consideration. To the extent that definitive information is available, potential hazardous activities that may be located within 5 and/or 10 miles ( $8 \mathrm{and} /$ or 16-km) of the proposed plant during its future operational life should also be considered.

Risk - According to RG 4.7, the acceptability of an evaluated site based on nearby potential hazards would depend on establishing the following:

- An accident at a nearby industrial, military, or transportation facility would not result in radiological consequences that exceed the dose specified in 10 CFR 10.34, or

- The accident poses no undue risk because it is sufficiently unlikely to occur (less than about $10^{-7}$ per year), or

- The nuclear power station can be designed so its safety will not be affected by the accident.

The risk analysis from nearby hazards is discussed in various SRP Sections including 2.2.3, 3.5.1.5, and 3.5.1.6, with analysis parameters specific to those sections. The outcome is also discussed in a variety of potential applicant documents including a construction permit, operating license, design certification, early site permit, and/or combined license. Review procedures associated with these particular documents is specific to various sections of 10 CFR Part 52. 
Risk Mitigation - If a nearby hazardous activity is identified, more detailed analysis would be required that include probability and accident analyses. Also, further investigation would be necessary if the nearby hazards analysis exceeds the evaluation criteria for risk analysis described in SRP Sections 2.2.3, 3.5.1.5, and 3.5.1.6.

If the probability of the identified activity or accident proved to be above the thresholds listed within the SRP, mitigation may be necessary and could be expensive (e.g., moving vulnerable plant components or control room locations, applying additional engineering safeguards, imposing control at the hazard source). Also, if a source of potentially hazardous materials was missed during the original evaluation or insufficient data was collected, additional research would be required detailing the new data and a subsequent risk analysis would take place. This could include revision of plant design safety features and/or revised analysis calculations.

\section{REFERENCES:}

1. 10 CFR 100.20(b), "Factors to be considered when evaluating sites."

2. 10 CFR 100.21(b)(e), "Non-seismic siting criteria."

3. 10 CFR 52, (various sections), "Licenses, Certifications, and Approvals for Nuclear Power Plants."

4. U.S. Nuclear Regulatory Commission, Regulatory Guide 4.7, "General Site Suitability Criteria for Nuclear Power Stations," April 1998.

5. U.S. Nuclear Regulatory Commission, NUREG-0800, SRP 2.2.1-2.2.2, "Identification of Potential Hazards in Site Vicinity."

6. U.S. Nuclear Regulatory Commission, NUREG-0800, SRP 2.2.3, "Evaluation of Potential Accidents."

7. U.S. Nuclear Regulatory Commission, NUREG-0800, SRP 6.4, "Control Room Habitability System." 


\section{Extreme Weather Conditions}




\section{Site Characteristic: $\quad$ Health AND SAFETy/EXTREME Weather Conditions}

\section{DESCRIPTION:}

Climatologic and meteorological data must be of high quality and representative of the site being evaluated. The potential for limiting conditions from extreme weather at a candidate site may involve numerous factors that includes local probable maximum precipitation, maximum probable wind speed and severe wind events, hurricanes, tornadoes and waterspouts, thunderstorms, lightning and hail, freezing rain and ice storms, dust storms, 100 year return snowpack, weight of the 48-hour probable maximum winter precipitation, maximum dry bulb temperature and ambient temperature, or any combination of these events such that design or safety parameters would be exceeded.

Non-radiological atmospheric considerations such as local fogging and icing conditions, cooling tower drift, cooling tower plume lengths, and plume interactions between cooling tower plumes, as well as plumes from nearby industrial facilities, should also be considered in evaluating the suitability of a potential site.

\section{IMPORTANCE:}

10 CFR 100.21(d) requires physical characteristics of the site, including meteorology, to be evaluated and site parameters established such that potential threats from such physical characteristics will pose no undue risk to the type of facility being proposed.

NUREG-0800 Sections 2.3.1 and 2.3.2 provides guidance for acceptance criteria of the meteorological parameters from the requirements of 10 CFR Part 50, Appendix A, General Design Criterion 2, "Design Bases for Protection Against Natural Phenomena," as it relates to consideration of the most severe of the natural phenomena that have been historically reported for the site and surrounding area, with sufficient margins for the limited accuracy, quantity, and period of time in which the historical data have been accumulated.

Data summaries from National Weather Service (NWS) stations or other installations in the nearby area (50-miles [80-km] radius) should be acquired and analyzed as specified in RG (RG) 1.70 Section 2.3.2 and RG 1.206 Section 2.3.2.1. When offsite data are used, a determination is made concerning how well the data represent site conditions and whether more representative data are available. Onsite data systems compliant with RG 1.23 could be installed if conditions prevent use of offsite data sources but would require at least one year (preferably two or more years) of collection time. After the initial siting phase is completed, onsite data should be collected and used.

\section{RISK:}

To ensure evaluation of extreme weather parameters is sufficient for a successful NRC review of an applicant document, high quality meteorological data and representativeness are required. The lack of quality atmospheric data poses a great risk to siting a new nuclear plant. Calculated values based on historical data from offsite sources is the highest "at risk" activity since all design and decisions proceed assuming that the information used during the siting evaluation was correct. If it is later determined that the offsite data used for the analysis was not representative of the proposed site, several years of work and substantial capital investment could be lost. An onsite meteorological system installed after the decision to use the proposed site could show that offsite data is not representative and may result in requiring in extensive project rework - or worse.

The study of tornadoes and other high wind meteorological conditions is based mainly on research and studies dealing with tornadoes and their characteristics. The ability to classify tornadoes that have been experienced in the proposed site area is the limiting factor to developing this parameter accurately. This parameter is of relatively low risk as the value can be derived from extensive literature research. Also, more data is becoming available all the time and more models have been developed to complete the knowledge base. 
Appendix C - Templates for Evaluating Site Characteristics

Research into hurricanes/tropical storms and the potential for snow loading is location based. An accurate historical picture of the frequency of occurrence should be individually considered for each site.

Other extreme weather parameters include hail, lightening, high wind events, etc., and are taken into consideration with more severe meteorological events and the safety features typically engineered into the plant design.

EVALUATION:

\section{Acceptable Site}

\section{Challenged Site Requiring Further Evaluation}

\section{Site Not Suitable}

\section{DISCUSSION:}

The most important data in the analysis of the outlined extreme weather parameters is the hourly historical averages for meteorological parameters such as wind speed, wind direction, ambient temperatures and wet bulb temperatures, delta temperatures, sigma theta, relative humidity, and precipitation. These averages are the source data of much of the analysis that determines bounding conditions, cooling system performance, reactor performance, and other design characteristics of the facility.

Data on hurricanes, tornadoes, thunderstorms, etc., need to come from reliable sources and quality research and studies. This data is analyzed and used as the design basis for structures, systems, and components (SSCs) and is important in the safe design and siting of a proposed plant.

Due to the violent nature of tornadoes, these severe storms are of particular concern in siting a nuclear plant. The historical account of tornado occurrence in a particular area is important but is only part of the evaluation for tornadoes. Much of the data for tornadoes comes from visual observation, theoretical calculations, and physical examination of the effects of the tornado on the environment. Research and classification of tornadoes is an ongoing project and care is needed in determining the parameters required. Data is compared to plant design parameters used in establishing pressure and tornado missile loadings. Since very few individual tornadoes are monitored directly, most data is derived from the ongoing research and the representativeness of the data to the site location.

Hurricanes and tropical storms are determined by the historical number of events and the classification of those events. Hurricanes are measured in Categories 1 through 5 based on storm wind speed. Hurricane damage depends on proximity to the landfall area, the speed of the storm moving inland, the straight line winds, the amount of rainfall and the size and number of thunderstorms and tornadoes produced in conjunction with the tropical storm.

Site Type - If the proposed site is an existing nuclear facility, then the likelihood that the meteorological data will be sufficient to do a competent examination is greatly enhanced since the meteorological data has already been gathered and evaluated. However, an operating nuclear plant may not have relative humidity or wet bulb temperature data which would have to be obtained from an offsite source if needed to assess the design acceptability a new facility.

If the proposed site is a Greenfield site it is important that the historical source data be representative. If the proposed site is a Brownfield site it is important that the historical source data be representative and that no interference exists from the industrial facilities found on the Brownfield site.

Evaluation Criteria - An "Acceptable Site" occurs when no unacceptable extreme weather parameters are identified in association with the potential site and representative historical meteorological data is available for those parameters necessary to determine bounding limits and design acceptability. 
A "Challenged Site Requiring Further Evaluation" occurs when unusual extreme weather parameters have been identified and further evaluation is necessary and the available historical data is questionable or missing key parameters.

A "Site Not Suitable" evaluation cannot occur at this level of site evaluation. All identified extreme weather parameters will require additional analysis based on current SRP guidance. If the probability and accident analyses exceed the defined thresholds, mitigation may be required.

Extreme weather data and representativeness:

Data summaries from NWS stations or other installations in the nearby area (50 mile [80-km] radius) should be presented as specified in RG 1.70 Section 2.3.2 and RG 1.206 Section 2.3.2.1. When offsite data are used, a determination is to be made how well the data represents site conditions and whether more representative data are available. Representativeness is based on distance from the site, topography, elevation, mountains and valleys, land use, nearby bodies of water or ocean coastlines, and data collection procedures. If the data being used is not representative of the site then the data evaluations may be invalid. Both RG 1.70 and RG 1.206 stress the necessity that the meteorological data submitted in license application documents should be fully documented and substantiated as to the validity of its representation of conditions at and near the proposed site. Absences of quality data representative of the site may lead to elimination of the site from further licensing consideration.

10 CFR 100.21(d) requires physical characteristics of the site, including meteorology, to be evaluated and site parameters established such that potential threats from such physical characteristics will pose no undue risk to the type of facility proposed.

Tornado and hurricane/tropical storm data:

SRP Sections 2.3.1-2.3.2 refer to the meteorological conditions that should be considered in the development of plant design and safety related features. Tornado parameters include maximum wind speed, translational speed, rotational speed, and maximum pressure differential with the associated time interval, to be used in establishing pressure and tornado missile loadings on SSCs important to safety.

RG 1.26 states that determination of design-basis events internal and external of the nuclear plant, including tornadoes, are defined as those accidents that have a probability of occurrence on the order of magnitude of $10^{-7}$ per year or greater and potential consequences serious enough to affect the safety of the plant to the extent that the guidelines in 10 CFR Part 100 could be exceeded. According to RG 1.76, nuclear power plants must be designed so that they remain in a safe condition under severe meteorological events, including those that could result in the most severe tornado that could reasonably be predicted to occur at the site.

RG 1.76 states that tornado wind speeds may not bound hurricane wind speeds for certain portions of the Atlantic and Gulf coasts. The NRC would address these extreme conditions on a case-by-case basis.

Risk - The highest risk from meteorological data supporting a proposed site selection comes from the representativeness of available data. This risk may be manifest because data is unavailable, of an inadequately long timeframe, not representative of the proposed site, or later determined to be unreliable or unusable after onsite data is collected. The consequences could place the entire project in licensing jeopardy.

Beyond representativeness of site meteorological data, tornado information is of lower risk since most designs will have little problem meeting bounding parameters.

Risk Mitigation - Risk can be mitigated by careful selection of source data. NWS, NOAA, and military sources of data are usually collected from the correct sensors and reported in the necessary formats. A thorough evaluation of data representativeness must be performed during the course of the initial site evaluation. The evaluation must use factors such as topography, elevation, land use, 
water-bodies, etc. Finding quality data is the best method of mitigating this risk. If a problem is found with plant design based on extreme weather analysis, revisions to plant SSCs would be required to support the project.

\section{REFERENCES:}

1. 10 CFR 50, Appendix A, General Design Criterion 2, "Design Bases for Protection Against Natural Phenomena."

2. 10 CFR Part 100, "Reactor Site Criteria."

3. U. S. Nuclear Regulatory Commission, NUREG-0800, SRP 2.3.1, "Regional Climatology."

4. U. S. Nuclear Regulatory Commission, NUREG-0800, SFP 2.3.2, "Local Meteorology."

5. U. S. Nuclear Regulatory Commission, Regulatory Guide 1.23, “Onsite Meteorological Programs."

6. U.S. Nuclear Regulatory Commission, Regulatory Guide 1.70, "Standard Format and Content of Safety Analysis Reports for Nuclear Power Plants."

7. U.S. Nuclear Regulatory Commission, Regulatory Guide 1.76, Rev. 1, "Design-Basis Tornado and Tornado Missiles for Nuclear Power Plants."

8. U.S. Nuclear Regulatory Commission, Regulatory Guide 1.206, "Combined License Applications for Nuclear Power Plants (LWR Edition).” 
Appendix C - Templates for Evaluating Site Characteristics

C-38 


\section{Appendix C-1e Radiological Considerations}

Atmospheric Dispersion - Accident Conditions 
Appendix C - Templates for Evaluating Site Characteristics

\title{
SiTE CHARACTERISTIC:
}

\author{
HEALTH AND SAFETY/RADIOLOGICAL \\ CONSIDERATIONS/ATMOSPHERIC DISPERSION - ACCIDENT \\ CONDITIONS
}

\section{DESCRIPTION:}

The objective of this criterion is to evaluate the suitability of the candidate sites with respect to short-term atmospheric dispersion characteristics as a measure of the relative level of concentrations that could occur during accident conditions at the sites.

Because short term exposures are of concern during accidents, worst-case (e.g., 5 percentile) short-term atmospheric dispersion $(\chi / \mathrm{Q})$ estimates are of concern for this siting criterion.

The efficiency of atmospheric diffusion is primarily dependent on wind speed, wind direction, and the change in air temperature with respect to height which affects atmospheric stability. These factors are used to calculate the short term atmospheric dispersion.

The best way to calculate $\chi / Q$ is using at least one year of on-site meteorological data; however, this data may not be available for all candidate sites. Data for the development of representative accident $\chi / \mathrm{Q}$ values for regions of interest and candidate areas are generally available from National Oceanic and Atmospheric Administration (NOAA), states, universities, or private sources (e.g., meteorological observations acquired for power generation or industrial facilities, and private airfields). Because exclusionary criteria are provided for two distances and five accident averaging periods, the expected $\chi / \mathrm{Q}$ values can only be determined from hourly meteorological observations. In the absence of hourly observations, joint frequency distributions (JFD) of wind speed and directions by stability class, if available, can be used to develop surrogate $\chi / \mathrm{Q}$ values for use in identifying exclusionary and avoidance areas and initially evaluating site suitability. Should atmospheric dispersion become a sensitive criterion for site selection, site-specific meteorological data should be obtained to calculate an atmospheric dispersion function $(\chi / Q)$ for more accurate site comparison.

\section{IMPORTANCE:}

The atmospheric dispersion values for the site are important because they are used to demonstrate that the post-accident doses at the plant exclusion area boundary (EAB) and low population zone (LPZ) meet the site criteria given in 10 CFR Part 100, "Reactor Site Criteria." § 100.21(c) gives the overall requirements relative to accident dose consequences as follows:

c) Site atmospheric dispersion characteristics must be evaluated and dispersion parameters established such that:

(1) Radiological effluent release limits associated with normal operation from the type of facility proposed to be located at the site can be met for any individual located offsite; and

(2) Radiological dose consequences of postulated accidents shall meet the criteria set forth in $\S$ 50.34(a)(1) of this chapter for the type of facility proposed to be located at the site;

The specific requirements relative to the EAB and LPZ are given in $\S 50.34(\mathrm{a})(1)(\mathrm{ii})(\mathrm{D})$ as follows:

(1) An individual located at any point on the boundary of the exclusion area for any 2 hour period following the onset of the postulated fission product release, would not receive a radiation dose in excess of 25 rem total effective dose equivalent (TEDE).

(2) An individual located at any point on the outer boundary of the low population zone, who is exposed to the radioactive cloud resulting from the postulated fission product release (during the entire period of its passage) would not receive a radiation dose in excess of 25 rem total effective dose equivalent (TEDE); 


\section{RISK:}

The NRC Staff will review license applications for site specific atmospheric dispersion values for the EAB and LPZ to confirm site suitability. If there is little margin between the site specific accident doses and the 10 CFR 100 regulatory dose limits, any significant change in the $\chi / Q$ values may result in the site being classified as unacceptable. This situation could be remedied by increasing the EAB or reducing post-accident radionuclide releases. This approach agrees with $\S 100.10(\mathrm{~d})$ which states "Where unfavorable physical characteristics of the site exist, the proposed site may nevertheless be found to be acceptable if the design of the facility includes appropriate and adequate compensating engineering safeguards."

\section{EVALUATION:}

\section{Acceptable Site}

\section{Challenged Site Requiring Further Evaluation}

\section{Site Not Suitable}

\section{DISCUSSION:}

Estimates of short-term $\chi / \mathrm{Q}$ s corresponding to the plant perimeter envelope (PPE) values would be developed for each of the candidate sites. In addition to the analysis discussed above, this evaluation should also take into account site-specific characteristics (e.g., topography and coastal effects) that could affect dispersion of accidental releases. In the absence of on-site meteorological data, professional judgment will be required to adopt regional data to account for these local effects.

Site Type - The evaluation should identify the type of site being evaluated, i.e., a "Greenfield," "Brownfield "or existing nuclear power plant" site. The evaluation should identify the unique applicability of site type-related differences, if any, for the treatment of atmospheric dispersion. In addition, the evaluation should take into consideration existing data and analyses that might be available, for example, in the case of an existing nuclear site or, perhaps, a "Brownfield site." In these cases, additional site-specific atmospheric dispersion analysis may not be necessary as existing information can be used with high confidence when compared to a Greenfield site.

Evaluation Criteria - A site would be classified as "Acceptable Site" if the EAB doses for the proposed technology meet the limits of $\S 50.34(a)(1)$. A site would be classified as "Challenged Site Requiring Further Evaluation" if the EAB doses do not meet the limits of $\S 50.34(\mathrm{a})$ (1) but could if design changes were implemented to limit accident radionuclide releases.

A site whose estimated dispersion characteristics do not satisfy the PPEs and increasing the exclusion area boundary or reducing the post-accident radionuclide releases is not possible would be classified as "Site Not Suitable" and eliminated from further consideration.

Atmospheric Dispersion Evaluation:

The assessment of atmospheric dispersion is required by 10 CFR Part 100, "Reactor Site Criteria" and 10 CFR Part 52, "Licenses, Certifications, and Approvals for Nuclear Power Plants."

Standard Review Plan (NUREG-0800) provides insight as to areas of review by the NRC Staff and should be consulted, as appropriate, to ensure that the evaluation is sufficiently comprehensive.

Site suitability can be judged by comparison of the site-specific atmospheric dispersion values with the specific values associated with a particular technology. 


\begin{tabular}{|c|c|c|}
\hline & \multicolumn{2}{|c|}{ Atmospheric Dispersion $(\chi / \mathrm{Q})$ - Accident } \\
\hline Location & Time & Composite EPRI ALWR Value \\
\hline EAB & $0--2 \mathrm{hr}$ & $1.0 \mathrm{E}--3 \mathrm{sec} / \mathrm{m}^{3}$ \\
\hline LPZ & $0--8 \mathrm{hr}$ & $1.35 \mathrm{E}--4 \mathrm{sec} / \mathrm{m}^{3}$ \\
\hline & $8--24 \mathrm{hr}$ & $1.00 \mathrm{E}--4 \mathrm{sec} / \mathrm{m}^{3}$ \\
\hline & $1--4$ day & $5.4 \mathrm{E}--5 \mathrm{sec} / \mathrm{m}^{3}$ \\
\hline & $4--30$ day & $2.2 \mathrm{E}-5 \mathrm{sec} / \mathrm{m}^{3}$ \\
\hline
\end{tabular}

The above Electric Power Research Institute (EPRI) Advanced Light Water Reactor (ALWR) $\chi / Q$ values are based on the typical radial distance to the EAB boundary of 0.5 miles $(800 \mathrm{~m})$, and a distance to the LPZ boundary established at a 2 mile $(3.2-\mathrm{km})$ radius, from the reactor plant location.

The calculation of atmospheric dispersion factors can be performed by using the PAVAN computer program, which is also used by the U.S. Nuclear Regulatory Commission for this type of evaluation. The computer program, PAVAN, implements the guidance provided in RG 1.145, "Atmospheric Dispersion Models for Potential Accident Consequence Assessments at Nuclear Power Plants"

The atmospheric dispersion evaluation should be based on the guidance provided in RG 1.145, "Atmospheric Dispersion Models for Potential Accident Consequence Assessments at Nuclear Power Plants." In accordance with SRP 2.3.4, two probabilistic approaches as described in RG 1.145 are applied for evaluating atmospheric dispersion characteristics and the more conservative approach is used.

A) A direction-dependent probabilistic approach which uses the highest $\chi / \mathrm{Q}$ value which is exceeded $0.5 \%$ of the time in each of 16 compass directions from the plant.

B) A direction-independent probabilistic approach which uses the $\chi / Q$ value which is exceeded $5 \%$ of the time independent of direction. $\chi / \mathrm{Q}$ values should be determined for the $\mathrm{EAB}$ and the LPZ distances assumed for the site.

Risk -The atmospheric dispersion analysis should clearly articulate the risk factors associated with the analysis or assumptions. The discussion of each risk factor should include the relevance of the site type to the level of risk. Some typical risk factors for atmospheric dispersion include the following:

- Proximity of meteorological data source to the site

- Quality of meteorological data

- Length of data record available

- Applicability of meteorological data to the site (considering terrain, distance to site, distance from land features which may influence measurements, elevation, distance from nearby structures)

- Topography of the site and of the area surrounding the data source.

Sites with poor meteorological conditions will result in higher atmospheric dispersion values which will, in turn, produce higher doses. To counteract this situation would require a larger EAB or compensatory design changes to reduce radionuclide releases. (Generally, the LPZ atmospheric dispersion values are acceptable for a 2 mile ([3.2-km] radius LPZ.) If the atmospheric dispersion factors are determined using other than site data, an appropriate margin (suggest a factor of 50\%) should be used to account for the possible increase in results due to later use of site data. 
Risk Mitigation - The risk of a potential site being rejected can be minimized by selecting a technology that has low offsite doses due to minimizing post-accident radionuclide releases. The atmospheric dispersion factors given in the PPE are an indication of the magnitude of offsite doses. A technology with a higher EAB atmospheric dispersion value would be easier to site.

\section{REFERENCES:}

1. U.S. Nuclear Regulatory Commission, NUREG/CR-2858, PNL-4413, "PAVAN: An Atmospheric Dispersion Program for Evaluating Design Basis Accidental Releases of Radioactive Materials from Nuclear Power Stations,” November 1982.

2. U.S. Nuclear Regulatory Commission, Regulatory Guide 1.145, "Atmospheric Dispersion Models for Potential Accident Consequence Assessments at Nuclear Power Plants," Revision 1, November 1982 (Revised February 1983 to correct page 1.145-7).

3. 10 CFR Part 100, "Reactor Site Criteria."

4. 10 CFR Part 52, "Licenses, Certifications, and Approvals for Nuclear Power Plants."

5. U.S. Nuclear Regulatory Commission, Regulatory Guide 4.7, "General Site Suitability Criteria for Nuclear Power Stations," Revision 2, April 1998.

6. U.S. Nuclear Regulatory Commission, Regulatory Guide 1.206, "Combined License Applications for Nuclear Power Plants (LWR Edition),” June 2007.

7. U.S. Nuclear Regulatory Commission, NUREG-0800, SRP 2.3.4, "Short-Term Atmospheric Dispersion Estimates for Accident Releases.”

8. EPRI, “Advanced Light Water Reactor Utility Requirements Document," Revision 8. 
Appendix C - Templates for Evaluating Site Characteristics 
Appendix C - Templates for Evaluating Site Characteristics

\section{Appendix C-1f Emergency Planning}




\section{Site Characteristic: $\quad$ Health and Safety/Emergency Planning}

\section{DESCRIPTION:}

A potential emergency at a nuclear power plant may involve the release of radioactive materials to the environment at levels that could affect the health and safety of the public living near the site under consideration. Onsite and offsite emergency plans are required to assure that adequate protective measures can be taken to protect onsite workers and the public in the event of a radiological emergency. Federal oversight of emergency planning for licensed nuclear power plants is shared by the Nuclear Regulatory Commission (NRC) and the Federal Emergency Management Agency (FEMA) through a memorandum of understanding. However, with respect to issuing an Early Site Permit (ESP) or combined license (COL), the final decision making authority on the adequacy of emergency planning and preparedness rests with the NRC.

\section{IMPORTANCE:}

Determining the suitability of a site for constructing a new nuclear power plant should consider the emergency planning regulatory requirements promulgated by the NRC. These regulations are contained mainly in 10 CFR 50.47 and Appendix E to Part 50 for operating licenses (OL) and ESP applications with a "full and integrated emergency plan" and COL, 10 CFR 52.17 for ESPs, and 10 CFR 52.79 for COLs.

$\mathrm{OL}$ and COL regulations require an analysis of the time required to evacuate and taking other protective actions for various sectors and distances within the plume exposure pathway emergency planning zone (EPZ) for transient and permanent populations.

With regard to the ESP, 10 CFR 52.17(b) regulations specifically require that the site safety analysis report identify physical characteristics of the site that could pose a significant impediment to the development of emergency plans.

In order for the $\mathrm{NRC}$ to issue a license to operate a commercial nuclear power plant, emergency plans must provide reasonable assurance that adequate protection can and will be taken in the event of a radiological emergency at the plant.

\section{RISK:}

The NRC Staff will evaluate the onsite emergency plan and FEMA will take the lead in evaluating the offsite emergency plans. These emergency plans will be evaluated against 16 emergency planning standards set forth in 10 CFR 50.47(b) and further described in NUREG-0654/FEMA-REP-1, Rev. 1, "Criteria for Preparation and Evaluation of Radiological Emergency Response Plans and Preparedness in Support of Nuclear Power Plants" (NUREG-0654). These planning standards define the responsibilities of the licensee and the state and local organizations involved in emergency response.

NRC regulations do not specify a specific evacuation time that must be met for a candidate site to be deemed suitable for construction and operation of a nuclear power plant. However, the formal analysis of evacuation times can identify physical characteristics unique to the proposed site that could pose a significant impediment to the development of emergency plans. Such impediments must be identified and mitigative strategies presented as necessary.

The inability to provide reasonable assurance that adequate protection can and will be taken in the event of a radiological emergency could result in the rejection of the site for the nuclear plant application. 


\section{EVALUATION:}

\section{Acceptable Site}

\section{Challenged Site Requiring Further Evaluation}

\section{Site Not Suitable}

\section{DISCUSSION:}

The overall objective of emergency planning is to ensure that the nuclear power plant operator is capable of implementing adequate measures to protect worker and public health and safety in the event of a radiological emergency. As a condition of their license, operators of nuclear power plants must develop and maintain emergency plans that meet comprehensive NRC emergency planning requirements. Increased confidence in public protection is obtained through the combined inspection of the requirements of emergency preparedness and the evaluation of their implementation.

The evaluation of site suitability with respect to emergency planning considers three major areas: risks or challenges to meeting regulatory requirements and related guidance; presence of significant impediments to development of emergency plans; and overall public acceptance of building a nuclear plant at the proposed site.

Emergency planning regulations and guidance focus on 16 planning standards. Each of these planning standards must be met in order for NRC to find reasonable assurance that adequate protection can and will be taken in the event of a radiological emergency. The evaluator should consider any barriers to addressing these planning standards in the ESP or COL application. Four "Risk Significant Planning Standards" must be achievable for the site to be considered as suitable, i.e., timely and accurate classification of events, timely and accurate notification of offsite governmental authorities, timely and accurate development of public protective action recommendations for offsite authorities, and assessment of offsite consequences. Three of these planning standards are mainly applicant or technology influenced and would not be expected to directly impact the site suitability evaluation. However, the fourth planning standard dealing with notification of offsite governmental authorities, can be directly impacted by the support (or lack thereof) these entities show towards operating a nuclear plant at the site under consideration.

Physical characteristics unique to the proposed site could pose a significant impediment to the development of emergency plans. The evaluator is expected to identify possible impediments to onsite and public evacuation at the selected site and determine which ones, if any, have realistic and important considerations for the purposes of this evaluation. For those that are not of high importance, they should be dismissed qualitatively, with a brief summary of the basis for dismissal. The remaining concerns should then be discussed in the emergency planning analysis.

Public confidence in nuclear plant operation and safety frequently surfaces in expressed concern with emergency planning, particularly public evacuation. The evaluator will need to gauge the overall public acceptance of a proposed nuclear plant and include an evaluation of the existing state and local emergency management infrastructure.

Site Type - The evaluation should identify the type of site, i.e., a "Greenfield," Brownfield or "existing nuclear power plant" site, as well as the location of the site being evaluated. The evaluation should consider the applicant's prior nuclear experience and the maturity of emergency plans based on the site type. In particular, the evaluation should consider existing site emergency plans if the site being evaluated has an existing nuclear power plant. Existing emergency planning can be directly applied to licensing a new nuclear plant. Onsite emergency response organizations would need to be expanded to accommodate a new unit, but the offsite (state and local) emergency response is largely unaffected by any additional units at an existing site. Emergency planning will still require a significant effort to support the license application requirements and the risks discussed below should be considered and addressed accordingly. 
Existing knowledge of any impediments to relocating the public and methods to facilitate movement and optimize evacuation times can be directly applied to the licensing of a new nuclear plant. Detailed evacuation time studies are not warranted for a site suitability evaluation, but proximity and size of population centers and sophistication of the roadway network can be qualitatively evaluated.

For Greenfield sites, the evaluation should consider whether an existing nuclear power plant(s) is located in the same state or local area as the site being evaluated. Offsite relationships are well-established if the site being evaluated is located in a state or area with an existing nuclear power plant. Additionally, prior NRC and FEMA acceptance of existing state and local emergency plans provide reasonable stability in the planning effort required for a new license application. In general, a proposed site in a state with an existing radiological emergency planning program presents less risk and cost to develop a successful radiological emergency preparedness and response program than for a site located in a state without an existing nuclear plant radiological emergency plan.

Evaluation Criteria - The site should be classified as an "Acceptable Site" if no barriers to meeting each of the 16 regulatory planning standards have been identified, no significant impediments to development of emergency plans have been identified, or public opinion is definitively in favor of new nuclear plant construction.

The site should be classified as a "Challenged Site Requiring Further Evaluation" if one or more planning standards (other than the four "Risk Significant Planning Standards") cannot be met, impediments to emergency plan development are identified but can be mitigated, or public support is not definitive yet political support is strong.

The site should be classified as a "Site Not Suitable" if any "Risk Significant Planning Standard" cannot be achieved, impediments to emergency plan development cannot be mitigated or represent significant cost to mitigate, and there is expected to be active public and political opposition.

\section{Emergency Planning Analysis:}

The regulations contained in 10 CFR 50.47 and Appendix E to Part 50 related to OL and COL, 10 CFR 52.17 for ESP, and 10 CFR 52.79 for COL applications should be considered in determining the feasibility of constructing a new nuclear power plant. RG 1.101, Rev. 5 states that the criteria and recommendations in NUREG-0654 are considered by the NRC staff to be acceptable methods for complying with the standards in 10 CFR 50.47.

RG 1.206, "Combined License Applications for Nuclear Power Plants" (RG 1.206) provides guidance to applicants for a COL and the information presented is reflected in NUREG-0800, "Standard Review Plan for the Review of Safety Analysis Reports for Nuclear Power Plants" (SRP). NUREG-0800 provides insight as to areas of review by the NRC Staff when a license application is submitted. Both documents should be consulted, as appropriate, to ensure that the evaluation is sufficiently comprehensive. If it is anticipated that the emergency planning requirements for an alternative advanced reactor technology may be different than that of large light water reactors (e.g., planning zone distances), the evaluator should verify the status of these requirements for the non-light water reactor during the evaluation.

Section IV of Appendix E to 10 CFR Part 50, through 10 CFR 52.79(a)21 and 10 CFR 50.34, requires that an application for an OL or a COL provide an analysis of the time required to evacuate various sectors and distances within the plume exposure pathway emergency planning zone (EPZ). Appendix 4 of NUREG-0654 provides guidance on preparing evacuation time estimates. For an ESP application, 10 CFR 52.17(b)1 requires that applicants identify physical characteristics unique to the proposed site that could pose a significant impediment to the development of emergency plans. Supplement 2 to NUREG-0654 contains additional guidance for ESP applicants for determining significant impediments to the evacuation or taking of other protective actions as well as determining if physical impediments pose an impediment to the development of emergency plans. 
NUREG-6863, "Development of Evacuation Time Estimate Studies for Nuclear Power Plants" provides additional information on evacuation time estimates.

As stated in Supplement 2 to NUREG-0654, the NRC regulations do not specify a minimum required evacuation time. However, if this evaluation identifies any potential impediments to evacuation, the significance of the impediments and the estimated difficulty in overcoming the identified impediments should be evaluated to determine final site acceptability.

The evaluator is expected to evaluate each of the pertinent regulatory requirements for content of the required emergency plans. [NOTE: These regulatory requirements are delineated in an addendum to this guide and included as Appendix D, "Emergency Planning Evaluation Template."]

Risk - The emergency planning analysis should clearly articulate the risk factors associated with the analysis or assumptions. The discussion of each risk factor should address the relevance of the site location to the associated level of risk. Some typical major risk factors for emergency planning are listed below.

\section{Regulatory Environment:}

Emergency planning requires coordination and cooperation from state and local agencies. Emergency planning for a new nuclear unit at or near an existing nuclear plant site presents the lowest level of risk to successfully licensing a new unit(s). When considering Greenfield sites, two types must be considered: Greenfield sites in states with existing radiological emergency preparedness (REP) programs and Greenfield sites in states without REP programs.

For Greenfield sites in states with existing REP programs, the risk exists that little or no radiological emergency preparedness experience may be present at the local level. Political considerations may also drive the level of cooperation that can be expected from state or local emergency management officials. Greenfield sites with no state REP experience would present the highest risk. In an area or state without existing nuclear power plants, there may be reluctance to provide information regarding existing emergency operations plans due to Homeland Security concerns.

In all cases, early interaction with elected officials and state and local emergency management organizations is needed to establish working and cooperative relationships to more accurately assess actual risk. Although existing regulations allow remedies where state and local governments choose not to participate in planning responsibilities, cost and public relations will suffer and present a tremendous risk to successfully license the plant. A cooperative working relationship with state and local emergency management organizations is essential to reliably develop the emergency plans necessary to license a commercial nuclear power plant. If the nuclear plant is to be co-located on a site with existing emergency planning procedures, the integration of nuclear emergency planning into the existing site emergency planning infrastructure should be evaluated.

\section{Special Populations:}

Guidance in RG 4.7 indicates that applicants must identify and consider unique site characteristics, such as egress limitations from the area surrounding the site that could pose a significant impediment to the development of emergency plans. Special population groups (e.g., those associated with hospitals, prisons, or other facilities with special emergency situation needs) must be taken into account. Sites with such emergency planning impediments, or with special population groups in the emergency planning zones, should be considered less suitable than sites that do not.

Characteristics to be considered in this evaluation include, but are not limited to:

- Traffic Capacity

- Number of egress alternatives

- Roadway network type 
- Population density within the EPZ

- Number of traffic control points

- Terrain characteristics unique to the proposed site.

Public Involvement:

Two aspects of public involvement should be considered: acceptance of a nuclear power plant by the public and interaction with elected officials and offsite emergency management agencies. As appropriate, any feedback from early interaction between applicant senior management and elected officials will be helpful in determining public acceptance. The evaluator should not initiate such discussions directly with elected officials unless directed to do so by the assessment project manager. The evaluator should determine if any outreach programs to the community have been initiated or are planned. The evaluator should have discussions with state and local emergency management organizations to determine the level of preparedness in relation to the emergency planning requirements supporting nuclear plant licensing.

Ultimately, the willingness for state and local emergency management agencies, local fire/rescue services, and state and local law enforcement agencies to participate in emergency planning is essential to securing a license for a new nuclear plant. Early involvement of elected officials and emergency management organizations is important to identifying any concerns with the construction of a new nuclear plant. Outreach programs can help mitigate the risk of a negative response from the stakeholders.

Risk Mitigation - Early interaction with elected officials and state and local emergency management organizations is needed to establish working and cooperative relationships to mitigate risk. Although existing regulations allow remedies where state and local governments choose not to participate in planning responsibilities, cost and public relations will suffer as a result and present a tremendous risk to successfully licensing the plant. A cooperative working relationship with state and local emergency management organizations is essential to successfully develop emergency plans required to license a commercial nuclear power plant.

Early involvement of elected officials and emergency management organizations is important to identifying any concerns with the construction of a new nuclear plant. Outreach programs can help mitigate the risk of a negative response from area stakeholders.

\section{REFERENCES:}

1. 10 CFR 50.47, "Emergency Plans."

2. 10 CFR 50, Appendix E, "Emergency Planning and Preparedness for Production and Utilization Facilities."

3. 10 CFR 52.17(a), "Contents of Applications; Technical Information."

4. 10 CFR 52.79(a)(21), (22), "Contents of Applications; Technical Information in Final Safety Analysis Report."

5. U.S. Nuclear Regulatory Commission, NUREG-0654/FEMA-REP-1, Rev. 1, "Criteria for Preparation and Evaluation of Radiological Emergency Response Plans and Preparedness in Support of Nuclear Power Plant."

6. U.S. Nuclear Regulatory Commission, NUREG-0654/FEMA-REP-1, Rev. 1, Supp. 2, "Criteria for Preparation and Evaluation of Radiological Emergency Response Plans and Preparedness in Support of Nuclear Power Plants: Criteria for Emergency Planning in an Early Site Permit Application."

7. U.S. Nuclear Regulatory Commission, NUREG-6863, "Development of Evacuation Time Estimate Studies for Nuclear Power Plants." 
8. U.S. Nuclear Regulatory Commission, NUREG-0800, "Standard Review Plan for the Review of Safety Analysis Reports for Nuclear Power Plants," SRP 13.3, "Emergency Planning."

9. U.S. Nuclear Regulatory Commission, Regulatory Guide 1.101, Rev. 5, "Emergency Planning and Preparedness for Nuclear Power Reactors."

10. U.S. Nuclear Regulatory Commission, Regulatory Guide 1.206, "Combined License Applications for Nuclear Power Plants," C.I.13.3, "Emergency Planning."

11. U.S. Nuclear Regulatory Commission, Regulatory Guide 4.7, "General Site Suitability Criteria for Nuclear Power Stations," April 1998. 
Appendix C - Templates for Evaluating Site Characteristics

C-52 
Appendix C - Templates for Evaluating Site Characteristics

\title{
Appendix C-1g \\ Population
}

\author{
Population Density \\ Population Centers
}




\section{Site Characteristic: $\quad$ Health and Safety/Population/Population Density}

\section{DESCRIPTION:}

The potential for impacting regional populations can be demonstrated by determining the population density relative to the site. According to NUREG-0800, the Nuclear Regulatory Commission (NRC) Staff will review data about the population in the region, including transient population, based upon the latest decennial census. This issue is difficult to mitigate and may cause complications for any site being licensed by the NRC for a nuclear facility. This template will focus on using NRC guidance to evaluate whether a site has population issues that will impact the likelihood of producing a successful application.

\section{IMPORTANCE:}

Part 100, "Reactor Site Criteria," of Title 10 of the Code of Federal Regulations states that population density be taken into account in determining the acceptability of a site for a nuclear power reactor.

RG 4.7 states that preferably a reactor would be located so that, at the time of initial site approval and within about 5 years thereafter, the population density, including weighted transient population, averaged over any radial distance out to 20 miles $(32-\mathrm{km})$ (cumulative population at a distance divided by the circular area at that distance), does not exceed 500 persons per square mile. A reactor should not be located at a site whose population density is well in excess of the above value.

The transient population should be included for those sites where a significant number of people (other than those just passing through the area) work, reside part-time, or engage in recreational activities and are not permanent residents of the area. The transient population should be taken into account for site evaluation purposes by weighting the transient population according to the fraction of time the transients are in the area.

\section{RISK:}

The NRC staff will review the population density out to 20 miles $(32-\mathrm{km})$ from the site. As stated in 10 CFR 100.21(h), if the density is more than 500 persons per square mile for the entire 20 -mile $(32-\mathrm{km})$ radius, at a time that is 5 years from initial license approval, the NRC may want to look at alternate sites with a smaller population density. The application may be at risk but it does not necessarily mean the preferred site will be rejected.

\section{EVALUATION:}

\section{Acceptable Site}

\section{Challenged Site Requiring Further Evaluation}

\section{Site Not Suitable}

\section{DISCUSSION:}

The potential impacts to the population in the region must be reasonable and appropriate. Locating reactors away from densely populated areas is part of the NRC's defense-in-depth philosophy and facilitates emergency planning and preparedness as well as reducing potential doses and property damage in the event of a severe accident. While population information is readily available from the U.S. Census, information regarding transient population and population projection is not consistently available. Data on transient population and population projection can often be obtained from state or county agencies, as well as local universities.

Site Type - The evaluation should identify the type of site being evaluated, i.e., a "Greenfield," "Brownfield," or "existing nuclear power plant" site. The evaluation should identify the unique applicability of site type-related differences, if any, for the treatment of this issue. In addition, the evaluation should take into consideration existing data and analyses that might be available, for example, in the case of an existing nuclear site or, perhaps, a "Brownfield site." In these cases the 
population density analysis may have been previously completed and evaluated, whereas a population density analysis will undoubtedly not have been completed for a Greenfield site.

Evaluation Criteria - As defined in RG 4.7 the population density should be less than 500 people per square mile for every mile in a 20 mile $(32-\mathrm{km})$ radius from reactor center.

An "Acceptable Site" meets this criterion by having a population density, including transient populations, below 500 people per square mile.

A "Challenged Site Requiring Further Evaluation" occurs if the site either does not meet this criteria or is likely to exceed the threshold if transient population or projection information is included.

A "Site Not Suitable" evaluation cannot occur based on 10 CFR 100.21.

Population Density Analysis:

The population density calculation can be approximated using LandView6 from the U.S. Census. The population from the last census in all the radii from 1 mile to 20 miles $(1.6-\mathrm{km}$ to $32-\mathrm{km})$ can be obtained from the program. The density value can be calculated using (Radius Population) $/\left(\pi^{*} r^{\wedge} 2\right)$.

To incorporate population projections, state or county projection information can be used to derive growth ratios that are applied to the latest decennial U.S. Census. These ratios are produced by dividing the projected population by the U.S. Census value for the county. The population density can be further refined by making county wide transient population ratios that can be also applied to the last U.S. Census value for the county. These ratios can then be applied to the LandView6 radii data to produce refined population density estimates.

Risk - The NRC staff will review the population density analysis to determine if the site meets the criteria. If there is evidence that the site does not meet the population density criteria, the NRC may express a desire to investigate an alternate site. In this instance, a reasonable argument supporting the location must be produced to keep the candidate site viable.

Risk Mitigation - Performing a full geographical information system (GIS) based population calculation, with a transient population analysis, will develop clear and supported population expectations from the site. Another option is to produce an argument using the sites benefits such as safety, environmental benefits, economic considerations, seismic characteristics, rail or highway access, shorter transmission line requirements, and less environmental impacts on undeveloped areas, wetlands, or endangered species.

\section{REFERENCES:}

1. 10 CFR 100.11, "Determination of Exclusion Area, Low Population Zone, and Population Center Distance."

2. 10 CFR 100.21, "Non-Seismic Siting Criteria."

3. 10 CFR 100.3, "Definitions."

4. U.S. Nuclear Regulatory Commission, Regulatory Guide 1.206, "Combined License Applications for Nuclear Power Plants (LWR Edition)."

5. U.S. Nuclear Regulatory Commission, Regulatory Guide 4.7, "General Site Suitability Criteria for Nuclear Power Stations," April 1998.

6. U.S. Nuclear Regulatory Commission, NUREG-1555, SRP 2.1, "Station Location."

7. U.S. Nuclear Regulatory Commission, NUREG-1555, SRP 2.5.1, "Demography."

8. U.S. Nuclear Regulatory Commission, NUREG-0800, SRP 2.1.1, "Site Location and Description."

9. U.S. Nuclear Regulatory Commission, NUREG-0800, SRP 2.1.3, "Population Distribution." 


\section{Site Characteristic: Health and Safety/Population/Population Centers}

\section{DESCRIPTION:}

The potential for impacting the regional population can be demonstrated by determining the nearest population centers to the site. According to NUREG-0800, the NRC Staff will review data about the population in the region, including transient population, based upon the latest decennial census. The NRC will review the nearest boundary of the closest population center containing 25,000 or more residents to determine if the boundary is at least one and one-third times the distance from the reactor to the outer boundary of the low population zone (LPZ). These issues are difficult to mitigate, and may cause complications for a plant being licensed by the NRC. This template will focus on using the NRCs guidance to evaluate whether a site has population issues that will reduce the likelihood of producing a successful application.

\section{IMPORTANCE:}

10 CFR 100.21, "Reactor Site Criteria," of Title 10 of the Code of Federal Regulations states "The population center distance, as defined in $\$ 100.3$, must be at least one and one-third times the distance from the reactor to the outer boundary of the low population zone." In applying this guide, the boundary of the population center shall be determined upon consideration of population distribution. Political boundaries are not controlling in the application of this guide. Part 100.21, "Reactor Site Criteria," of Title 10 of the Code of Federal Regulations states that the population center distance is the distance from the reactor to the nearest boundary of a densely populated center containing more than about 25,000 residents.

\section{RISK:}

The NRC staff will evaluate if a population center (a populated area with 25,000 or more people) is within one and one-third times the distance from the reactor to the outer boundary of the LPZ. The LPZ is an area immediately surrounding the exclusion area which contains residents. The LPZ can vary by site but it is usually defined as a 2 mile $(3.2-\mathrm{km})$ radius. If a population center is closer than one and one-third times this distance, the NRC may express a desire to look at alternative sites.

\section{EVALUATION:}

\section{Acceptable Site}

\section{Challenged Site Requiring Further Evaluation}

\section{Site Not Suitable}

\section{DISCUSSION:}

The potential impacts to the population in the region must be reasonable and appropriate. Locating reactors away from population centers is part of the NRC's defense-in-depth philosophy and facilitates emergency planning and preparedness as well as reducing potential doses and property damage in the event of a severe accident.

Site Type - The evaluation should identify the type of site being evaluated, i.e., a "Greenfield," "Brownfield," or "existing nuclear power plant" site. The evaluation should identify the unique applicability of site type-related differences, if any, for the treatment of this issue. In addition, the evaluation should take into consideration existing data and analyses that might be available, for example, in the case of an existing nuclear site or, perhaps, a Brownfield site. In these cases the population center analysis may have been already completed and evaluated whereas a population center analysis will not have been completed for a Greenfield site.

Evaluation Criteria - A population center must be at least one and one-third times the distance from the reactor to the outer boundary of the low population zone. A population center is defined as a densely populated center containing more than 25,000 residents. A LPZ is designated by the applicant and is the area immediately outside the exclusion area boundary (EAB) to a distance that reasonable 
and appropriate to protective measures that could be taken in the event of a serious accident. The LPZ is usually a 2 mile $(3.2-\mathrm{km})$ radius from the site center point.

An "Acceptable Site" meets these criteria by not having any population centers within 3 miles (4.8$\mathrm{km})$.

A "Challenged Site Requiring Further Evaluation" occurs if there is a population center within 3 miles $(4.8-\mathrm{km})$.

A "Site Not Suitable" evaluation occurs when a population center is identified within one and one third times the distance from the reactor center to the outer boundary of the LPZ.

Population Center Analysis:

Population center information can be obtained from the U.S. Census Bureau. Any town or urban area within 3 miles $(4.8-\mathrm{km})$ from the site should be evaluated and projected to at least 5 years after the initial licensing date. If any urban areas contain more than 25,000 people at this distance the site fails to meet the criteria.

Risk - The NRC staff will review the population center analysis to determine if the site meets the criteria. If there is evidence that the site does not meet the population center criteria the NRC will want to find an alternate site.

Risk Mitigation - If the criterion is not met, a dose analysis could be performed to find the radius in which an individual would not receive a radiation dose in excess of 25 rem total effective dose equivalent (TEDE) and revise the LPZ. Also, a geographical information system (GIS) based population center analysis, with precise population projections, could be performed to see if the threshold distance could be revised.

\section{REFERENCES:}

1. 10 CFR 100.11, "Determination of Exclusion Area, Low Population Zone, and Population Center Distance."

2. 10 CFR 100.21, "Non-Seismic Siting Criteria."

3. 10 CFR 100.3, "Definitions."

4. U.S. Nuclear Regulatory Commission, Regulatory Guide 1.206, "Combined License Applications for Nuclear Power Plants (LWR Edition)".

5. U.S. Nuclear Regulatory Commission, Regulatory Guide 4.7, "General Site Suitability Criteria for Nuclear Power Stations."

6. U.S. Nuclear Regulatory Commission, NUREG-1555, SRP 2.1, "Station Location."

7. U.S. Nuclear Regulatory Commission, NUREG-1555, SRP 2.5.1, "Demography."

8. U.S. Nuclear Regulatory Commission, NUREG-0800, SRP 2.1.1, "Site Location and Description."

9. U.S. Nuclear Regulatory Commission, NUREG-0800, SRP 2.1.3, "Population Distribution." 
Appendix C - Templates for Evaluating Site Characteristics

C-58 
Appendix C - Templates for Evaluating Site Characteristics

\section{Appendix C-2a Ecology}

Terrestrial Ecology

Aquatic Ecology 


\section{Site CHARACTERISTIC: ENVIRONMENTAL/ECOLOGY/TERRESTRIAL ECOLOGY}

\section{DESCRIPTION:}

The potential for adverse impacts at a proposed site may involve numerous factors which could cause alterations to local faunal or floral communities attributable to removal or alteration of upland or wetland habitats.

\section{IMPORTANCE:}

Federal regulations including 10 CFR 51.10 require compliance with the National Environmental Policy Act (NEPA) and the Endangered Species Act (ESA), i.e., federal agencies are charged with ensuring actions under their jurisdiction do not jeopardize or adversely modify critical habitat of federally listed species and consulting with the United States Fish and Wildlife Service (USFWS) and other appropriate agencies on the protection of threatened and endangered (T\&E) species. In addition to the ESA, Draft RG DG-4015 (Proposed Revision 1 of RG 4.2, Supplement 1, dated September 2000, Preparation of Environmental Reports for Nuclear Power Plant License Renewal Applications) states that the Migratory Bird Treaty Act (MBTA) and Bald and Golden Eagle Protection Act (BGEPA) must be assessed. The NRC Environmental Standard Review Plan (ESRP, NUREG-1555) states a thorough description of the on-site and off-site potential impacts from construction and operation of a power plant should be performed. NRC RG 4.7 states "When early site inspections and evaluations indicate that critical or exceptionally complex ecological systems will have to be studied in detail to determine the appropriate plant designs, proposals to use such sites should be deferred unless sites with less complex characteristics are not available." The Endangered Species Act, 16 USC 1531, requires that any action authorized, funded, or carried out by a federal agency in the U.S. must not likely jeopardize the continued existence of any listed endangered or threatened species or result in the destruction or adverse modification to critical habitat.

\section{RISK:}

The NRC staff will review the terrestrial ecology discussion with the intention of measuring the temporal and spatial scale of temporary and permanent impacts. Large losses of habitat (upland or wetland), adverse impacts to federally or state protected species and/or their associated habitat, inability to sufficiently mitigate for impacted wetlands, or the inability to demonstrate adequate environmental protection may result in the rejection of the site for the nuclear power plant application. The risk of insufficient quality or quantity of data is magnified if state or federal T\&E species are involved. Care should be exercised when making presence/absence species determinations. An "absence" determination will require significant amounts of high quality evidence.

\section{Evaluation: Overall Site Evaluation for Terrestrial Ecology:}

\section{Acceptable Site}

\section{Challenged Site Requiring Further Evaluation}

\section{Site Not Suitable}

\section{DISCUSSION:}

The overall evaluation of terrestrial ecology is indicated above. This evaluation is based on the individual criteria evaluations as discussed below. The overall evaluation should reflect the worst-case of the individual evaluation(s).

Site Type - The evaluation should recognize the type of site being evaluated, i.e., a "Greenfield," "Brownfield "or "existing nuclear power plant" site. Many of the parameters discussed below may have already been addressed for an industrial site or one with an existing power plant. The intensity of each assessment and the quality of data required for a final site selection will vary with the type of site and its proximity to other areas of local importance. Potential sites located in Greenfields may 
require more investigation to determine biotic communities and potential impacts while existing developed sites may possess extensive data.

Evaluation Criteria - Removal or Alteration of Upland Habitat

Examine the size and location of the entire proposed facility including all off-site facilities to ensure that unnecessary amounts of terrestrial upland habitat are not lost or impacted permanently.

Determine the ecological value by assessing the function of the different habitat types associated with the proposed site. Determine if any preferential habitat for resident or transient species may be located in the proposed location. Evaluate the habitats lost to construction in terms of the surrounding area to determine the rarity of habitat type. Determine if any critical habitat has been designated in the area.

The site may be classified as "Acceptable Site" for Removal or Alteration of Upland Habitat if no preferential habitat for resident or transient species will be permanently impacted and no designated critical habitat for state- or federally-listed species will be impacted.

The site may be classified as "Challenged Site Requiring Further Evaluation" for Removal or Alteration of Upland Habitat if large amounts of preferential habitat for resident or transient species may be temporarily impacted but cost-effective mitigation efforts will be made.

The site may be classified as "Site Not Acceptable" for Removal or Alteration of Upland Habitat if large amounts of preferential habitat for resident or transient species will be permanently impacted with no mitigation efforts (or mitigation efforts become cost-prohibitive) or if designated critical habitat will be impacted.

\section{EVALUATION: Removal or Alteration of Upland Habitat}

\section{Acceptable Site}

\section{Challenged Site Requiring Further Evaluation}

\section{Site Not Suitable}

EVALUATION CRITERIA - Removal or Alteration of Wetland Habitat

Examine the proposed location for wetlands that the United States Army Corps of Engineers (USACE) could potentially assert jurisdiction over. The USACE technical guidelines for defining wetlands are contained in the USACE 1987 Wetland Delineation Manual (USACE 1987). Examine National Wetland Inventory Maps along with Federal Emergency Management Agency (FEMA), aerial, soil, and topographic maps for the potential occurrence of wetlands on the proposed location. Ground-truthing of these potential sites is essential. If wetlands must be impacted, the avoidance-minimization- mitigation sequence must be coordinated through the USACE and $\S 404$ permit process.

The site may be classified as "Acceptable Site" for Removal or Alteration of Wetland Habitat if jurisdictional wetland habitat will not be impacted.

The site may be classified as "Challenged Site Requiring Further Evaluation" for Removal or Alteration of Wetland Habitat if jurisdictional wetland habitat will be impacted but cost-effective mitigation efforts will be made to compensate for the loss.

The site may be classified as "Site Not Acceptable" for Removal or Alteration of Wetland Habitat if jurisdictional wetland habitat will be impacted but mitigation efforts will not be made (or mitigation efforts become cost-prohibitive).

\section{EVALUATION: Removal or Alteration of Wetland Habitat}

\section{Acceptable Site}

\section{Challenged Site Requiring Further Evaluation}




\section{Site Not Suitable}

EVALUATION CRITERIA - Threatened and Endangered Species

Look for state and federal T\&E species, migratory bird species, bald and golden eagles, or potential habitat that would support them that may occur in or around the proposed site. Research the state or local sensitive/rare species that possibly occur or have potential habitat in the proposed location. Determine if any preferential habitat may be located in the proposed location. Determine if any critical habitat has been designated in the area. Look for state and federal agency reports, university and peer-reviewed articles on habitat preferences and requirements for all listed species that may be found on the plant site.

The site may be classified as "Acceptable Site" for Threatened and Endangered Species if T\&E, protected bird species, and sensitive/rare species potential habitat or designated critical habitat will not be impacted.

The site may be classified as "Challenged Site Requiring Further Evaluation" for Threatened and Endangered Species if T\&E, protected bird species, and sensitive/rare species potential habitat will be impacted but cost-effective mitigation efforts will be made.

The site may be classified as "Site Not Acceptable" for Threatened and Endangered Species if T\&E, protected bird species, and sensitive/rare species potential habitat will be impacted and mitigation efforts will not be made (or mitigation efforts become cost-prohibitive) or if designated critical habitat will be impacted.

\section{Evaluation: Threatened and Endangered Species}

\section{Acceptable Site}

\section{Challenged Site Requiring Further Evaluation}

\section{Site Not Suitable}

Risk - Specific information about the site in question may not be available. High quality data from comparable areas in relative close proximity may be used to assess the site. The absence of data from a given location can also require initiating intensive studies targeting species or biotic communities in question.

Risk Mitigation - Biological impacts may be mitigated by demonstrating a limited spatial or temporal effect or through agreements and permits with affected state and federal agencies. Localized effects, while significant, may not be measurable a short distance from the site and thus produce a small or negligible regional-scale impact. Careful planning and modifications to the plant footprint may avoid wetlands and other sensitive habitat. Unavoidable wetland losses may be mitigated through various strategies coordinated through the local Corps of Engineers office. Commitments to restoring temporary disturbances to a natural state may be necessary.

\section{REFERENCES:}

1. 10 CFR 51.10, "Application of Regulations of Council on Environmental Quality."

2. 16 USC 1531, "The Endangered Species Act."

3. U.S. Nuclear Regulatory Commission, Draft Regulatory Guide DG-4015 (Proposed Revision 1 of Regulatory Guide 4.2, Supplement 1, dated September 2000) Preparation of Environmental Reports for Nuclear Power Plant License Renewal Applications.

4. U.S. Nuclear Regulatory Commission, NUREG-1555, "Environmental Standard Review Plan."

5. U.S. Nuclear Regulatory Commission, Regulatory Guide 4.7, "General Site Suitability for Nuclear Power Stations," April 1998.

6. USACE 1987, Corps of Engineers, "Wetland Delineation Manual." 


\section{Site CHARACTERISTIC: $\quad$ ENVIRONMENTAL/ECOLOGY/AQUATIC ECOLOGY}

\section{DESCRIPTION:}

The following discussion relates relative only to plant designs requiring cooling water. The potential for adverse aquatic impacts at a site where extensive amounts of water are used for plant cooling may involve numerous factors which cause alterations to local faunal communities attributable to entrainment/impingement, temperature shock, changes in flow regime, removal or alteration of habitat, or changes in behavior related to heated effluents which may affect migration or spawning. Contamination by conventional pollutants is not likely as such a site but National Pollution Discharge Elimination System (NPDES) controls will be put in-place to assure no release of chemicals in concentrations detrimental to aquatic life.

\section{IMPORTANCE:}

33 U.S.C. 1251 (Federal Water Pollution Control Act) declares the goal to restore and maintain the chemical, physical and biological integrity of the nation's waters. Various Federal regulations that support this goal include 10 CFR 51.10 which requires Federal agency compliance with the National Environmental Policy Act (NEPA). The NRC's Environmental Standard Review Plan (environmental standard review plan [ESRP], NUREG-1555) states that a thorough assessment of on-site and off-site potential impacts from construction and operation of a nuclear plant must be included in any application. NRC RG 4.7 also states 'When early site inspections and evaluations indicate that critical or exceptionally complex ecological systems will have to be studied in detail to determine the appropriate plant designs, proposals to use such sites should be deferred unless sites with less complex characteristics are not available." RG 4.7 also states "Where the ecological sensitivity of a site under consideration cannot be established from existing information, more detailed studies, as discussed in Regulatory Guide 4.2, may be necessary." The Endangered Species Act (16 USC 1531, as amended) requires that any action authorized, funded, or carried out by a federal agency in the U.S. must not likely jeopardize the continued existence of any listed endangered or threatened species or result in the destruction or adverse modification to critical habitat. For nuclear plants using ocean water for cooling, The Magnuson-Stevens Fishery Conservation and Management Act (16 U.S.C. 1801 et seq.) establishes the goal and policies of Congress relating to the protection and management of commercial fisheries resources including essential habitat. The Marine Mammal Protection Act, with limited exceptions, prohibits the taking of marine mammals and defines measures intended to promote the replenishment of depleted stocks.

\section{RISK:}

During a license application review, the NRC staff will evaluate the aquatic discussion presented in the application with the intention of measuring the temporal and spatial scale of temporary and permanent impacts. The risk of unacceptably large losses of habitat, individuals of any species protected by state or federal regulation, or changes in local biotic assemblages, or the inability to demonstrate sufficient environmental protection may result in rejection of the application for the nuclear plant site. The risk of insufficient quality or quantity of data is magnified if state or federal threatened and endangered (T\&E) species are involved. Thus, care should be exercised when making presence/absence determinations. Significantly more high quality evidence will be required to make an "absence" determination.

\section{Evaluation: Overall Site Evaluation for Aquatic Ecology:}

\section{Acceptable Site}

\section{Challenged Site Requiring Further Evaluation}

\section{Site Not Suitable}




\section{DISCUSSION:}

The overall evaluation of Aquatic Ecology is outlined above. The evaluation is based on the individual criteria evaluations as indicated below. The overall evaluation should reflect the worst-case of the individual evaluation(s).

Site Type - The evaluation should recognize the type of site being evaluated, i.e., a "Greenfield," "Brownfield or "existing nuclear power plant" site. Many of the parameters discussed below may have already been addressed for past or existing industrial sites or a nuclear power plant. The intensity of each assessment and the quality of data required for a positive site selection will vary with the type of site and its proximity to other sites of local importance. Potential sites located in Greenfield areas may require more initial investigation to determine biotic communities and identify potential impacts while already developed sites may possess extensive data.

\section{Evaluation Criteria - Entrainment/Impingement:}

Determine the potential for excessive entrainment/impingement by examining the composition and density of impingable size fish. Examine the spawning patterns and preferred habitat of local fish species of economic or recreational importance to determine the potential density and composition of the plankton community. Look for entrainment/impingement studies from other facilities in the area if one does not exist for the site undergoing evaluation. Examine university or state agency fish and plankton surveys. If data are older than 5 years, explain why the studies would or would not be relevant for assessing the effects of present and projected future plant operation over the term of license renewal. It may be that both the potentially affected resources and the effect of the plant on them can be expected to remain unchanged over the term of license renewal. Ensure that the intake design and water demand are compliant with Clean Water Act (CWA) 316(b). These criteria are more heavily weighted if T\&E species or NRC "important" species are documented in the area. The proposed plant should not cause or contribute to measurable decreases in fish numbers through direct mortality or changes in reproductive success.

The site may be classified as "Acceptable Site" for Entrainment/Impingement if the intake is not located downstream of preferred spawning habitat of any commercially or recreationally important species, valid studies suggest no significant presence of eggs or plankton in the water column, and no state- or federally-listed species are known to inhabit the area surrounding the intake.

The site may be classified as "Challenged Site Requiring Further Evaluation" for Entrainment/Impingement if spawning areas for commercially or recreationally important species may be located upstream of the intake, either appropriately sized screens or a fish return system is not included in the design package, or at least one state- or federally-listed species has a historic distribution that includes the area surrounding the intake but its current occurrence is uncertain.

The site may be classified as "Site Not Acceptable" for Entrainment/Impingement if significant spawning areas for commercially or recreationally important species are known to occur in the area of the intake, neither plankton screens nor a fish return system is included in the design package, or at least one state- or federally-listed species is known to occur in the area of the intake.

\section{EVALUATION: Entrainment/Impingement}

Acceptable Site

\section{Challenged Site Requiring Further Evaluation}

\section{Site Not Suitable}




\section{EVALUATION CRITERIA - Temperature Shock:}

Determine the change in temperature $(\Delta \mathrm{T})$ effect of the thermal effluent on the receiving water through mass balance equations or hydrologic modeling. Determine the size and duration of the plume and compare those results to the Water Quality Standards applicable to the site. Consider the effect a diffuser may have on the size and duration of the thermal plume. Consider the thermal tolerances of the most sensitive local fish and any recreational and/or commercial fisheries in the area. Determine if the thermal plume could block migration pathways. Examine university or state agency fish surveys. Use local references when possible to determine thermal tolerances. If local references are not available, look for thermal tolerance data from areas of comparable climate and seasonality. Review peer-reviewed journal articles relating to behavior of target species related to thermal plumes. The potential plant should not cause or contribute to measurable decreases in fish numbers through direct mortality or changes in the reproductive success.

The site may be classified as "Acceptable Site" for Temperature Shock if modeling efforts have demonstrated that the effluent will comply with state Water Quality Standards for $\Delta \mathrm{T}$ and the maximum thermal limit for the receiving waters at the appropriate point of compliance (e.g., mixing zone boundary) at regulatory low flows and the thermal plume is not expected to cross an area inhabited by a thermally-sensitive species.

The site may be classified as "Challenged Site Requiring Further Evaluation" for Temperature Shock if modeling efforts have demonstrated that a diffuser may be necessary to modify the shape or areal extent of the plume to comply with Water Quality Standards at regulatory low flows or some temperature-sensitive species may be found in the area of the discharge and the thermal plume.

The site may be classified as "Site Not Acceptable" for Temperature Shock if modeling efforts have demonstrated that the ratio of the heated effluent to the receiving water regulatory low flows will not allow sufficient mixing to reduce the $\Delta \mathrm{T}$ and the maximum thermal limit for the receiving water to a level that will comply with Water Quality Standards or a significant population of at least one thermally-sensitive species is documented in the area of the discharge.

\section{Evaluation: Temperature Shock}

\section{Acceptable Site}

\section{Challenged Site Requiring Further Evaluation}

\section{Site Not Suitable}

\section{EVAluATION CRITERIA - Changes in Flow Regime:}

Determine the ratio of intake to mean annual flow, regulatory low flow and extreme low flow (life-of-the-plant recurrence) if one can be determined. Look for the nearest United States Geological Survey (USGS) gauge or other reliable flow monitoring site. Determine the effect of water loss (plant consumption) on downstream users including wildlife. Examine the size and location of the intake and discharge structures to ensure that no counter-currents, diversions or scouring will be induced by the structures. The proposed plant should not adversely impact the flow regime of the receiving water or water availability for existing withdrawals.

The site may be classified as "Acceptable Site" for Changes in Flow Regime if the withdrawal is expected to meet 316(b) requirements at all flows and the intake and discharge structures are not expected to create changes in the flow that could adversely impact the surrounding substrate (counter-currents or eddies).

The site may be classified as "Challenged Site Requiring Further Evaluation" for Changes in Flow Regime if the withdrawal exceeds 316(b) requirements during some dry periods creating a need for temporary cessation of operations or the intake or discharge structures demonstrate a potential for localized substrate disturbance. 
The site may be classified as "Site Not Acceptable" for Changes in Flow Regime if the withdrawal is expected to exceed 316(b) requirements often enough to prevent cost-effective operation of the plant or the intake or discharge structures are expected to create significant substrate disturbance and resuspension of sediments leading to habitat loss and exceedances of Water Quality Standards (e.g., total suspended solids, turbidity, etc).

\section{Evaluation: Changes in Flow Regime}

\section{Acceptable Site}

\section{Challenged Site Requiring Further Evaluation}

\section{Site Not Suitable}

EVALUATION CRITERIA - Removal or Alteration of Habitat:

Examine site topographic maps and the proposed location for water of the U.S. (stream, intermittent channel, etc.) over which the United States Army Corps of Engineers (USACE) could potentially assert jurisdiction. Examine the size and location of the expected intake and discharge structures to ensure that significant amounts of aquatic habitat are not lost. Look for state and federal threatened and endangered species that may have specific spawning, hunting, or refuge habitat in the area. Examine the structure and location of the intake and discharge structures to ensure that no counter-currents or scouring will be induced by the structures. Determine if sedimentation may become an issue requiring periodic dredging and disturbance and resuspension of local substrate. Look for state and federal agency reports, university, and peer-reviewed articles on local habitat preferences and requirements. Determine if the heated effluents will cause a change in the habitat by creating a temperature regime less favorable to native species. The potential plant should not cause or contribute to changes to the local vegetative community that result in measurable decreases in fish numbers through direct mortality or changes in the reproductive success.

The site may be classified as "Acceptable Site" for Removal or Alteration of Habitat if the intake or discharge structures are not designed or placed in such a manner that a significant amount of breeding, foraging, or nursery habitat is lost and construction/operation of the intake or discharge structures create habitat more favorable for native species.

The site may be classified as "Challenged Site Requiring Further Evaluation" for Removal or Alteration of Habitat if the intake or discharge structures are designed or placed in such a manner that some breeding, foraging, or nursery habitat are temporarily lost but cost-effective mitigation measures may be employed or the construction /operation of the intake or discharge structures create habitat more favorable for non-native species but cost-effective management strategies are available.

The site may be classified as "Site Not Acceptable" for Removal or Alteration of Habitat if the intake or discharge structures are designed or placed in such a manner that significant amounts of breeding, foraging, or nursery habitat will be lost or construction/operation of the intake or discharge structures create habitat more favorable for non-native species and cost-effective management strategies are not available.

\section{EVALUATION: Removal or Alteration of Habitat}

\section{Acceptable Site}

\section{Challenged Site Requiring Further Evaluation}

\section{Site Not Suitable}

\section{Evaluation CRITERIA - Changes in Behavior Related to Heated Effluents:}

Examine temperature tolerances and preferences of locally important commercial or recreational species. Review peer-reviewed journal articles relating to behavior of target species related to thermal plumes. Determine if the thermal plume could intersect important or rare habitat (including spawning 
habitat) that could support locally important commercial or recreational species or T\&E species. Evaluate if the thermal plume could be block migration pathways or interfere with "spawning runs." Determine if removal of the plume (during shutdown) could adversely affect species accustomed to the temperature. The proposed plant should not release heated effluents in quantities sufficient to significantly alter the behavior of fauna in the area.

The site may be classified as "Acceptable Site" for Changes in Behavior Related to Heated Effluents if there are no demonstrated migratory pathways through the area around thermal plume.

The site may be classified as "Challenged Site Requiring Further Evaluation" for Changes in Behavior Related to Heated Effluents if historical migratory pathways exist but the occurrence of the migrating species in the area of the plant is no longer certain.

The site may be classified as "Site Not Acceptable" for Changes in Behavior Related to Heated Effluents if thermally-sensitive migrating species are demonstrated to be in the area of the thermal plume at least part of the year.

\section{Evaluation: Changes in Behavior Related to Heated Effluents}

\section{Acceptable Site}

\section{Challenged Site Requiring Further Evaluation}

\section{Site Not Suitable}

Risk - Adequate information about the site in question may not be available. High quality data from comparable areas in the proximity may then be relied upon which may lose representativeness to some degree. Later plant design changes such as those related to intake and discharge structures or discharge temperatures may invalidate some initial plant parameter presumptions and invalidate the consequent determination of site acceptability.

Risk Mitigation - The absence of data from a given location can be mitigated by initiating dedicated studies targeting the species or community in question. Biological impacts may also be mitigated by demonstrating a limited spatial or temporal effect. Localized effects, while significant, may not be measurable a short distance from the candidate site and thus produce a small or negligible regional-scale impact. Careful site layout can avoid most (if not all) channels through the site. Mitigation for those that cannot be avoided must be coordinated through the Corp of Engineers.

\section{REFERENCES:}

1. 10 CFR 51.45, "Environmental Report."

2. 10 CFR 51.10, "Application of Regulations of Council on Environmental Quality."

3. U.S. Nuclear Regulatory Commission, Regulatory Guide 4.2, "Environmental Report."

4. U.S. Nuclear Regulatory Commission, Regulatory Guide 4.7, "General Site Suitability for Nuclear Power Stations."

5. U.S. Nuclear Regulatory Commission, NUREG-1555, "Environmental Standard Review Plan."

6. 33USC1251, "Federal Water Pollution Control Act (Clean Water Act.)"

7. Entergy Nuclear, "Site Selection Criteria Guidelines for an Early Site Permit."

8. U.S. Nuclear Regulatory Commission, Draft Regulatory Guide DG-4015, Proposed Revision 1 of Regulatory Guide 4.2, Supplement 1, dated September 2000, "Preparation of Environmental Reports for Nuclear Power Plant License Renewal Applications." 
Appendix C - Templates for Evaluating Site Characteristics 


\section{Appendix C-2b Land Use}

Transmission Corridors and Transportation Routes Historic/ Archeological/Cultural Resource Issues 
Appendix C - Templates for Evaluating Site Characteristics

\section{SiTE CHARACTERISTIC:}

\section{ENVIRONMENTAL/LAND USE/TRANSMISSION CORRIDORS AND TRANSPORTATION ROUTES}

\section{DESCRIPTION:}

In the process of selecting a candidate site, transmission corridor, or transportation route, the potential for negatively impacting land use on the site, in the vicinity, or in the region, must be considered. These include the public's aesthetic experience associated with nearby sensitive areas or viewsheds, conflicts with existing or intended public land use objectives (i.e., local recreational use, mineral resource extraction, national parks, Indian tribal lands and reservations, etc.), and disruption of lands dedicated to unique agricultural economic markets, such as growing specialty crops and the disturbance of prime agricultural lands.

\section{IMPORTANCE:}

10 CFR 51.71(d) requires that "...consideration will be given to compliance with environmental quality standards and requirements that have been imposed by Federal, State, regional and local agencies having responsibility for environmental protection, including applicable zoning and land-use regulations." This includes Indian tribal lands or reservations. 10 CFR 51, Appendix A(7) discusses the presentation of analysis should also be included for alternative candidate sites.

NRC RG 4.7 states that any potential conflicts between governing land use plans and the potential site should be examined and resolved through consultation. Candidate sites located "...in areas uniquely suited for growing specialty crops may be considered a type of land conversion involving unacceptable economic dislocation." Further, “...the potential aesthetic impact of nuclear power stations at sites near natural-resource-oriented public use areas is of concern, and evaluation of such sites is dependent on consideration of specific station design layout."

According to NUREG-1555, Environmental Standard Review Plan (ESRP) 2.2.2, the above mentioned code of federal regulations are the "... acceptance criteria for the review of land use in transmission line corridors, access corridors, and other offsite areas that will be modified for the sole purpose of supporting construction or operation of the proposed project."

\section{RISK:}

During a review of a license application, the Nuclear Regulatory Commission (NRC) Staff will assess the significance of direct and indirect environmental effects of plant construction to site, vicinity, and regional land use. Should potential conflicts with intended land use be identified and no satisfactory means of mitigating adverse environmental impacts presented or viable alternative sites offered, the result could be rejection of the application. Conflicts may include allowing construction on a candidate site and the potential negative impact to aesthetics of a neighboring special use property, or construction that would directly alter, for the short-term and/or long-term, the use of a designated land, neighboring public lands, Indian lands, or specialty crop land in opposition to plans and policies of cognizant governing bodies.

\section{EVALUATION:}

\section{Acceptable Site}

\section{Challenged Site Requiring Further Evaluation}

\section{Site Not Suitable}

\section{DISCUSSION:}

Assessment personnel should perform a detailed analysis ascertaining past and current land use for the candidate site, including establishing ownership history, ownership of mineral resources, and historical use or intended land use within the proposed site boundary. A United States Geological Survey (USGS) land-use classification of the site should be performed. Any egress limitations or restrictions of the site should be identified. The information in these records would be used to 
evaluate initial site suitability, and subsequent assessment of the relationship of the site location with respect to vicinity and regional land use practices and policies.

Site Type - The evaluation should identify the type of site being evaluated, i.e., a "Greenfield," "Brownfield, "or "existing nuclear power plant" site. In addition, the evaluation should take into consideration existing data and analyses that might already be available, for example, in the case of an existing nuclear site or, perhaps, a Brownfield site. In a Brownfield or "existing nuclear" example, the site may have already been so altered that the impacts to area aesthetics, disruption of unique soil types or specialty crops, or potential impacts to neighboring public land use, may have already been identified and addressed. Impacted agencies' concerns may have been taken into consideration as such locations and mitigation procedures already adopted for reuse of the site. More intensive research and analysis of potential conflicts can be expected to be necessary if the assessment deals with a Greenfield site where a previous history has not been established.

Evaluation Criteria - For each of the analysis parameters, evaluation criteria are based on the Environmental Standard Review Plan (ESP, NUREG-1555) and guidance rationale provided by NRC RG 4.7, Rev 2 .

An "Acceptable Site" occurs if no conflicts between the applicant's proposed facility and the objectives of federal, regional, state, and local (and in the case of proposed location on a reservation, Native American tribal) land-use plans are identified.

A "Challenged Site Requiring Further Evaluation" occurs if there are or are likely to be conflicts between the applicant's proposed site and the surrounding identified land use patterns.

A "Site Not Suitable" evaluation occurs when potential conflicts with local land use are identified and no satisfactory means of mitigation is foreseeable.

\section{Land Use Analysis:}

A_land use analysis performed for each of the parameters to include aesthetic impacts, the identification of unique soils that may be disrupted, and potential impact to local public use lands. The analysis should consider the following steps:

- Identify any special land use (e.g., culturally sensitive buildings, recreational facilities, agricultural use, and prime farmland and unique soils) that could be affected by the site. This information can be obtained from local and state zoning and planning publications and the 2007 Census of Agriculture.

- Determine the regional sensitive land use (e.g., hospitals, residences, state, federal, and local parks, wilderness areas, Native American lands, local culturally sensitive lands, and sensitive viewsheds). This information can be obtained from local Chambers of Commerce publications, National Park Service, and local and state publications.

- Identify the public use policy, standard, guideline and/or plan that may provide public or regulatory oversight of the issue.

- Consider the collected information and evaluate the candidate site accordingly. It may be useful to estimate the potential geographic and temporal extent and magnitude of the impact.

Risk - While the majority of land use patterns can be identified from publicly available data, some information will only be available by consultation with local residents, Native American tribes, and the various state and local agencies. Thus, some impacts may not be identified at this level of review if interaction with these entities is constrained. Also, some of the mitigation efforts associated with this issue could be costly and time consuming.

Risk Mitigation - RG 4.7 states "sites adjacent to lands devoted to public use may be considered unsuitable. In particular, the use of some sites or transmission lines or transportation corridors close to special areas administered by federal, state, or local agencies for scenic or recreational use may 
cause unacceptable impacts regardless of design parameters." According to NUREG-1555, if upon evaluation of impacts a judgment is made that the "impact is adverse, cannot be successfully mitigated, and is of such magnitude that it should be avoided," it would be necessary to discuss alternative designs and subsequently re-address the issue with the appropriate agency to find an alternative mitigation option.

\section{REFERENCES:}

1. 10 CFR 51.71(d), "Draft Environmental Impact Statement."

2. 10 CFR 51, Appendix A (7), "Environmental Consequences and Mitigating Actions."

3. U.S. Nuclear Regulatory Commission, Regulatory Guide 4.7, "General Site Suitability Criteria for Nuclear Power Stations," April 1998.

4. U.S. Nuclear Regulatory Commission, NUREG-1555 ESRP 2.2, "Land."

5. U.S. Nuclear Regulatory Commission, NUREG-1555 ESRP 4.1, "Land-Use Impacts."

6. U.S. Nuclear Regulatory Commission, NUREG-1555 ESRP 5.1, “Land-Use Impacts.”

7. U.S. Nuclear Regulatory Commission, NUREG-1555 ESRP 5.8, "Socioeconomic Impacts."

8. U.S. Nuclear Regulatory Commission, NUREG-1555 ESRP 9.3, “Alternative Sites.” 


\section{Site CHARACTERISTIC:}

\section{DESCRIPTION:}

A historic property is “... any prehistoric or historic district, site, building, structure, or object included in, or eligible for inclusion in, the National Register of Historic Places (NRHP) maintained by the Secretary of the Interior (36 CFR 63). This term includes artifacts, records, and remains that are related to and located within such properties. The term includes properties of traditional religious and cultural importance to an Indian tribe or Native Hawaiian organization that meet the National Register Criteria." These criteria are listed in 36 CFR 60.4. Historic properties typically include prehistoric archaeological sites, historic archaeological sites, aboveground historic sites manifested by standing structures such as houses, barns, or grist mills (usually more than 50 years old), and traditional cultural properties. A traditional cultural property is one that is eligible for or listed on the NRHP because of its association with the cultural practices or beliefs of a living community that (a) are rooted in that community's history (b) are important in maintaining the continuing cultural identity of the community (e.g., native American sacred lands, raw material gathering sites, ritual areas, and ethnic neighborhoods). Even if such a property is not eligible for or listed on the NRHP, its traditional value to an ethnic group may still warrant its protection as a traditional cultural property. A historic cemetery that meets the NRHP criteria is also a historic property, but as a general rule, most historic cemeteries are not considered to be historic properties. However, they are still important because most state and local governments have laws, regulations, and ordinances in place to protect cemeteries from harm, and some of these requirements involve criminal penalties. In the site-selection process, evaluation of a candidate site is necessary to avoid selection of a site where future nuclear power plant construction and operations would disturb or destroy historic properties and cemeteries.

\section{IMPORTANCE:}

For a federal undertaking, such as issuing a construction permit or operating license for a new nuclear power plant, the National Historic Preservation Act of 1966 (Section 106) and the federal regulations in 36 CFR 800 require the lead federal agency (i.e., U.S. Nuclear Regulatory Commission, NRC) to define the areas of potential effect (APE) on historic properties, identify historic properties within the APE, assess the potential adverse effects of the undertaking on any historic properties that are present, and mitigate these adverse effects. Issuance of a construction permit or operating license would result in a nuclear power plant construction and operations activities that could result in such adverse if any historic cemeteries are present within defined APEs on or near the site.

\section{RISK:}

Available documents and records must be reviewed to determine whether any historic properties or cemeteries are present on or near a candidate site. The presence of historic properties or cemeteries on a candidate site or in close proximity to it may result in its rejection for construction of a new nuclear power plant.

\section{EVALUATION:}

\section{Acceptable Site}

\section{Challenged Site Requiring Further Evaluation}

\section{Site Not Suitable}

\section{DISCUSSION:}

Evaluators should perform an archival search for existing documents and records pertinent to the identification of prehistoric archaeological sites, historic archaeological sites, aboveground historic sites (standing buildings and structures), historic districts, historic objects, traditional cultural 
properties, and cemeteries on and near a candidate site for a new nuclear power plant. The information in these records will be used to evaluate candidate site suitability with regard to historic properties.

Site Type - The evaluation should identify the type of candidate site that is being evaluated (i.e., "Greenfield," "Brownfield," or an "existing nuclear power plant" site.) It should also be noted whether the site is an open field known to have deeply and extensively disturbed soil. It is important to factor site type into the analysis because it is highly probable that a Greenfield site has never been the subject of past cultural resource studies. This means that historic properties and cemeteries may be present on or near the site but information on them is unlikely to be present in any existing document. To a more limited extent, the same may be true of a Brownfield site if its past use involved only private sector activities. In most states, private sector sites have not been subject to federal, state, or local cultural resource survey and management requirements. Private sector Brownfield sites with extensive past construction and open field sites known to have widespread and deeply disturbed soils have a low probability of containing intact historic properties or cemeteries because they have been disturbed or destroyed by past earthmoving and construction activities. Federal Brownfield sites and existing nuclear power plant sites have typically been subject to past cultural resource studies or record reviews, and written reports are usually available.

Evaluation Criteria - The site may be classified as an "Acceptable Site" if it has been studied for cultural resources and documents are available showing that either no historic properties or cemeteries are present within the site boundary, or they are present in locations where impacts are known to be avoidable. If a site located outside of a floodplain has not been studied for cultural resources but the on-site soils have been disturbed extensively and to depth so that no intact historic properties would be present, the site would be fully acceptable. Furthermore, under both of those circumstances, no historic properties (aboveground historic sites and traditional cultural properties) or cemeteries would be present outside of the site boundary at locations where they would be adversely impacted visually or by noise. However, a candidate site would be a fully acceptable if such off-site visual and noise impacts were known to be avoidable. An NRHP-eligible or listed archaeological site cannot be impacted visually or by noise because it is buried underground.

The site may be classified as a "Challenged Site Requiring Further Evaluation" under two circumstances:

(1) A site has not been studied for cultural resources in the past, which means that no historic property or cemetery documentation is available for the site or nearby areas, or

(2) A site has been studied for cultural resources and documentation is available. Available documentation indicates that archaeological sites, aboveground historic sites, traditional cultural properties, or cemeteries are present within the site boundary and/or outside the site boundary at locations where they would be impacted visually or by noise. However, their current NRHP status (recommended eligible, eligible, or listed) is either unknown because it has never been assessed or it is in doubt because of previous "ineligible" recommendations that were not supported by systematic shovel testing.

The site may be classified as a "Site Not Suitable" when historic properties or cemeteries are known to be present within the site boundary and impacts upon them are known to be unavoidable. It also applies when historic properties (aboveground historic sites or traditional cultural properties) or cemeteries are present outside of the site boundary at locations where they would be adversely impacted visually or by noise and such impacts are known to be unavoidable. An NRHP-eligible or listed archaeological site cannot be impacted visually or by noise because it is buried underground.

The Environmental Standard Review Plan (ESRP, NUREG-1555) and NRC RG 4.2 provide insight as to areas of review by the NRC Staff and should be consulted as appropriate to ensure that the evaluation is sufficiently comprehensive. In addition, NRC RG 4.7 should be reviewed prior to performing the analysis. 


\section{Method of Analysis:}

Five sequential steps are required to complete the historic properties analysis.

The first step is to identify and acquire the existing documentation relevant to the candidate site, which includes old maps, archaeological and historic site survey files, architectural inventory files, environmental reports, environmental assessments, and environmental impact statements, cultural resource survey and excavation reports, and any other pertinent documentation. State archaeological and historic site survey files, the NRHP, and any existing state and local registers of historic places should be the primary document sources. Other excellent sources are local urban planning offices, local historical societies, the historical room in local public libraries, and the site owner(s).

The second step is to review acquired documents to identify cultural resource information specific to the land within the boundary of the candidate site and on surrounding land outside of the site boundary (up to a 10 mile [16-km] radius of the reactor center point, as practical, and depending on local terrain, ground cover vegetation, and the prospects for visual and noise impacts on aboveground historic sites, traditional cultural properties, and cemeteries).

For the third step, identify and locate the cultural resources (e.g., archaeological sites, aboveground historic sites, traditional cultural properties, and cemeteries) that have been previously found within the boundary of the candidate site and in the surrounding area outside of the site boundary.

Fourth, identify any cultural resources (e.g., archaeological sites, aboveground historic sites, traditional cultural properties, or cemeteries) that have been previously recommended as eligible, determined as eligible, or listed on the NRHP or state/local registers. These are defined as historical properties. Those that are either eligible for or listed on state/local registers are also of concern to the $\mathrm{NRC}$ and should be regarded as historic properties too for purposes of this historic properties analysis.

Lastly, considering the collected information, site type, past soil disturbance, and risk factors, evaluate the candidate site according to the evaluation criteria already provided.

Risk - One basic risk is associated with historic properties analysis solely using existing documentation. Quite often, such documentation on a site is old and incomplete. This means that a previously unidentified historic property can be present on a site but its presence may be missed in the analysis, which can lead to an inaccurate candidate site evaluation. Awareness of this risk is particularly important when evaluating Greenfield sites. In reality, the only way to thoroughly and confidently assess a candidate site for the presence of historic properties and cemeteries is to implement an on-the-ground intensive survey with systematic shovel testing and archaeological testing (if necessary).

Risk Mitigation - An intensive field survey with systematic shovel testing can be implemented in the candidate site APEs to identify whether any historic properties or cemeteries are present. If none are present, the candidate site is considered a fully acceptable and the State Historical Preservation Office (SHPO) will clear it for plant construction and operations. If human cultural remains (e.g., an archaeological site) are found in the APEs during the intensive survey but the survey data are inadequate to determine if it qualifies as a historic property, follow-on testing will be necessary to gather additional information. If a historic property or cemetery is identified during either field investigation, the site can be converted into a fully suitable site in two ways: (1) potential impacts on the discovered historic property or cemetery can be mitigated through subsequent data recovery operations or cemetery removal in accordance with state and local laws (such operations tend to be expensive and time-consuming), or (2) potential impacts on a historic property or cemetery can be intentionally avoided during design, construction, and operation of the proposed plant. In most cases, the SHPO prefers avoidance over data recovery because data recovery and cemetery removal involve controlled destruction of historic property or a cemetery whereas avoidance preserves these resources for future generations. However, avoidance may not be technically feasible at some candidate sites, 
depending on plant design parameters and the unique physical characteristics of the candidate site. The appropriateness of mitigation or avoidance must be assessed on a case-by-case basis.

\section{REFERENCES:}

1. U.S. Nuclear Regulatory Commission, Regulatory Guide 4.2, "Preparation of Environmental Reports for Nuclear Power Stations."

2. U.S. Nuclear Regulatory Commission, Regulatory Guide 4.7, "General Site Suitability Criteria for Nuclear Power Stations."

3. U.S. Nuclear Regulatory Commission, NUREG-1555, ESRP 2.5.3, "Historic Properties."

4. U.S. Nuclear Regulatory Commission, NUREG-1555, ESRP 4.1.3, "Historic Properties."

5. U.S. Nuclear Regulatory Commission, NUREG-1555, ESRP 5.1.3, "Historic Properties."

6. 16 USC 470 et seq., "National Historic Preservation Act of 1966."

7. 36 CFR 60.4, "Criteria for Evaluation."

8. 36 CFR 63, "Determinations of Eligibility for Inclusion in the National Register of Historic Places."

9. 36 CFR 800, "Protection of Historic Properties." 
Appendix C - Templates for Evaluating Site Characteristics

\section{Appendix C-2c Water Use}

Hydrologic Impacts 


\section{Site CHARACTERISTIC: $\quad$ ENVIRONMENTAL /WATER USE / HYDROLOGIC IMPACTS}

\section{DESCRIPTION:}

The analysis for hydrologic impacts can include potential impacts to both surface water and groundwater. Evaluation of potential surface water and groundwater impacts during plant construction and operation includes physical, thermal, radiological, and chemical influences. Radiological impacts are evaluated in the Radiological Pathways template. Thermal impacts on surface water quality are discussed in the Aquatic Ecology template. This template will focus on the chemical and physical water quality impacts.

\section{IMPORTANCE:}

Impacts to water quality can generally be mitigated and are seldom considered a "fatal flaw" (as far as a determination of site suitability is concerned); however, these mitigation actions can become costly. Adequate design alternatives can be developed to meet applicable Federal Water Pollution Control Act (FWPCA) requirements, National Pollution Discharge Elimination System (NPDES) permit requirements, and the NRC's regulations implementing the National Environmental Policy Act (NEPA). Depending on the plant location, additional state and local water quality standards may apply. Anticipation and management of water quality impacts is important to determine design alternatives, acquire the appropriate permits, and mitigate potential environmental impacts.

\section{RISK:}

Failure by the applicant to certify to the Nuclear Regulatory Commission (NRC) that all discharges from the facility will comply with applicable effluent limitations and other water pollution control requirements will result in denial of the construction permit, early site permit, or combined license, unless the requirement is waived by the state or the state fails to act within a reasonable period of time.

\section{EVALUATION:}

\section{Acceptable Site}

\section{Challenged Site Requiring Further Evaluation}

\section{Site Not Suitable}

\section{DISCUSSION:}

Site Type - The type of site being evaluated (i.e., a "Greenfield," "Brownfield "or "existing nuclear power plant" site) can have a significant impact on the analysis of hydrologic impacts, including surface water and groundwater quality. Potential sites located in Greenfields may require more investigation to characterize water quality while existing power plants and Brownfield sites may possess extensive data. The intensity of each assessment will vary depending upon the quantity and quality of readily available data from existing plant sources and publicly available sources.

Evaluation Criteria - An "Acceptable Site" for the evaluation is one that does not present surface water or groundwater quality factors which may impede the issuance of necessary permits and licenses.

A "Challenged Site Requiring Further Evaluation" is one in which surface water or groundwater quality issues are identified and engineering design alternatives or mitigation measures may be necessary to meet water quality standards.

A "Site Not Suitable" evaluation occurs when required mitigation measures are not available or reasonable, such as when a site is located in an area classified as a Class I groundwater aquifer. 


\section{Surface Water Controls:}

If plant design requires the discharge of thermal and chemical effluents, those effluents to navigable streams are governed by the FWPCA (33 U.S.C. 1251 et seq.), also known as the Clean Water Act (CWA) as amended, 40 CFR Part 122, 40 CFR Part 423, and state water quality standards. Other state and local regulations may also apply. Section 401(a)(1) of the FWPCA states, in part, that any applicant for an NRC construction permit, early site permit, or combined license for a nuclear power station provide to the NRC certification from the state that any discharge will comply with applicable effluent limitations and other water pollution control requirements. Guidance indicates that this state certification is necessary unless the requirement is waived by the state or the state fails to act within a reasonable length of time.

A NPDES permit to discharge effluents to navigable streams pursuant to Section 402 of the FWPCA may be required for a nuclear power station to operate in compliance with the Act, but it is not a prerequisite to an NRC construction permit, operating license, or combined license. Water quality impacts from dredging, scouring, siltation from construction disturbances, thermal discharges, or any other physical alteration may need to be managed to comply with the NPDES permit.

Where station construction or operation has the potential to physically or chemically degrade water quality to the possible detriment of other users, more detailed analyses and evaluation of water quality may be necessary.

\section{Groundwater Classification:}

The U.S. Environmental Protection Agency (EPA) issued its Groundwater Protection Strategy in August 1984 and provided Guidance for Groundwater Classification in December 1986 (EPA, 1986) under its responsibilities as outlined in the Safe Drinking Water Act (SDWA). The Strategy established three general classes of groundwater representing a hierarchy of groundwater resource values to society as follows:

- Class I - Special groundwater

- Class II - Groundwater currently and potentially a source of drinking water

- Class III - Groundwater not a source of drinking water.

Class I groundwater aquifers are highly vulnerable to contamination and are (1) irreplaceable sources of drinking water and/or (2) ecologically vital. Many states have adopted their own system based on the EPA strategy and have mapped the locations of groundwater classes. Groundwaters classified as Class I by state or federal agencies should be avoided.

Within a 2 mile $(3.2-\mathrm{km})$ radius of the candidate site, develop a utility function based on the percentage of Class II and Class III groundwaters. If these groundwaters have not been designated, utilize the procedures and data outlined in EPA guidance to evaluate the groundwaters within 2 miles $(3.2-\mathrm{km})$ of the site. EPA guidance (EPA 1987) utilizes a numerical ranking system called "DRASTIC", using readily available information on the following seven hydrogeologic characteristics:

$\mathrm{D}$ - Depth to the water table

R - Net Recharge

A - Aquifer media

S - Soil media

T - Topography

I - Impact of the vadose zone

C - Hydraulic conductivity of the subject groundwater flow system 
DRASTIC provides a standardized technical basis for evaluating the relative vulnerability of shallow aquifers to groundwater pollution. The higher an area scores on the index, the more susceptible to groundwater contamination. The numerical value obtained is related to two broad climatic regions in the country, based on whether the annual evapotranspiration exceeds mean annual precipitation. While it is always important to manage any potential releases of groundwater pollutants, sites with higher scores based on the DRASTIC evaluation may require additional mitigation.

\section{Protection of Potable Water Supplies:}

The EPA redefined "Public Water System" in SDWA Section 1401(4) as amended by 1996 SDWA Amendments (63 FR 41939, August 5, 1998). A public water system was previously defined to include only piped water systems (if such system has at least 15 service connections or regularly serves at least 25 individuals). The definition has now been broadened to include systems providing water for human consumption that deliver this water by constructed conveyances, such as irrigation canals.

Siting criteria relating to distance from public water systems appear to be more state-specific. The State may require the applicant to provide information pertaining to public water supply wells, which may be disturbed during construction or plant operation. Public water supply wells may be federally- or state-regulated.

The National Primary Drinking Water Regulations, Radionuclides; Final Rule (EPA) 65 FR 76707 of December 7, 2000, finalizes maximum contaminant level goals, maximum contaminant levels, and monitoring, reporting, and public notification requirements for radionuclides. This Rule is only applicable to community water systems. The Final Rule includes requirements for uranium, which is not currently regulated, and revisions to monitoring requirements for combined radium-226 and radium-228, gross alpha particle radioactivity, and beta particle and photon radioactivity. Site-specific groundwater monitoring would be conducted prior to plant construction.

Groundwater impacts under operating and accident conditions with respect to present and future users should be anticipated, by evaluating hydrologic parameters such as dispersion and dilution capabilities, potential groundwater contaminant pathways, general hydrologic complexity, location relative to water supply aquifers, aquifer classification by DRASTIC, etc. This evaluation may warrant more reliable investigation to assess the potential reactor impacts on groundwater. $10 \mathrm{CFR}$ Part 100 states that site environmental parameters, which include hydrological characteristics, be characterized and used in or compared to those used in the plant probabilistic risk assessment (PRA) and environmental analysis.

Risk - Failure to meet the NPDES permit requirements can result in fines, temporary shutdown of activities, construction delays, and could result in non-issuance of permit renewals. Potentially costly engineering design alternatives may be necessary for sites with complex hydrologic conditions or located in hydrologically sensitive areas.

Risk Mitigation - Engineering controls and design alternatives may need to be implemented to meet FWPCA requirements for thermal and chemical effluents and manage potential surface water and groundwater quality impacts. These mitigation measures should be anticipated and managed to the degree possible to control costs. 


\section{REFERENCES:}

1. 10 CFR Part 20, "Standards for Protection Against Radiation."

2. 10 CFR Part 50, Appendix A, General Design Criterion 2, "Design Bases for Protection Against Natural Phenomena."

3. 10 CFR Part 100, "Reactor Site Criteria."

4. U.S. Nuclear Regulatory Commission, "Design Basis Floods for Nuclear Power Plants," Regulatory Guide 1.59, Revision 2, August 1977. ${ }^{1}$

5. U.S. Nuclear Regulatory Commission, "Ultimate Heat Sink for Nuclear Power Plants," Regulatory Guide 1.27, Revision 2, January 1976.

6. U.S. Nuclear Regulatory Commission, "Standard Format and Content of Safety Analysis Reports for Nuclear Power Plants," Regulatory Guide 1.70, Revision 3, November 1978.

7. U.S. Nuclear Regulatory Commission "General Site Suitability for Nuclear Power Stations," Regulatory Guide 4.7, Revision 2, April 1998.

8. Entergy Nuclear, "Site Selection Criteria Guidelines for an Early Site Permit." 
Appendix C - Templates for Evaluating Site Characteristics 


\title{
Appendix C-3 Sociological Impact Characteristics Templates
}

\author{
Public Acceptance \\ Aesthetics \\ Environmental Justice Considerations \\ Socioeconomic Effects
}


Appendix C - Templates for Evaluating Site Characteristics

\section{Appendix C-3a \\ Public Acceptance}




\section{Site Characteristic: $\quad$ Sociological Impacts / Public ACCeptance}

\section{DESCRIPTION:}

Along with evaluating the physical characteristics that determine the suitability of a potential candidate site for industrial use, it is necessary to identify and evaluate potential public concerns of the communities surrounding the proposed plant site. Concerns that could be a factor include public resistance to the use of nuclear power, fear that an environmental resource or culturally sensitive area would be unduly compromised, the potential disproportionate impact to minority and/or low income populations, or preference to economic growth opportunities based on occupations, such as tourism, and not those related to industry or power generation.

\section{IMPORTANCE:}

For initial feasibility study purposes, it is important to identify and eliminate sites where the potential exists for extensive public resistance to the idea of locating a nuclear plant in the vicinity. As the process moves towards submittal of Nuclear Regulatory Commission (NRC) permit applications, the identification of potential community partners or stakeholders and attaining their acceptance and involvement becomes a key component to successfully locating a plant at a site. As described in RG 4.2 and NUREG-1555 Section 9.3, there is a discussion of a "proposed" site compared to "alternative" sites. In this discussion, the site-selection methodologies are identified and the topic of public concerns is an aspect of the evaluated criteria. Therefore, for any site considered for licensing, it is important to characterize and document public acceptance or concerns since it must be included in the licensing application and has the potential to excessively delay the licensing process.

\section{RISK:}

During the feasibility study, if the extent of public concern of the idea of locating a plant is extensive and not recognized in the beginning of the process, then time and resources may be needlessly expended should the site be later rejected. Also, once a license application is submitted to the NRC, staff will evaluate the characterization of public acceptance at the proposed site along with the other parameters of site-selection. If the environmental review discussion submitted by the applicant is not found to be sufficient, the NRC may request additional field work and analysis. Also, if excessive public concerns are identified, there is a risk that a submitted license application would be contended, thereby incurring increased cost and time.

\section{EVALUATION:}

\section{Acceptable Site}

\section{Challenged Site Requiring Further Evaluation}

\section{Site Not Suitable}

\section{DISCUSSION:}

According to RG 4.7, at the initial stage of the feasibility study, investigations would be limited to reconnaissance-type research to ascertain if a history of opposition exists, or if the public would accept the idea of siting industrial facilities in an area. Data gathering would not rely on face-to-face interviews with public representatives. Instead, the focus of data gathering would begin with identifying any sensitivity to land use, environmental justice, or cultural practices that may be impacted by the construction or operation of the plant (see Land use, Environmental Justice, and the Ecology templates). The next step is gathering published planning documents from various agencies and organizations to determine the type of economic development being promoted in the area. Finally, research the available news accounts detailing the political atmosphere of siting industry and/or power plants in an area and whether a strong "culture" of public resistance or history of intervention exists. 
Site Type - If a proposed site is associated with an "existing nuclear power plant" location, than public acceptance may not present a significant problem because a positive relationship can be presumed to exist between the current plant operator and the public at large. However, the inverse may also be true where negative relationships exist and fuel interference to the addition of new nuclear structures in the area. If a legacy of nuclear or hazardous material operations already exists with a vacated Brownfield site, introducing the idea of siting a nuclear plant may be perceived as a viable reuse. Examining the history of public perception associated with the Brownfield site would provide insight regarding the potential for public acceptance. A Greenfield site where no history of public acceptance exists would be the most difficult to characterize and data would need to be acquired as previously described.

Evaluation Criteria - At the initial stage this evaluation, acceptance or elimination of a potential proposed site based on public acceptability is a somewhat subjective decision process. Gauging the extent of potential public concern and deciding on levels of acceptability has no set measurement criteria. However, guidelines for this decision can be established.

An "Acceptable Site" designation occurs when no public concerns are identified and public acceptance would seem a matter of course (i.e., a proposed site associated with an established nuclear power plant where the operator has a positive relationship with the community.)

A "Challenged Site Requiring Further Evaluation" designation occurs when historically, public acceptance of potential industrial sites in an area has garnered both positive and negative support, but opposition has not become extensive or extreme in nature (i.e., both Brownfield and Greenfield sites might fall under this evaluation).

A "Site Not Suitable" designation occurs when the suitability study reveals that a potential industrial or nuclear proposed site has historically garnered an extreme amount of public concern and contention. If societal conditions have not changed since the last occurrence, it could be likely that resistance to siting a new plant still exists. Also, this designation may occur when new concerns are identified and the "impacted" community or group is well organized and set against the proposed project.

It is important to note that since this parameter is somewhat subjective, it is anticipated that the Evaluation Criteria definitions may require refinement based upon local knowledge and business needs.

Risk - If a prospective license applicant does not control the release of information to the public, adverse public perception is quite possible. Also, if excessive public concerns are identified, the licensing and public relation processes could be lengthy and expensive.

Risk Mitigation - When a "proposed" site has been selected and announced, involving the public early and provide information detailing the benefits of the project. This will increase the probability of public acceptance of a new plant being sited in or near their community.

\section{REFERENCES:}

1. U.S. Nuclear Regulatory Commission, Regulatory Guide 4.2, "General Site Suitability Criteria for Nuclear Power Stations," Section 9.2.1 "Selection of Candidate Areas."

2. U.S. Nuclear Regulatory Commission, Regulatory Guide 4.7, "General Site Suitability Criteria for Nuclear Power Stations," "Introduction."

3. U.S. Nuclear Regulatory Commission, NUREG-1555 ESRP 9.3, "Alternative Sites." 
Appendix C - Templates for Evaluating Site Characteristics

\section{Appendix C-3b Aesthetics}




\section{Site CHARACTERISTIC: $\quad$ SOCIOLOGICAL IMPACTS/AESTHETICS}

\section{DESCRIPTION:}

In the process of preparing a site assessment study, the potential for adverse aesthetic impacts in the vicinity or in the region should be considered. Aesthetic impacts would most likely take place during construction and/or operation phases of the project. During the construction phase, impacts could include construction noise, odors, dust, etc., at the plant and along transmission and access corridors. During the operation phase, the aesthetic perception created by the plant layout, landscaping, architectural features, and operational activities could be of concern.

\section{IMPORTANCE:}

According to RG 4.7, "The potential aesthetic impact of nuclear power stations at sites near natural-resource-oriented public use areas is of concern, and evaluation of such sites is dependent on consideration of specific station design layout" (see the Land Use Template discussion).

NUREG-1555 states "The depth and extent of the input to the Environmental Impact Statement (EIS) should be governed by aesthetic and land-use considerations that could be affected by station layout and by the nature and magnitude of the expected impacts." Aesthetics issues caused by location of industry and power facilities in an area can produce negative socioeconomic impacts for both the surrounding populations and the economic foundation of a community.

\section{RISK:}

The Nuclear Regulatory Commission (NRC) Staff will evaluate the aesthetic mitigation plans to determine the significance of potential impacts to the surrounding area and assess whether the aesthetic design features integrated into the project are reasonable and affective. If the mitigation plans are found to be insufficient, then the NRC may request new design features and/or mitigation strategies to reduce impact. This process could become expensive and possibly cause delays.

\section{EVALUATION:}

\section{Acceptable Site}

\section{Challenged Site Requiring Further Evaluation}

\section{Site Not Suitable}

\section{DISCUSSION:}

Knowledge of the selected plant technology and design features are key elements in understanding potential aesthetic impacts a candidate plant may have on the surrounding area. As a site feasibility study is undertaken, understanding the potential for adverse aesthetic impacts caused by the design of a plant and the location of a plant should be taken into consideration during the identification of any area land use issues. Socioeconomic issues such as environmental justice are also a parameter that should be considered.

Site Type - Should an "existing nuclear power plant" be associated with siting new nuclear structures, than the negative impacts caused by proposed design features may not be a great concern. Impacts from construction could still be an issue but tend to be temporary in nature. Regarding analysis of feasible sites associated with Brownfield locations, aesthetics mitigation may have already been completed and evaluated by earlier projects. An aesthetics analysis will not have been completed for a Greenfield site and no prior mitigation plans will have been developed for consideration and use.

Evaluation Criteria - An "Acceptable Site" evaluation occurs when no aesthetic impacts are identified near the candidate site or in association with related facilities such as switchyards, station access roads and railroads.

A “Challenged Site Requiring Further Evaluation” occurs when potential aesthetic impacts are identified. 
A "Site Not Suitable" evaluation cannot be achieved at this stage because such a determination is dependent upon the failure of applied mitigation options.

Risk - There is no risk of application rejection from the NRC due to aesthetic concerns. However, this issue may require mitigation if impacts are identified. There is a possibility the mitigation efforts can be unreasonably expensive to implement.

Risk Mitigation - Many impacts on land use at the site and in the site neighborhood arising from construction and operation of the plant, transmission lines, and transportation corridors can be mitigated by appropriate designs and architectural practices. Aesthetic impacts can be reduced by selecting sites where existing topography and forests can be utilized for screening station structures from nearby scenic, historical, or recreational resources. Restoration of natural vegetation, creative landscaping, and the integration of structures with the environment can mitigate adverse visual impacts.

\section{REFERENCES:}

1. U.S. Nuclear Regulatory Commission, Regulatory Guide 4.7 "General Site Suitability Criteria for Nuclear Power Stations."

2. U.S. Nuclear Regulatory Commission, NUREG-1555, SRP 3.1 "External Appearance and Plant Layout." 
Appendix C - Templates for Evaluating Site Characteristics 


\section{Appendix C-3c Environmental Justice Considerations}




\section{Site CHARACTERISTIC:}

\section{SOCIOLOGICAL IMPACTS / ENVIRONMENTAL JUSTICE CONSIDERATIONS}

\section{DESCRIPTION:}

The potential for environmental justice issues at a candidate site is primarily based upon the identification of disproportionate impacts to low income and minority populations as defined by LIC-203, Appendix D. Often, these issues are difficult to mitigate and may cause complications for a site being licensed by the U.S. Nuclear Regulatory Commission (NRC). This template will focus on identifying low income and minority populations using the NRC's guidance. The proximity of identified low income and minority populations to the site, as well as transmission and transportation routes to the site, will be used as an indicator for potential environmental justice considerations.

\section{IMPORTANCE:}

RG 4.7 states “...the NRC is committed to carry out the measures set forth in Executive Order 12898, "Federal Actions to Address Environmental Justice in Minority Populations and Low-Income Populations" (59 FR 7629), to consider the effects of its actions on minority and low-income communities. Siting decisions should reflect fair treatment and meaningful involvement of all people, regardless of race, ethnicity, culture, income or educational level to assure equitable consideration and to minimize disproportionate effects on minority and low-income populations."

\section{RISK:}

The NRC Staff will evaluate the environmental justice considerations to identify the possibility of an environmental justice issue. If low income or minority populations are identified, the NRC will evaluate the impacts on these populations that may be disproportionate and significant. Any significant or disproportionate impacts may prompt the NRC to include regulatory actions that involve significant site modification or mitigation.

The identification of a disproportionately high and adverse human health or environmental effect on a minority or low-income population does not preclude a proposed agency licensing action from going forward, nor does it necessarily compel a conclusion that a proposed action is environmentally unsatisfactory. Rather, the identification of such an effect should heighten agency attention to alternatives (including alternative sites), mitigation strategies, monitoring needs, and preferences expressed by the affected community or population.

The NRC Staff also considers the suitability of a site located near distinctive communities. They require a demonstration that the construction and operation of the nuclear station, including transmission and transportation corridors, will not adversely affect the distinctive character of the community. However, identifying distinctive communities requires more detailed analysis that is not appropriate as part of an initial feasibility study. It is important to note, however, that while a site may be acceptable at this level, research into distinctive communities will need to be addressed at the next stage.

EVALUATION:

\section{Acceptable Site}

\section{Challenged Site Requiring Further Evaluation}

\section{Site Not Suitable}

\section{DISCUSSION:}

Low income and minority populations located within the region around the plant should be identified. The proximity of identified low income and minority populations to the site, transmission and transportation routes to the site will be used as an indicator for potential environmental justice considerations. 
Site Type - The evaluation should identify the type of site being evaluated, i.e., a "Greenfield," "Brownfield," or "existing nuclear power plant" site. The evaluation should identify the unique applicability of site type-related differences, if any, for the treatment of this issue. In addition, the evaluation should take into consideration existing data and analyses that might be available, for example, in the case of an existing nuclear site or, perhaps, a Brownfield site. In these cases, an environmental justice analysis may have been previously completed and evaluated. An environmental justice analysis will not have been completed for a Greenfield site.

It is important to note that while this parameter may have previously been evaluated, updated information will still need to be obtained to ensure that the situation has not changed since the last review.

Evaluation Criteria - An "Acceptable Site" evaluation occurs when no low income or minority populations are identified near the site or along transmission or transportation routes.

A "Challenged Site Requiring Further Evaluation" occurs when low income and minority populations are identified near the site or along transmission and transportation routes.

A "Site Not Suitable" evaluation cannot be achieved at this stage because such a determination is dependent upon the failure of the mitigation options to be applied. Environmental justice mitigation requires detailed analysis and incorporates decision-making not available during the site suitability assessment process.

\section{Environmental Justice Analysis:}

To identify low income and minority populations, a geographical information system (GIS) based analysis should be performed. Environmental Systems Research Institute (ESRI) data can be used for the initial screening.

According to LIC-203, a "minority population" is considered to be present if: (1) the minority population in the census block group or environmental impact site exceeds 50 percent, or (2) the minority population percentage of the environmental impact area is significantly greater (typically at least 20 percentage points) than the minority population percentage in the geographic area chosen for the comparative analysis, for example, the county or state.

A "low-income population" is considered to be present if: 1) the low-income population in the census block group or the environmental impact area exceeds 50 percent, or 2) the percentage of households below the poverty level in an environmental impact area is significantly greater (typically at least 20 percentage points) than the low-income population percentage in the geographic area chosen for the comparative analysis.

Using these thresholds, identify the U.S. Census blocks and block groups that exceed the criteria as listed above. The result is the identification of the regional low income and minority populations.

Risk - There is no risk of application rejection from the NRC due to this issue. However, this issue is easily contested legally which could lead to extensive site alteration and mitigative efforts that could cause the site to be unreasonably expensive.

Risk Mitigation - By performing an extensive environmental justice review, the anticipated impacts to the identified low income and minority population can be evaluated. If it can be argued that the impacts are not disproportionate, then the risk of mitigation and site alteration is reduced. 


\section{REFERENCES:}

1. Executive Order 12898 (59 FR 7629), "Federal Actions To Address Environmental Justice In Minority Populations and Low-Income Populations."

2. Council on Environmental Quality "Environmental Justice” Dec 10, 1997.

3. U.S. Nuclear Regulatory Commission, Regulatory Guide 4.7 "General Site Suitability Criteria for Nuclear Power Stations." "

4. NRR Office Letter No. 906 Rev 1, "Procedural Guidance for Preparing Environmental Assessment Considering Environmental Issues."

5. NRR Office Instruction No. LIC-203, Rev 1 "Procedural Guidance for Preparing Environmental Assessments Considering Environmental Issues."

6. U.S. Nuclear Regulatory Commission, NUREG-1555, SRP 2.5.4 "Environmental Justice." 
Appendix C - Templates for Evaluating Site Characteristics

Appendix C-3d

Socioeconomic Effects 


\section{SITE CHARACTERISTIC: $\quad$ SOCIOLOGICAL IMPACTS / SOCIOECONOMIC EFFECTS}

\section{DESCRIPTION:}

The potential for impacting local and regional communities can be caused by a variety of factors during the construction and operation of a nuclear plant. The impacts on regional communities, transportation facilities, and community services should all be reviewed. The community infrastructure and services that are impacted may require mitigation before a regulatory licensing action can be completed. In many cases, the mitigative efforts can be achieved through coordination between the applicant and the local community and government agencies; however, some of these efforts could prove quite expensive. This template will focus on using the guidance of the U.S. Nuclear Regulatory Commission (NRC) to evaluate whether a site has issues that will reduce the likelihood of producing a successful application.

\section{IMPORTANCE:}

The NRC will evaluate the impact of construction and operation on the local labor supply, transportation facilities, taxes, schools, police resources, fire-fighting resources, potable water, wastewater, historical characteristics, distinguished cultural characteristics, and any other local infrastructure that may be impacted. If any significant impacts are found, the NRC will look for coordination between the applicant and the impacted communities for the resolution of these issues.

\section{RISK:}

The NRC will evaluate the suitability of a site including consideration of purpose and probable adequacy of socioeconomic impact mitigation plans for such economic impacts on any community where local acceptance problems can be reasonably foreseen.

\section{EVALUATION:}

\section{Acceptable Site}

\section{Challenged Site Requiring Further Evaluation}

\section{Site Not Suitable}

\section{DISCUSSION:}

The siting, construction, and operation of a nuclear power station may have significant impacts on the socioeconomic structure of a community and stress the local labor supply, transportation facilities, and community services in general. There are often changes in the tax base and in community expenditures due to additional population (e.g., construction and operational workforces). In addition, the "boom and bust" cycle of population, and its associated impacts, often caused by a construction workforce is carefully reviewed by the NRC.

Site Type - The evaluation should identify the type of site being evaluated, i.e., a "Greenfield," "Brownfield," or "existing nuclear power plant" site. The evaluation should identify the unique applicability of site type-related differences, if any, for the treatment of this issue. In addition, the evaluation should take into consideration existing data that might be available, for example, in the case of an existing nuclear site or, perhaps, a Brownfield site. In these cases a socioeconomics analysis may have been previously completed and evaluated. It is important to note that while this parameter may have been previously evaluated, updated information will still need to be obtained to e7nsure that important conditions have not changed since the last review.

Evaluation Criteria - An "Acceptable Site" for the suitability evaluation is one that does not exceed the capacity or adequacy of any of the existing or currently-planned infrastructure or community services.

A "Challenged Site Requiring Further Evaluation" is one in which the capacity of existing or currently-planned infrastructure or community services is exceeded but can be reasonably mitigated. 
A "Site Not Suitable" evaluation occurs when the capacity of existing or planned infrastructure and community services will be exceeded and it is not reasonable to mitigate impacts.

Local Labor Supply:

The effects on the regional labor supply due to plant construction and operation could cause a regional labor shortage and affect the regional communities. This can be predicted using local unemployment reports. If the unemployment rate is high for the region, the addition of new jobs is favorable to the communities in the region. If there is a labor shortage, the impacts may require mitigation. This information can be obtained from the Bureau of Labor Statistics and can be obtained at a county and state level.

\section{Transportation Facilities:}

The current transportation system should be evaluated to determine if the addition of workforce vehicles and construction and operational deliveries would cause an impact. To be conservative, an estimation of one vehicle per person would be sufficient for this level of review. If the current transportation system cannot handle the number of cars and trucks expected to be present during peak construction, mitigation efforts may be required. To evaluate this issue, the Highway Capacity Manual, published by the Transportation Research Board, provides information on the Quality of Service (QOS) and capacities of highways within the United States. With this information, calculate the current capacity of roads leading to the site. Estimate the number of vehicles and deliveries required for the construction and operation of the planned plant and identify if the road exceeds its current capacities. If the traffic is expected to exceed the capacity of the current transportation system, mitigation may be warranted.

\section{Community Services:}

If community service capacity such as police, fire fighting, schools, potable water, and waste water will be exceeded during construction or operation, mitigation may be warranted. To evaluate this category, gather information related to local social services (hospitals, police, firefighters, schools, etc.). Next, compare the police to citizen, firefighter to citizen, doctor to citizen, and student to teacher ratios, to state and national averages. Then, compare the current water and wastewater capacities to the anticipated impacts due to construction and operational workers water needs, as well as any plant operational water needs. If any of these comparisons indicate that the additional population and service requirements cause the current capacities to be exceeded, mitigation may be warranted.

\section{Fiscal Assessment:}

If a community is expected to be impacted and their infrastructure needs to be improved, the timing and amount of taxes used to make improvements needs to be evaluated. If any shortfalls are expected, a mitigation plan will need to be evaluated. The ownership of this mitigation will most likely be a collaborative effort between the applicant and the city or local government agency being impacted. This assessment is based on expected taxes paid by the plant, immigrating workers, and mitigative efforts. For this study, evaluate current tax information and see if local governments are experiencing budget shortfalls. If budget shortfalls exist then the community may be less able to upgrade any social services or transportation networks without financial assistance.

Risk - In cases where the local community resources are stressed (e.g., lack of available funding to upgrade services and resources), mitigative efforts may be required. In some instances, these efforts could become expensive.

Risk Mitigation - A full evaluation of the impacts on the communities will have to be evaluated. Mitigative efforts will have to be discussed with local authorities and thoroughly planned. Funding problems for these mitigative efforts through taxes will have to be resolved. 
Appendix C - Templates for Evaluating Site Characteristics

\section{REFERENCES:}

1. U.S. Nuclear Regulatory Commission, Regulatory Guide 4.7, "General Site Suitability Criteria for Nuclear Power Stations."

2. U.S. Nuclear Regulatory Commission, NUREG-1555, SRP 2.5.2, "Community Characteristics." 


\title{
Appendix C-4 \\ Other Site Characteristics Templates
}

\author{
Land Availability \\ Site Constructability Factors \\ Potential for Brownfield Contamination Issues
}

Features that Could Affect Development of Security Measures and Adequate Security Plans

Sample Template (with instructions) 
Appendix C - Templates for Evaluating Site Characteristics

\section{Appendix C-4a Land Availability}




\section{Site CHARACTERISTIC: $\quad$ OTHER / LAND AVAILABILITY}

\section{DESCRIPTION:}

This parameter includes the availability of necessary land area and buffer zones for the plant, including switchyard and transmission facilities, and the cost of acquiring of those lands. The necessary land area and buffer zones are described below.

For Brownfield sites, performing due diligence and any attendant regulatory-mandated cleanup activities should also be considered and identified for evaluation using the template for potential site decontamination issues.

\section{IMPORTANCE:}

Federal regulations including 10 CFR 100.21 and 10 CFR 100.3 require every site to have an exclusion area (EA) and defines that as the area surrounding the reactor, in which the reactor licensee has the authority to determine all activities including exclusion or removal of personnel and property from the area.

The specific requirements relative to the EA are given in 10 CFR 50.34(a)(1)(ii)(D) and specify that an individual located at any point on the boundary of the exclusion area for any 2 hour period following the onset of the postulated fission product release, would not receive a radiation dose in excess of 25 rem total effective dose equivalent (TEDE). It also states that an individual located at any point on the outer boundary of the low population zone (LPZ), who is exposed to the radioactive cloud resulting from the postulated fission product release (during the entire period of its passage) would not receive a radiation dose in excess of 25 rem TEDE.

A site should include enough contiguous land to meet the requirements summarized above.

Additionally, the cost to obtain the property and/or land rights may have a large effect on overall plant costs.

\section{RISK:}

The required EA size will be based on radiological criteria, as described in the siting template for Atmospheric Dispersion. The Nuclear Regulatory Commission (NRC) Staff will review the sizing of the EA and the licensee control over that area to ensure they meet the criteria in 10 CFR 50.34, 10 CFR 100.21 and 10 CFR 100.3.

If it is questionable whether there is sufficient land available at a cost that is acceptable, then it might not be possible to ensure that the EA size and control requirements will be met. Failure to meet EA size and control requirements could cause the site to be deemed unacceptable for licensing. The license applicant should have confidence that they will be able to provide the requisite level of control within the exclusion area boundary $(\mathrm{EAB})$.

\section{EVALUATION:}

\section{Acceptable Site}

\section{Challenged Site Requiring Further Evaluation}

\section{Site Not Suitable}

\section{DISCUSSION:}

Discuss the basis for the evaluation result, including the type of site evaluated, the information gathered, the evaluations examined or performed and the evaluation criteria. Where risks have been identified, discuss risk mitigation factors.

Site Type - Identify the type of site being evaluated, i.e., a "Greenfield," "Brownfield "or "existing nuclear power plant" site. The types of evaluations to be performed will depend on the site type. For an existing nuclear power plant site, land availability/cost might not be an issue. For a Brownfield 
site, the potential for regulatory-mandated cleanup activities should be evaluated, using the template "Potential for Brownfield Contamination Issues." For a Greenfield site, discuss the potential for compensatory environmental or land use reparations, which might be required to make up for the land lost to the plant.

Evaluation Criteria - A site may be evaluated as an "Acceptable Site" if it is determined that there is sufficient land in an appropriate configuration available at an acceptable cost to allow the plant facilities to be sited in such a way as to satisfy the requirements of 10 CFR 100 and 10 CFR 50.34 with respect to $\mathrm{EAB}$ and control.

A site may be evaluated as a "Challenged Site Requiring Further Evaluation" if it is found to be probably accepted upon further examination of certain problematic issues. Such issues might relate to permit issues, ownership boundary issues, compensation issues, site configuration issues (shape, affecting distance to nearest $\mathrm{EAB}$ ), transmission right of way issues, etc. A site also may be considered challenged if the cost of relocating an existing site structures or facilities has yet to be calculated.

A site may be evaluated as "Site Not Suitable" if it is estimated that the nearest EAB distance will not meet the requirements of 10 CFR 100 and 10 CFR 50.34 or if it has been determined that it would not be possible to demonstrate control over all of the activities within the EAB.

\section{Land Availability Analysis:}

The prospect of obtaining ownership or control over enough land to encompass the EA zone should be determined early in the site evaluation process. The licensee should have confidence that they will be able to provide the requisite level of control over the EA.

The Exclusion Area is that area surrounding the reactor in which the licensee has authority to determine all activities including exclusion or removal of personnel and property from the area. Specifically, applicants must ensure that there is adequate land area at the site so that an exclusion area can be established for the new unit(s) which satisfies the requirements of 10 CFR 100.

This area may be traversed by a highway, railroad, or waterway provided they are not so close to the facility as to interfere with normal operations and provided appropriate and effective arrangements are made to control traffic on highways, railroads, or waterways in case of emergency to protect the public health and safety. Residence within the exclusion area shall normally be prohibited. In any event, residents shall be subject to ready removal in case of necessity. Activities unrelated to operation of the reactor may be permitted in an EA under appropriate limitations provided no significant hazards to the public health and safety will result.

The evaluation should determine existing residence within the planned EA. Residence are normally not allowed or it should otherwise be determined that residents would be subject to ready removal in case of necessity. If it is determined that there will be activities in the nearby area that are unrelated to operations of the reactor, a site may be judged as challenged and additional evaluations conducted as necessary to determine if appropriate limitations can be placed on the activities, such that that no significant hazards to the public health and safety will result.

In determining land availability and cost acceptability, the evaluator should review land ownership records, aerial/satellite imagery, maps, and population data.

Risk - There is a risk of license application rejection from the NRC if other sites are deemed to be superior to the proposed site with respect to this issue. If site acquisition involves many displacements, or if site preparation involves major environmental disruption, then the desired site could be rejected by the NRC in favor of an alternative site or contested legally which could lead to extensive site alteration and mitigative efforts and cause the site to be unreasonably expensive to develop. 
Risk Mitigation - For sites where the prospective licensee may not currently have such control over the required land mass to secure a license, a review of ownership should be conducted. Where land ownership records are available they should be used. Alternatively, satellite photo images that are publically available can be used for a more qualitative assessment, e.g., is it farmland, approximately how many people live on the land, is there likely to be multiple owners of the land, etc. Review of as much data as can be obtained about land ownership and the likelihood of being able to acquire control over the land will reduce risks associated with this issue.

\section{REFERENCES:}

1. 10 CFR 100.21, "Non-Seismic Siting Criteria."

2. 10 CFR 100.3, "Definitions." 
Appendix C - Templates for Evaluating Site Characteristics

C-104 
Appendix C - Templates for Evaluating Site Characteristics

\section{Appendix C-4b Site Constructability Factors}




\section{SITE CHARACTERISTIC: OTHER / SITE CONSTRUCTABILITY FACTORS}

\section{DESCRIPTION:}

The feasibility of constructing a nuclear plant at a prospective site is dependent on two main issues: (1) the ability to deliver construction equipment and major plant components to the reactor location, and (2) the ability to deliver plant outputs desired by the customer, i.e., electricity to the transmission grid, process heat and/or steam to the required location, etc. Each of these parameters need to be met in a manner that is acceptable with respect to incurred cost. There are numerous other factors that have major impacts and/or risks to construction costs including the availability of an adequate and skilled work force, difficulty establishing a footprint for the reactor building, and availability of construction materials.

\section{IMPORTANCE:}

Overall construction costs can vary greatly from site to site depending in large part on the existing infrastructure surrounding the site. The plant must obviously connect to the utilities' electrical grid and there may be substantial obstacles to providing that connection for Brownfield and Greenfield sites. Factors include the relative difference in distance to the nearest load center, whether it is feasible to procure land for a right of way, and whether it is likely to receive approval from the Federal Energy Regulatory Commission (FERC) for a future transmission line.

Large reactor components must be delivered either by rail or by barge although some newer small modular reactor concepts are pursuing component transport via established roads. If the site is accessible by barge, this would offer a very good method of transporting heavy loads. If not, then a connection to an in-service railroad line may be a necessity. Similar to the transmission line, if the distance is too great, the land cannot be procured, or state approvals are unlikely, then it could be cost prohibitive to install a railroad spur to the site.

For locations where process heat and/or steam is a desired output, the feasibility of accomplishing construction in a cost effective manner without undue impact to the prospective customer must be analyzed. There are logistical limitations to providing process heat and/or steam especially if the customer facilities cover large areas of land. Information provided by the end use customer should be used to compare against plant design features of the proprietary reactor type and the site location relative to the end use location.

\section{RISK:}

The major risk factors include the ability to install transmission lines (if there are no existing lines), the ability to transport heavy loads associated with construction equipment and plant components to the site, and the ability to deliver sufficient process heat and/or steam to the desired location.

EVALUATION:

\section{Acceptable Site}

\section{Challenged Site Requiring Further Evaluation}

\section{Site Not Suitable}

\section{DISCUSSION:}

Discuss the basis for the evaluation result, including the type of site evaluated, the information gathered, the evaluations examined or performed and the evaluation criteria. Where risks have been identified, discuss risk mitigation factors.

Site Type - The evaluation should recognize the type of site being evaluated, i.e., a "Greenfield," "Brownfield "or "existing nuclear power plant" site. For an existing nuclear power plant site, constructability may not even an issue unless a new transmission line corridor is required or unique hazards are created for the existing operational plant. For a Brownfield or Greenfield site, however, this issue becomes increasingly more important. For example there must be a means to get

$$
\text { C-106 }
$$


construction equipment and large reactor components to the construction location. With little or no infrastructure available such as a railroad spur, new roads may be required to support construction.

Evaluation Criteria - A site may be evaluated as an "Acceptable Site" if it is determined that there is sufficient access to the transmission line grid, there is a means to get major plant equipment to the site, it is feasible to get process heat and/or steam to the required location as necessary, all in a cost effective manner.

A site may be evaluated as a "Challenged Site Requiring Further Evaluation" if the location might be found acceptable upon further examination of specific issues. Such issues can include permit issuance, ownership boundary issues, compensation issues, transmission right of way issues, etc. For sites requiring process heat and/or steam, the evaluator must look into the distance and traverse path available for getting the heat product to the desired location at the required design condition. A site also may be evaluated as challenged if the cost of installing a railroad spur or new transmission line has yet to be calculated.

A site may be evaluated as "Site Not Suitable" if it is determined not feasible to deliver either construction equipment or major plant components (e.g., reactor vessel) or it is judged cost-prohibitive to do so. A site may be evaluated as unsuitable if it is determined infeasible to provide transmission access or it is judged cost-prohibitive to do so. A site may be evaluated as unsuited if it is determined infeasible to provide process heat and/or steam at the required design conditions or it is judged cost-prohibitive to do so.

\section{Construction Cost:}

All of the following issues are related to plant construction cost. Some of these issues are capable of making a site unacceptable on its own individual merits. Construction challenges should be looked at from the whole and include considerations such as availability of a labor pool, terrain and volumes of earth and rock that must be moved, availability of concrete or the ability to make concrete on site, etc. The evaluator is responsible for identifying key construction issues applicable to the site and making an overall determination of acceptability.

Transmission Lines - The evaluator should determine whether existing transmission line capability is available to deliver power to and from the new reactor or whether a new transmission line is required. For an existing nuclear site this evaluation may only require a brief review to determine if there is sufficient capacity in the existing transmission lines to accommodate the new reactor. Alternatively, investigate the feasibility of installing a new transmission line within the existing right-of-way. For Brownfield and Greenfield sites the evaluator must review system grid drawings and determine available connection points. Then an assessment of potential locations for a right-of-way, obstacles to ownership of the property, and the likely regulatory issues that must be addressed is required.

Heavy Loads - For an existing nuclear site the shipment of heavy loads should not be problematic because it has been done in the past for that location. For Brownfield and Greenfield sites the evaluator must determine whether there is an acceptable way to get major plant components and construction equipment to the site. Barging is a good method if available. Rail shipments are also feasible as long as there is the possibility of connecting to an in-service rail line at a reasonable cost. Over the road transport of plant equipment is a consideration that must be evaluated in the context of proposed plant design and is a feature being promoted by certain small modular reactor concepts. The evaluator should identify the local rail lines and determine feasibility of installing a local spur, i.e., availability of the land, right-of-way access, and length of travel. The capacity of public road haulage must be assessed in the context of prerequisite requirements specific to the small reactor design being considered.

Process Heat - For locations where process heat and/or steam is an intended output the feasibility of accomplishing this in a cost effective manner must be analyzed. There are logistical limitations to providing process heat and/or steam especially if customer facilities cover large expanses of land. Information provided by the end user should be used to compare against design features of the reactor 
type and the site location relative to the end use location. The evaluator must consider the distance and traverse path to providing the desired heat product to the location at the required design conditions.

Labor Force - The construction of a nuclear power plant is very labor-intensive. With the possibility of a wave of new nuclear plants being constructed simultaneously there is likely to be a shortage of skilled field labor to complete the construction. Commuting distance proximity to a skilled labor pool may make one site much more favorable than another. The evaluator should make an assessment of the ability to retain a work force at the site during the construction period. Considerations include the ability of the community to support temporary workers. This item is further discussed in the Template on Socioeconomics.

Excavation - The amount of excavation and associated cost is likely to vary considerably from site to site. For an existing nuclear site, and probably for a Brownfield site, this should not be a significant factor unless bedrock is located relatively close to the surface. For a Greenfield site the evaluator should perform a high level review to determine the feasibility and potential costs associated with a major excavation. One consideration is the topography of the site and the amount of dirt that will require excavation in order to establish a footprint for the plant. For example, areas with slopes greater than $12 \%$ mean slope, or greater than 400 feet $(123 \mathrm{~m})$ relief within the minimum site area, would be considered unacceptable. The other consideration is the required depth of the reactor building versus the level at which bedrock exists. The evaluator should determine the approximate depth of the bedrock based on readily available geotechnical data of the region or other source of estimation and estimate the impacts of the existence of bedrock at the reactor building foundation.

Concrete Availability - Nuclear plant construction typically requires large quantities of concrete to be available. If the site is not located near a cement factory or rock quarry such that concrete can be manufactured locally, it may make that site construction cost prohibitive.

Risk - Three construction risk parameters are so important that any one of them could, if appropriate mitigations are not found, render a candidate site unacceptable. These are plant access to appropriate capacity transmission lines (for nuclear power plants dedicated to generating electricity for the grid), accessibility of the site for heavy or oversized loads as defined by components and equipment necessary to build the plant, and the ability to supply heat to end use processes that conform to minimum underlying specifications set by the customer. Other issues may also challenge site constructability but past industry experiences generally offer cost-acceptable mitigation approaches.

Risk Mitigation - For each of the risk parameters an evaluation needs to be conducted early-on in the process because one could render the site unacceptable. Sites that may require a new transmission line corridor will require a review of ownership of land that would provide for the right-of-way. Where land ownership records are available they should be used. Alternatively, satellite photo images publically available can be used for a more qualitative assessment, e.g., is it farmland, approximately how many people live on the land, is there likely to be multiple owners of the land, etc. As much data that can be obtained about the ownership, and likelihood of being able to acquire control over the land will reduce the risk of this issue.

For sites that have no access to barge traffic a railroad spur or heavy haul roadway may be required. The evaluator should look at the accessibility to an in-service railroad line and the feasibility of installing a spur to the site. Again, where land ownership records are available they should used. Alternatively, satellite photo images publically available can be used for a more qualitative assessment, e.g., is it farmland, approximately how many people live on the land, is there likely to be multiple owners of the land, etc.

For sites requiring process heat and/or steam the distance that must be traversed may prohibit the site for use because the product cannot be delivered at the required design conditions. It is important to know precisely the design conditions required by the customer because there may be a design solution that can be considered. 


\section{Appendix C-4c Potential for Brownfield Contamination Issues}




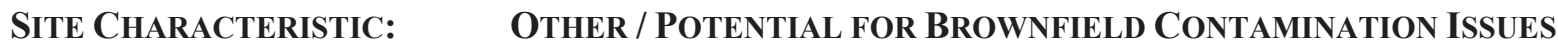

\section{DESCRIPTION:}

The potential for (residual) contamination(s) at a candidate site (i.e., Brownfield or existing nuclear power plant) may involve radiological contamination or non-radiological contamination. The potential contamination could be in any form and includes spills, settling ponds, buried solids, buried containers, gas containers and contaminated structures or equipment.

\section{IMPORTANCE:}

The possibility of residual contamination (most likely non-radioactive) at a Brownfield site can complicate excavation and construction and can greatly delay project activities while the contamination is adequately characterized and dispositioned. Similarly, new excavation at an existing nuclear plant site might encounter some form of contamination (radioactive or non-radioactive), though probably less likely. Extensive regulations come into play for decontamination activities and some situations may be subject to legal action or court order. Also, if contamination is discovered during the initial site suitability assessment or after construction activities begin, it might not be possible simply to ignore it. Therefore, if the evaluating client already owns the site property, then cleanup might be later mandated even if the site is not further developed.

\section{RISK:}

The risks associated with potential contamination at existing nuclear power plant site include the possibility that discovery of contamination and its subsequent treatment could hinder ongoing nuclear plant operations.

Brownfield site contamination evaluation risks include the possibility that the initial assessment grossly underestimates the extent of the contamination or that subsequent satisfactory treatment (i.e., removal/disposal) of the contamination might prove to be physically impossible or prohibitively expensive. Another risk is that the removal process could result in additional spread of contamination, further complicating the cleanup process and increasing the cost. Therefore, an accurate first assessment of the possibility of contamination is crucial.

\section{EVALUATION:}

\section{Acceptable Site}

\section{Challenged Site Requiring Further Evaluation}

\section{Site Not Suitable}

\section{DISCUSSION:}

The further development of existing nuclear power plant site and the redevelopment of Brownfield sites are subject to a variety of federal, state, and local laws, regulations, policies, and guidelines, including those related to the identification of site contamination and site cleanup. Such sites also may be governed by the standard practices of other government, nongovernment, and private institutions.

The Resource Conservation and Recovery Act (RCRA), enacted in 1976, is the principal federal law governing the disposal of solid waste and hazardous waste. The applicable laws, regulations, policies, and guidelines will vary by site, depending on the regulatory authority that manages the cleanup. Therefore, it is important to identify the appropriate regulatory agency(s), have them determine the site specific requirements and approvals/permits needed for invasive site investigations, and work closely with the appropriate regulatory authority throughout the cleanup process. The U.S. Environmental Protection Agency (EPA) also can be a valuable resource by providing regulatory and policy support to facilitate selection of technologies. 
Several steps are involved in determining the potential for and extent of contamination of a site. These include coordinating with the pertinent regulatory agencies, retaining the services of a consultant to carry out the site investigations, and conducting the necessary investigations that may include site sampling and analytical laboratory analysis. Procuring the services of qualified and experienced subject matter experts are an important step in determining the existence and extent of contamination, if any, on a Brownfield site.

Site Type - Contamination issues are primarily associated with "existing nuclear power plant" sites and Brownfield sites. The evaluator should identify the prior use of the candidate site to aid in the identification of possible contaminants and the development of the appropriate evaluation techniques.

Evaluation CRITERIA - Non-Radiological Contamination Potential:

An "Acceptable Site" would be one where metals or limited chemicals are present at background levels or otherwise make it a Brownfield with limited public risk.

A "Challenged Site Requiring Further Evaluation" would be exemplified by a RCRA closure site or site managed under state RCRA rules. Many materials are often not defined as hazardous by EPA but meet a more stringent state definition for regulate metals or other chemicals. Alternately, the extent of contamination requires an environmental assessment for the purpose of providing sufficient information regarding the nature and extent of contamination to assist in making informed business decisions about the property.

A "Site Not Suitable" would contain materials that are listed or characteristically hazardous and result in a potentially large risk of metals and/or chemicals.

EVAluation CRITERIA - Radiological Contamination Potential:

"Acceptable site" has no residual contamination or no possibility to cause a water pathway that will result in a radiological dose via the water pathway beyond regulatory limits.

A "Challenged Site Requires Further Evaluation" means the extent of contamination requires an invasive environmental assessment characterization for the purpose of providing sufficient information regarding the nature and extent of contamination to assist in making informed business decisions about the property.

"Site Not Suitable" indicates a real possibility exists that will result in a radiological dose via the water pathway beyond regulatory limits.

Fundamentally, any site possessing a history of radiological contamination should have no way to cause a water pathway radiological dose beyond regulatory limits. Most states have established cleanup standards for legacy site contamination. Many states also recognize two different land reuse scenarios in relation to meeting applicable standards, i.e. rural/residential and commercial/industrial, with the former generally requiring a more rigorous control strategy than the latter. A Brownfield site generally has stronger justification to use an industrial release risk assessment scenario for subsequent reuse rather than the residential/farmer scenario. For existing nuclear power plant sites there will be readily available data to support an assessment of cost due to the requirements in 10 CFR $50.75(\mathrm{~g})$, "Reporting and Recordkeeping for Decommissioning Planning," and participation in the Nuclear Energy Institute (NEI) Groundwater Protection Initiative Program.

The critical cost of a decommissioning project is the volume of soil that must be removed during final decommissioning. The single driver for this cost is the concentration that meets final release, defined by the U.S. Nuclear Regulatory Commission (NRC) as 25 mrem to a member of the public. This is calculated with "RESRAD", a U.S. Department of Energy (DOE) computer model that the NRC has endorsed as the standard calculation method. The water pathway associated with the residential farmer scenario will significantly reduce the concentrations that can be left behind at site release. 
An industrial release can increase the radiological concentrations allowed to remain after remediation by an order of magnitude or more for some isotopes. There are a number of pathways that can be analyzed in the model depending on the approved release scenario. For an industrial scenario, water and food pathways are eliminated and site exposure time is significantly reduced. This in turn has the effect of leaving a higher level of contamination in place when the site is released for reuse. It is identical to a-risk based Brownfield scenario which assumes that a site will be industrial or in some other way used to limit exposure pathways and duration.

\section{Contamination Analysis:}

A due diligence environmental assessment should be conducted to ascertain the nature and scope of an identified contamination. This assessment is the systematic determination of the potential for environmental conditions, issues, and liabilities at a Brownfield site. Since by their nature Brownfield sites are considered to be impacted in some degree by past uses and therefore the potential does exist for the presence of legacy contamination, environmental due diligence is essential to successful Brownfield site transaction and redevelopment. Implementing this assessment activity support two basic objectives:

Transactional: In order to provide assurance for lenders, investors and other stakeholders involved with the property transaction

Legal: To meet liability protection and regulatory obligations under federal and state environmental laws, as applicable.

An environmental assessment is the first step in evaluating the potential environmental issues with a Brownfield site. It generally involves a review of readily available information on the potential presence of contamination, the potential, existing or past contaminant releases, and the possible paths of exposure that would be of concern. Interviews with community members and others can also be conducted to determine past practices associated with a particular site. This initial effort could be combined with developmental data gathering, particularly in regard to the potential land use for the site. An assessment can provide information to developers, municipal planners and the community early in the assessment process on potential environmental concerns which would be helpful in initial planning regarding land use and the viability of the property for redevelopment.

A component of this process is All Appropriate Inquiry (AAI). EPA defines All Appropriate Inquiry as the requirements for assessing the environmental conditions of a property prior to its acquisition. AAI is a Phase I process identified in the Brownfield Law and as such, EPA Brownfield Grantees are required to assess and characterize properties in accordance with AAI standards. Such inquiries must be conducted or updated within one year prior to the date of acquisition of a property. If all appropriate inquiries are conducted more than 180 days prior to the acquisition date, certain aspects of the inquiries must be updated.

The inquiries must be conducted by a Qualified Environmental Professional (QEP) which is defined as "someone who possesses sufficient specific education, training, and experience necessary to exercise professional judgment to develop opinions and conclusions regarding conditions indicative of releases or threatened releases of hazardous substances on, at, in, or to a property, sufficient to meet the objectives and performance factors of the rule." (American Society for Testing and Materials [ASTM] International's E1527-00 standard, "Standard Practice for Environmental Site Assessments: Phase I Environmental Site Assessment Process" may be used to comply with the AAI requirements.)

The AAI generally includes:

- Interviews with past and present owners, operators and occupants;

- Reviews of historical sources of information

- Reviews of federal, state, tribal and local government records 
- Visual inspections of the facility and adjoining properties

- Commonly known or reasonably ascertainable information

- Degree of obviousness of the presence or likely presence of contamination at the property and the ability to detect the contamination

- Searches for environmental cleanup liens

- Assessments of any specialized knowledge or experience of the prospective landowner (or grantee)

- An assessment of the relationship of the purchase price to the fair market value of the property, if the property was not contaminated; and commonly known or reasonably ascertainable information.

More information on EPA's AAI rule can be found at http://www.epa.gov/Brownfields/regneg.htm.

\section{$\underline{\text { Site Reconnaissance }}$}

A site reconnaissance supplements the Phase I assessment by visually observing the site and its surrounding areas. This reconnaissance should expand the understanding of site conditions. Specific objectives of the reconnaissance include documenting the physical features of the site (i.e., dimensions, buildings etc.) and the surrounding area, recording any differences from the information gathered in the Phase I, identifying any sources of hazardous substances and pathways that may be of concern, and identifying any new features that may have an impact in the assessment and decision regarding the site. Preparation for the reconnaissance will include reviewing all information garnered from the Phase I, arranging for site access, and identifying any health and safety concerns.

Risk - One potential risk is site rejection because the possibility exists to cause a water pathway that will result in a radiological dose to the water pathway beyond 4 mrem.

A second risk is that site contamination might be more extensive or pervasive than the initial feasibility assessment was able to determine. This can lead to unexpected delays and expense later in the site development phase.

If the evaluating client already owns the site, another risk is that the discovery of contamination, itself, whether or not the site is selected, might require the contamination to be addressed.

Risk Mitigation - A follow-on (Phase II) environmental assessment can be performed to better characterize the hazard. This assessment involves the collection of media samples, the testing of the samples in an appropriately accredited laboratory and then comparing the results to environmental media standards established by the state and/or federal government. The sampling can include:

- Building interiors

- Soil samples from suspected impacted areas

- Ground water samples and water level measurements

- Surface water and sediment samples

- Soil gas samples to evaluate for the potential for vapor intrusion

- Background soil samples to establish base line conditions

- Ecological conditions evaluation

- Presence of historic fill.

If the Phase II assessment identifies impacts over applicable standards, then further study is needed to delineate the impact and determine the risk associated with the impact. A Site Feasibility Assessment culminates in the selection of a Remedial Action, which includes the identification and engineering 
analysis of remedial action alternatives for the site which are cost-effective and consistent with the development requirements (i.e., proposed use, critical time schedule, funding goals). During this phase, remedial action objectives are identified, technologies or approaches that meet those objectives are screened, and detailed engineering analysis is conducted.

Another aspect of the feasibility assessment is to perform small tests of potential remedial treatment options on site specific samples. This is called bench scale treatability studies and involves exposing contaminated soil from the site to various types of treatment liquids and concentrations. This is most appropriate when considering an in situ remedial technology such as enhanced biodegradation, chemical oxidation or thermal desorption.

A Remedial Investigation (RI) can be performed, which includes the activities needed to collect data to characterize the horizontal and vertical extent of contamination; identify potential sources of continued contamination including the presence of "hot spots"; determine the surface and subsurface characteristics of the site including soil characteristics and depth to groundwater; and assess risk to human health and environment through the identification of paths of exposure and actual or potential receptors.

There are a wide range of remedial options available for cleaning up impacted sites. These range from simple excavation of impacted soil from a tank leak to complex multiple phases of injection of treatment liquids to remove concentrated volatile organic compounds (VOCs). Various web sites are available that list remedial technologies and describe their application, cost and effectiveness. Several are:

- Federal Remediation Technologies Roundtable (www.frtr.gov)

- Green Remediation Web (http://www.clu-in.org/greenremediation/)

- Interstate Technology and Regulatory Council (www.itrcweb.org)

- Brownfields and Land Revitalization Technology Support Center (www.Brownfieldstsc.org).

\section{REFERENCES:}

1. Brownfield Site Contamination Investigation, NJIT (http://www.njit.edu/tab/managing/pre-development/contamination-investigation.php).

2. "Road Map to Understanding Innovative Technology Options for Brownfields Investigation and Cleanup," Based on the Fourth Edition published in September 2005 (EPA-542-B-05-001) (http://www.Brownfieldstsc.org/roadmap/home.cfm).

3. The Brownfields and Land Revitalization Technology Support Center (http://www.Brownfieldstsc.org/). 


\section{Appendix C-4d Features that Could Affect Development of Security Measures and Adequate Security Plans}




\section{Site Characteristic: $\quad$ OTHER / Features that COULD AFFECT DEVELOPMENT OF SECURITy Measures AND Adequate SeCURITy Plans}

\section{DESCRIPTION:}

According to 10 CFR 100.21(f), "Site characteristics must be such that adequate security plans and measures can be developed." A key parameter in this site characteristic is sufficient site area such that adequate security standoff distances can be established and there are no public transportation routes that traverse the site.

\section{IMPORTANCE:}

Physical protection requirements for nuclear power plants as well as special nuclear materials are described in 10 CFR Part 73. Security plans and measures are important to prevent plant damage and possible radiological consequences to members of the public as a result of acts of sabotage.

\section{RISK:}

If the distance to the nearest exclusion area boundary is greater than 360 feet (110 meters), the site characteristics are not normally limiting with regard to the ability to develop adequate security plans. Additional design features, analyses, or other requirements may be necessary if the required standoff distances cannot be satisfied by the site layout and boundaries.

\section{EVALUATION:}

\section{Acceptable Site}

\section{Challenged Site Requiring Further Evaluation}

\section{Site Not Suitable}

\section{DISCUSSION:}

Generally, a distance of about 360 feet (110 meters) to any vital structure or vital equipment would provide sufficient space to satisfy security measures of 10 CFR 73.55 (e.g., protected area barriers, detection equipment, isolation zones, vehicle barriers). If the distance to a vital structure or vital equipment is less than about 360 feet (110 meters), special measures or analyses may be needed to show that adequate security plans can be developed.

A possible exception occurs if the exclusion area is traversed by a highway, railroad, or waterway. Traversal of such routes through the exclusion area is permitted, provided they are not so close that they interfere with normal operations of the facility, and provided appropriate and effective arrangements have been made to control traffic on such routes in case of emergency. If a transportation route passes closer than about 360 feet (110 meters) to a vital structure or vital equipment, special measures or analyses may be needed to show that adequate security plans can be developed.

If the site being evaluated is co-located with other facilities, or will have interfaces with other facilities, impediments and/or challenges to cyber security implementation should be considered and evaluated. For example, if onsite and/or offsite emergency planning communications will be integrated, cyber security requirements would apply.

Site Type - The evaluation should identify the type of site being evaluated, i.e., a "Greenfield," "Brownfield," or "existing nuclear power plant" site. If a candidate site is considered a Brownfield site and has experienced previous industrial use, or the site is associated with an existing nuclear power plant, existing security measures and plans may be available for review to determine acceptability of the additional of new nuclear plant capacity on the site. But, because the physical security measures and plans are unique to each site and somewhat dependent on the type of facility technology being utilized (i.e., location of vital areas for the technology may differ), an analysis 
would still be necessary to adequately identify the risks to development of security measures and plans. The same strategy would be necessary for a Greenfield site.

Evaluation Criteria - The site should be classified as "Acceptable Site" when the site is sufficiently large to accommodate the necessary standoffs (i.e., greater than 110 meters standoff), and there are no public roadways, waterways or railroads that traverse the site. There should be no significant anticipated cyber security challenges.

The site should be classified as "Challenged Site Requiring Further Evaluation" when the site boundary must be somewhat less than the generally acceptable standoff distance of 110 meters, or there are transportation routes that traverse the site, but where security measures to protect the plant are still considered possible; or if significant cyber security challenges and anticipated.

A "Site Not Suitable" evaluation might be warranted for an extremely small area site with very short standoff distances to vital equipment areas.

For the evaluation parameters, evaluation criteria for identifying issues that could prevent establishment of adequate security measures or security plans should include site area, reactor plant layout or plot plan with identification of plant vital areas and equipment locations from the technology vendor(s), and data that adequately describes the locations and distances from the candidate plant to nearby transportation routes (highways, railroads, waterways).

Risk - According to RG 4.7, if the distance to the nearest exclusion area boundary is greater than 360 feet (110 meters), and if nearby transportation routes pass farther than about 360 feet (110 meters) to a vital structure or vital equipment, the site characteristics are not normally limiting with regard to the ability to develop adequate security plans. Additional design features, analyses, or other requirements may be necessary if the required standoff distances cannot be satisfied by the site layout and boundaries.

Risk Mitigation - If the distance to the nearest exclusion area boundary is greater than 360 feet (110 meters), or if a transportation route passes closer than about 360 feet (110 meters) to a vital structure or vital equipment, special measures or analyses may be needed to show that adequate security plans can be developed.

\section{REFERENCES:}

1. 10 CFR 100.21, "Non-seismic siting criteria," paragraph 10 CFR 100.21(f).

2. U.S. Nuclear Regulatory Commission, Regulatory Guide 4.7, "General Site Suitability Criteria for Nuclear Power Stations - Industrial, Military, and Transportation Facilities."

3. U.S. Nuclear Regulatory Commission, NUREG-0800, SRP 2.2.1-2.2.2, "Identification of Potential Hazards in Site Vicinity."

4. SECY 2007-0167, Regulation of Advanced Nuclear Power Plants; Statement of Policy.

5. 10 CFR Part 73, Physical Protection of Plants and Materials; 10 CFR 73.55, "Requirements for Physical Protection of Licensed Activities in Nuclear Power Reactors Against Radiological Sabotage."

6. 10 CFR Part 73, Physical Protection of Plants and Materials; 10 CFR 73.54, "Protection of Digital Computer and Communication Systems and Networks." 
C-118 


\section{Appendix C-4e Sample Template}

(With instructions) 


\section{NOTE TO EVALUATORS}

This is an example format of the information that site characteristic templates should include. There are two kinds of information to be included: (1) site characteristic-related information; and (2) a summary or description of the assessment data and methods that are to be used to perform the assessment.

Identify the site characteristic using the hierarchical format shown below.

SITE CHARACTERISTIC: $\quad$ (Identify the site characteristic and whether it is related to health/safety, environmental, sociological, or other considerations.)

\section{DESCRIPTION:}

(Describe the site characteristic. Include descriptive information found in appropriate regulatory guidance documents, such as RGs (including RG 1.206, if a COLA is involved), NUREG-0800, 10 CFR sections, etc.

The fundamental question to answer is "What are the key features of this characteristic to consider in the evaluation?" The emphasis is on existing regulatory considerations for obvious reasons. The same critical features that the NRC will evaluate should be evaluated herein. However, other considerations that affect site suitability for the project (e.g., economic) also might be identified.

If the description of the site characteristic would be different for different reactor technologies, then differentiate that discussion here.)

\section{IMPORTANCE:}

(Describe the site characteristic importance. The reactor General Design Criteria might be applicable. However, use any information sources, including NRC Safety Evaluation Reports, your own expert knowledge, etc., to put the characteristic into perspective and provide a frame of reference for the evaluation in weighing relative importance of the various features of the characteristic.)

\section{RISK:}

(Identify major risks associated with failing to successfully meet the selected characteristic as well as the feasibility of risk-mitigation measures for various features of the parameter. For example, is the site feasible for constructing dams, dikes, drains, etc. in the case of flooding, or might it be feasible to increase the elevation of the site using engineered fill, etc.

Also, provide guidance for grading risks such that a semi-quantitative evaluation can be made. For example, probable maximum flood $(P M F)$ elevation $=5 \mathrm{ft}$ below plant grade could be an “Acceptable Site." PMF elevation > 5 ft above plant grade could mean "Site Not Suitable." There could be other gradations or scales, depending on the individual parameter and its features.)

EVALUATION:

\section{Acceptable Site}

\section{$\square$ Challenged Site Requiring Further Evaluation}

\section{$\square$ Site Not Suitable}

\section{DISCUSSION:}

Site Type - (The evaluation should identify the type of site being evaluated, i.e., a "Greenfield," "Brownfield " or existing nuclear power plant site. Additional site types can be added in response it project needs. The evaluation should identify the unique applicability of site type-related differences, if any, for the treatment of this issue.)

Evaluation Criteria - (Identify the criteria for each of the three possible evaluation outcomes. The evaluator is to determine the significant factor(s) applicable to their subject and articulate them in 
this section along with acceptance values or guidance for determination of acceptability and should be as specific and detailed as feasible. The Standard Review Plan (NUREG-0800) provides insight as to areas of review by the NRC Staff and should be consulted, as appropriate, to ensure that the evaluation is sufficiently comprehensive.)

[NOTE: There may be multiple features to be discussed for any particular characteristic.]

(The evaluator should identify existing data and analyses that were used for the evaluation. Methods may be different for different site types, for example, an existing nuclear site or a "Brownfield site.")

[NOTE: There may be multiple features to be discussed for any particular characteristic.]

Risk - (The template should clearly articulate the risks factors associated with the analysis or assumptions. The discussion of each risk factor should include the relevance of the site type to the level of risk.)

[NOTE: There may be multiple features to be discussed for any particular parameter.]

Risk Mitigation - (The question that we are attempting to answer is "What do we do if we do not fully meet the evaluation criteria?"

A risk mitigation/management strategy should be discussed here. What are the likely next step(s).

Typically, they might involve additional investigation and might include field work such as obtaining borings for further analysis. They might also include obtaining additional data and performing calculation(s) or analysis.)

[NOTE: There may be multiple features to be discussed for any particular site characteristic.]

\section{REFERENCES:}

(Provide a list of all technical and regulatory references used in the preparation of the template, as well as known references that could aid the evaluation. This may include computer-modeling references, industry guidance, helpful websites, etc. 
C-122 


\section{APPENDIX D \\ EMERGENCY PLANNING TEMPLATE - ADDENDUM}




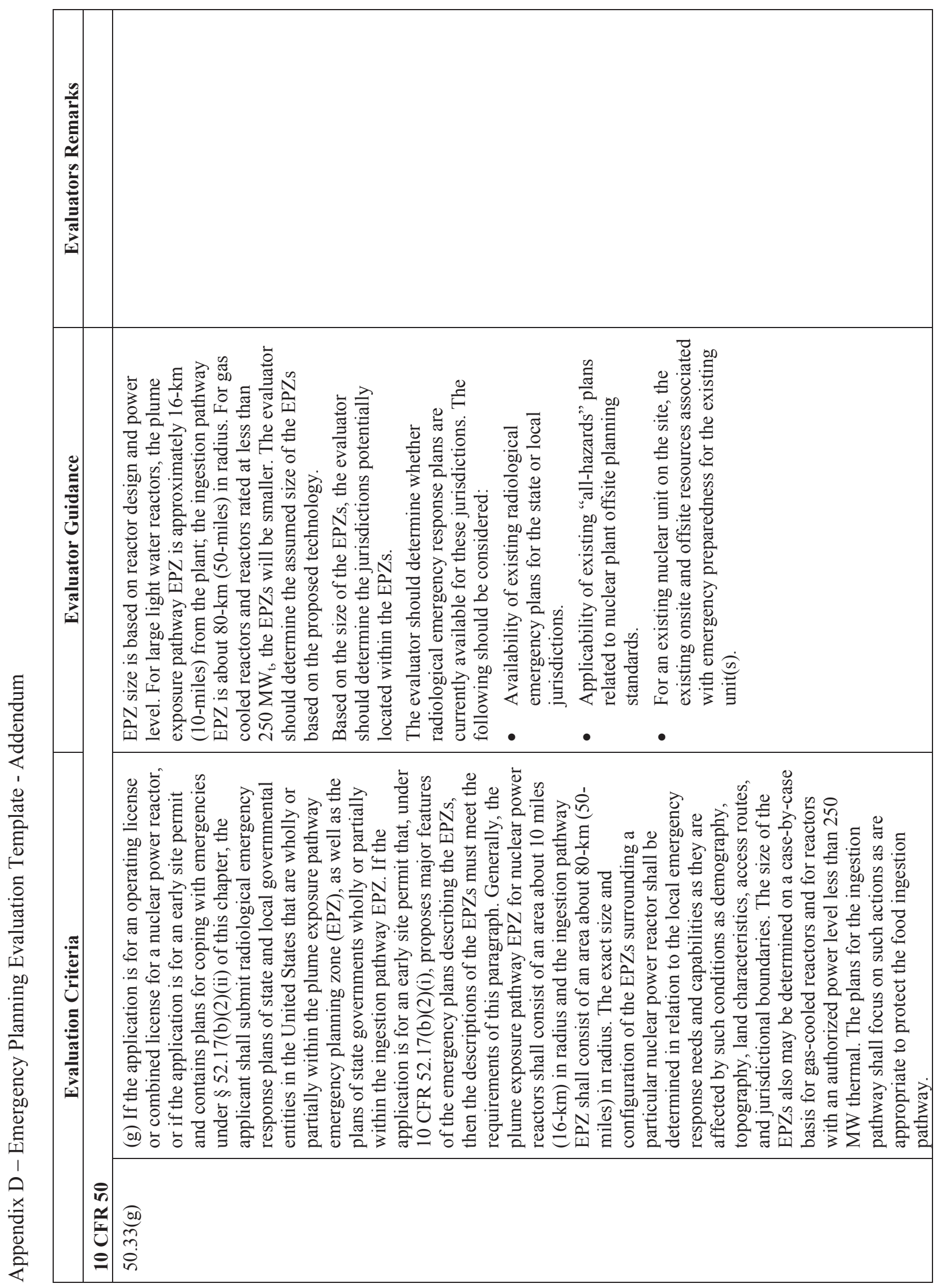




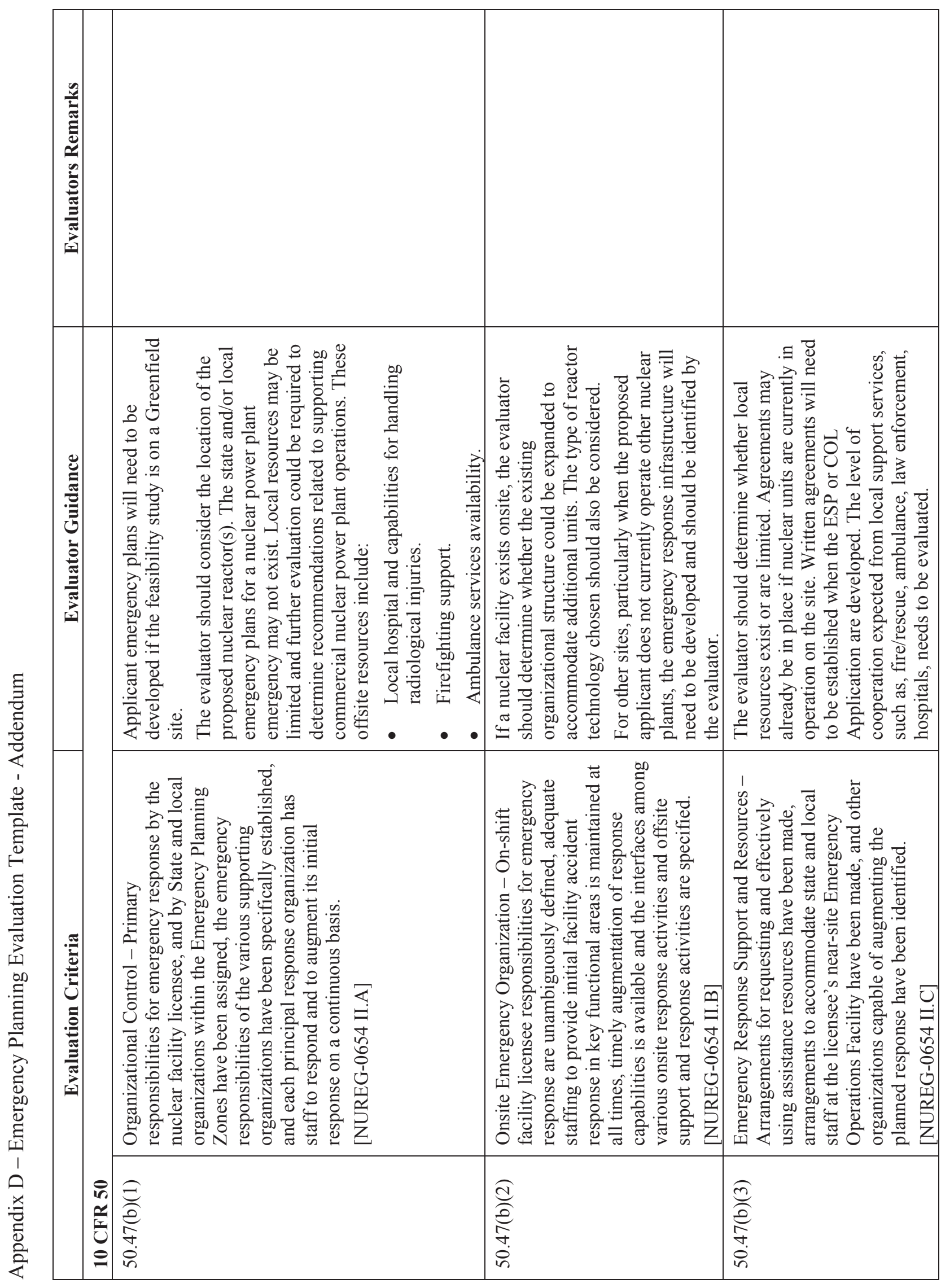




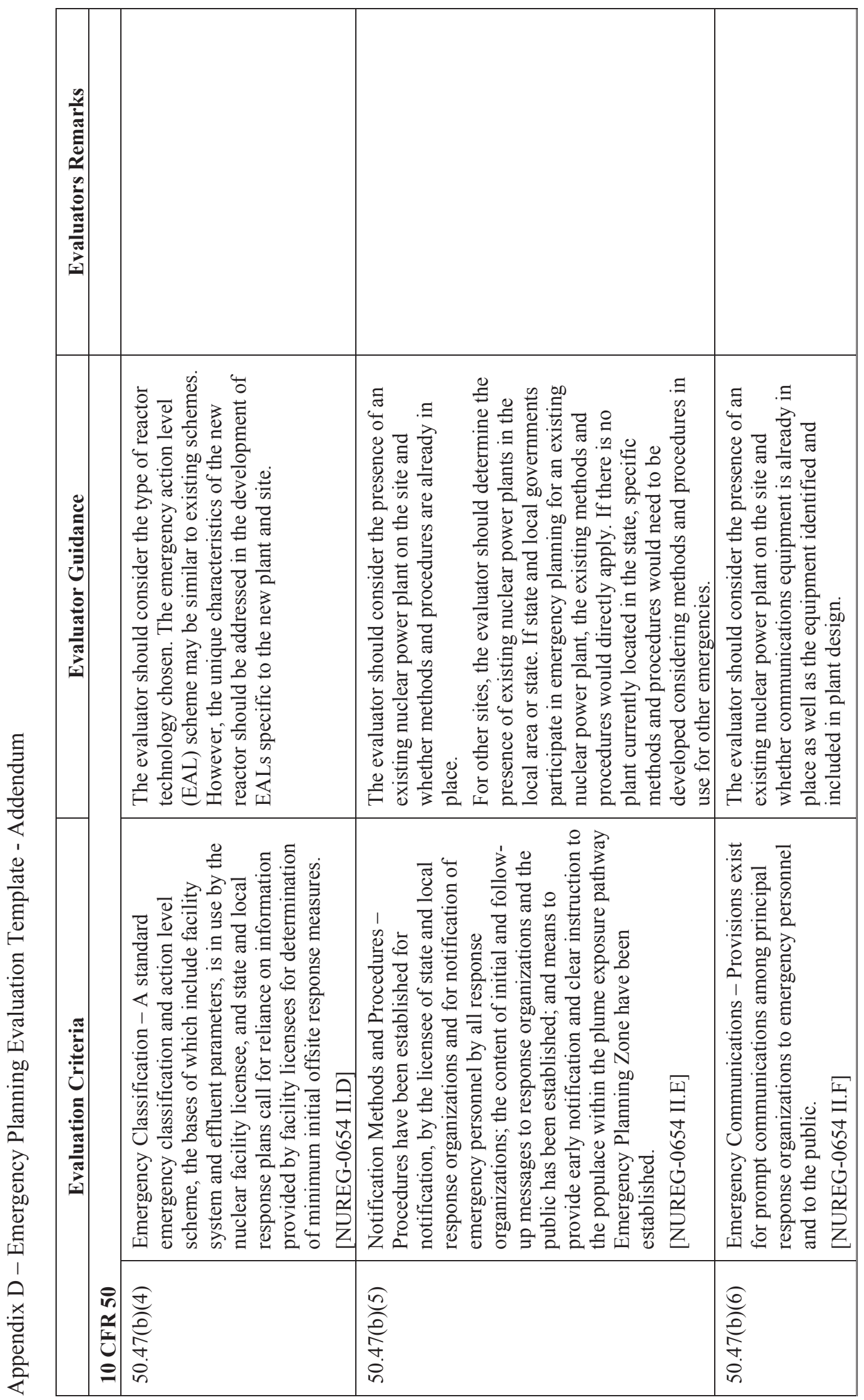




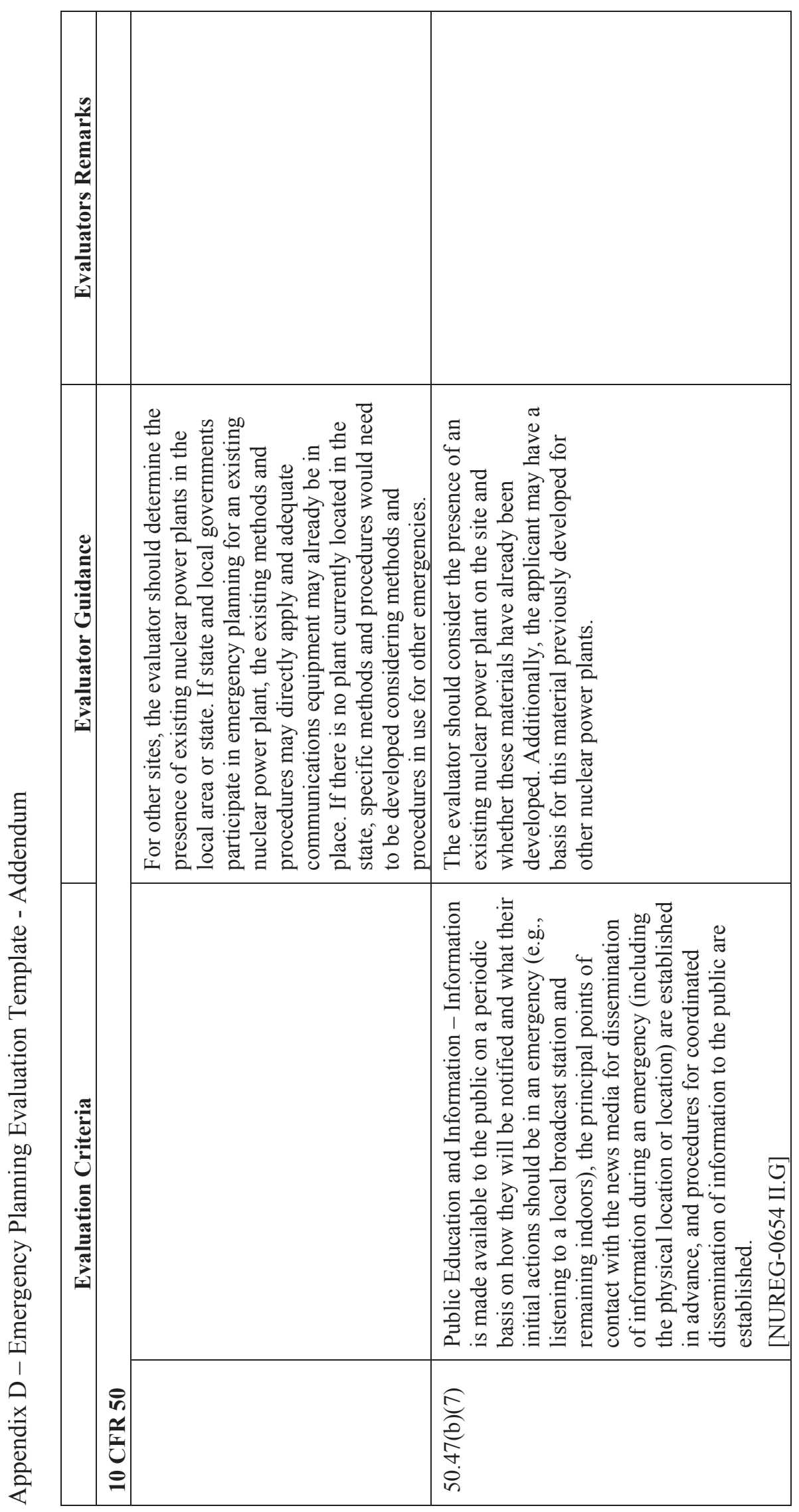




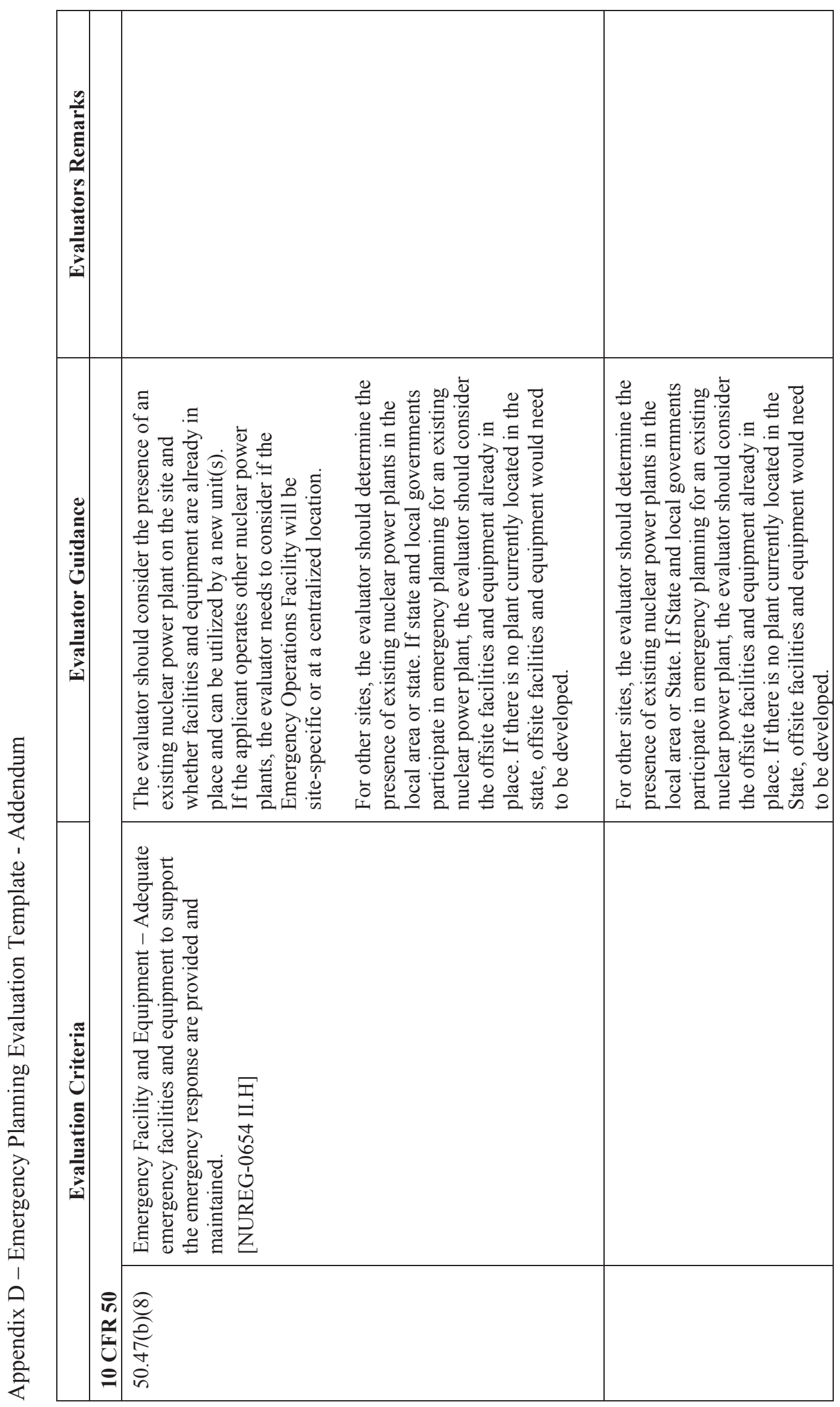




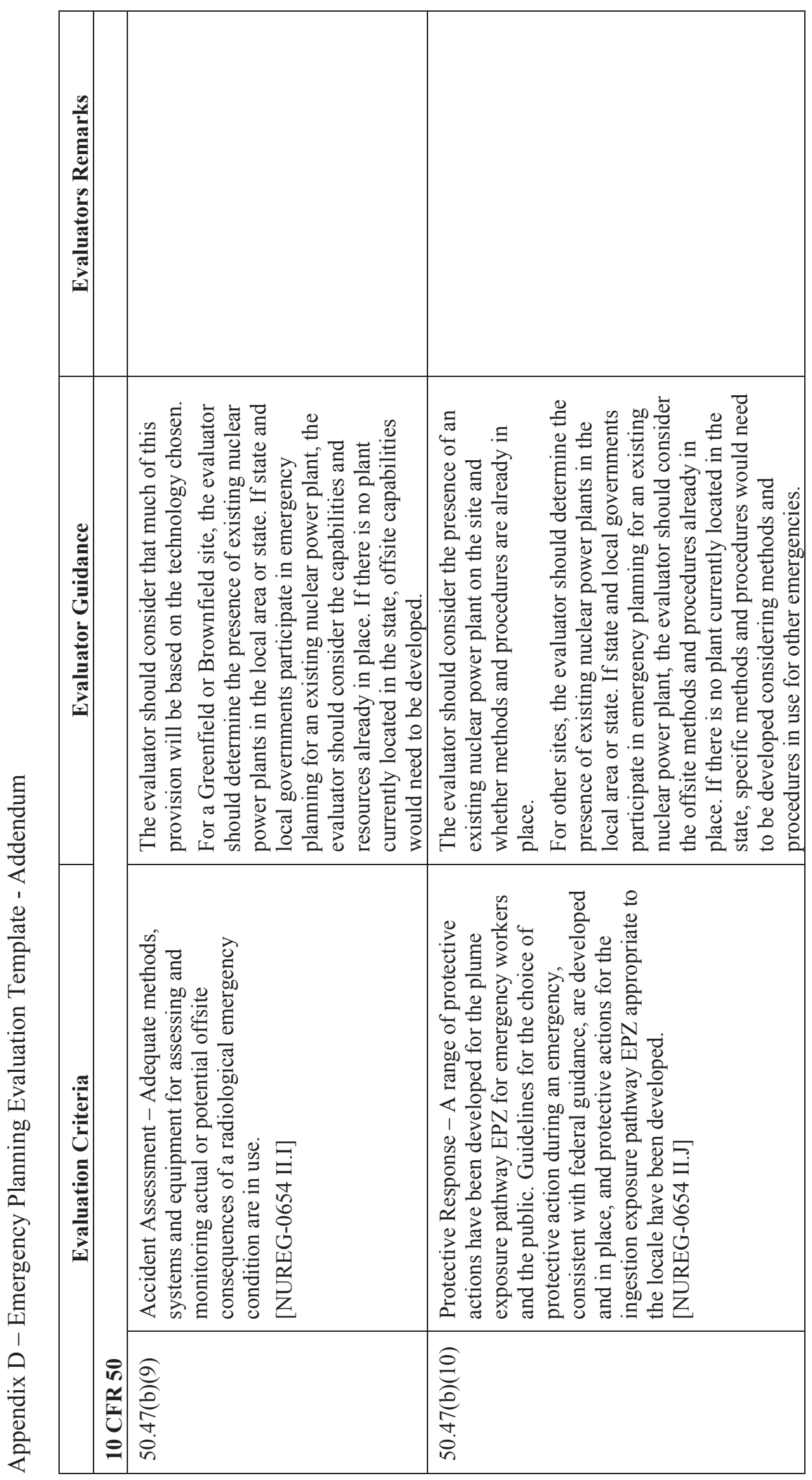




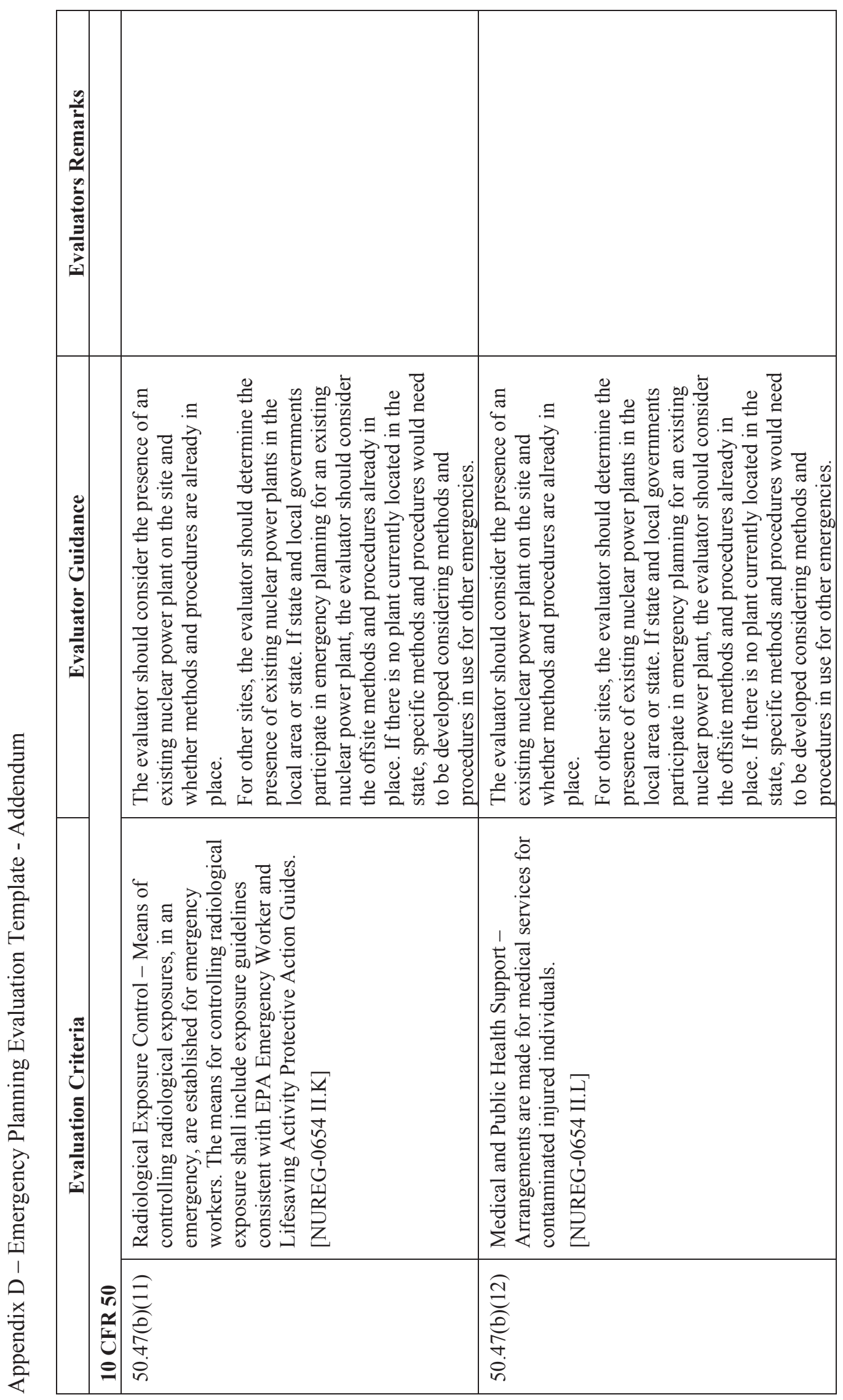




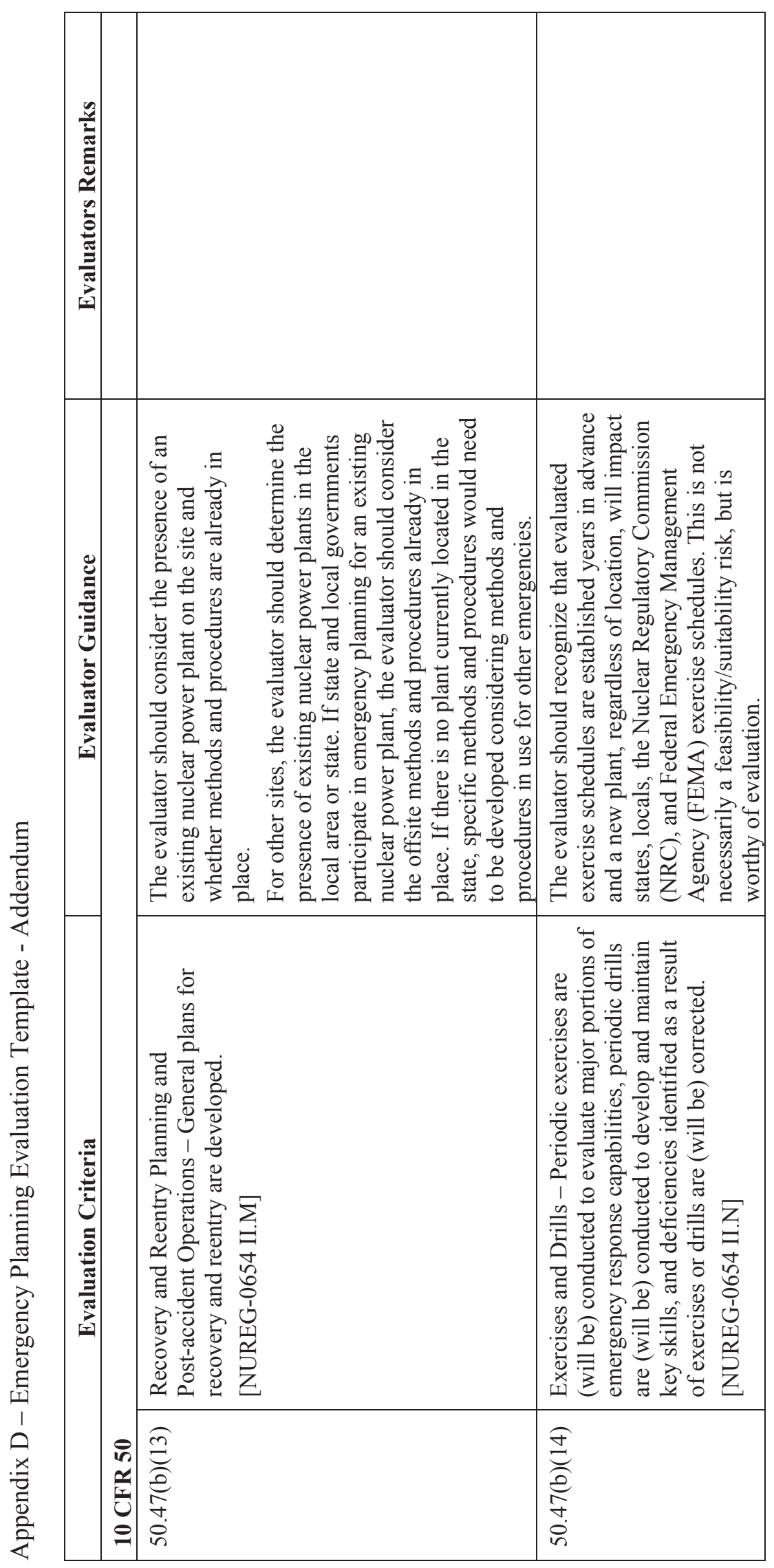




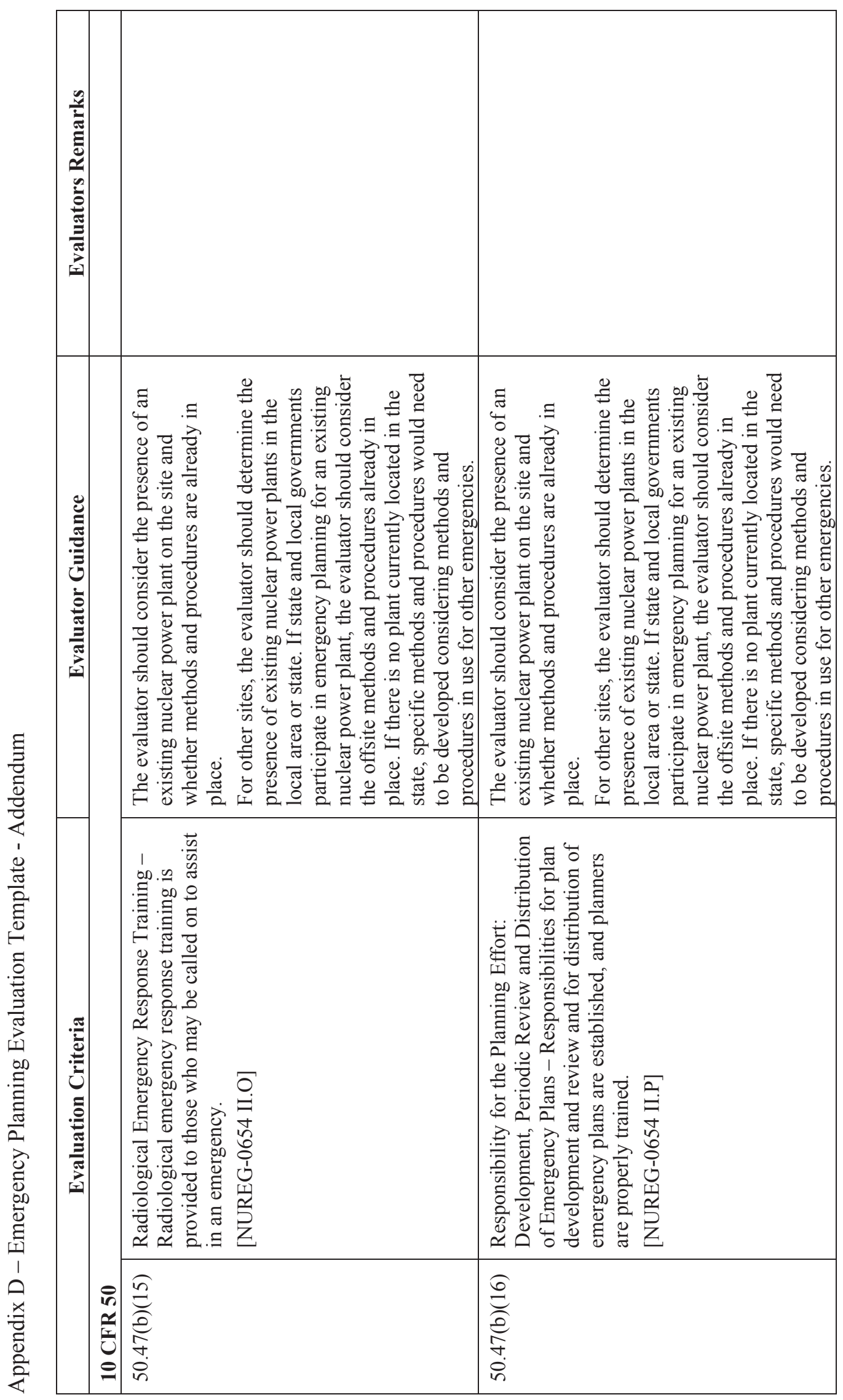




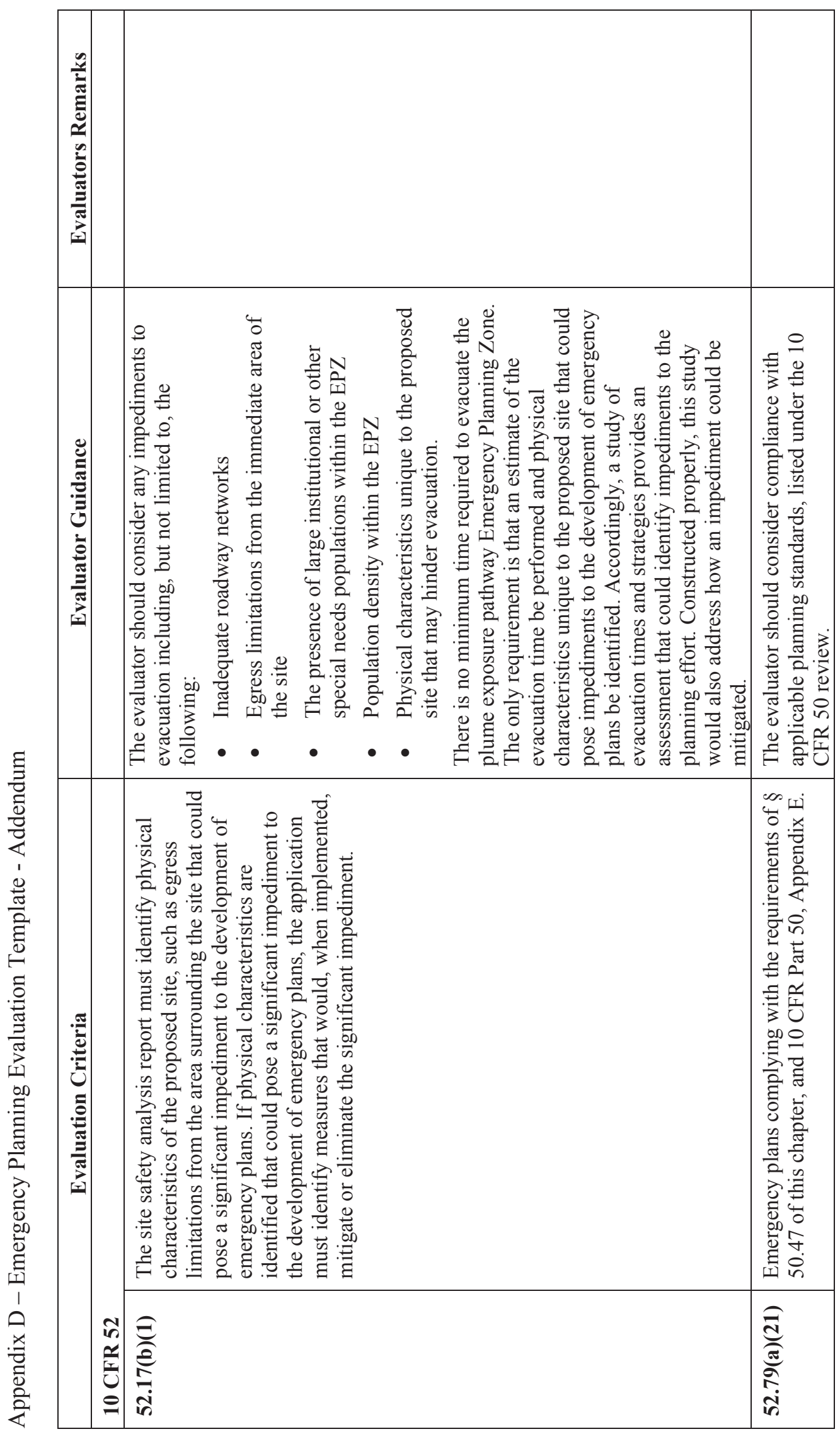

$\bar{b}$ 


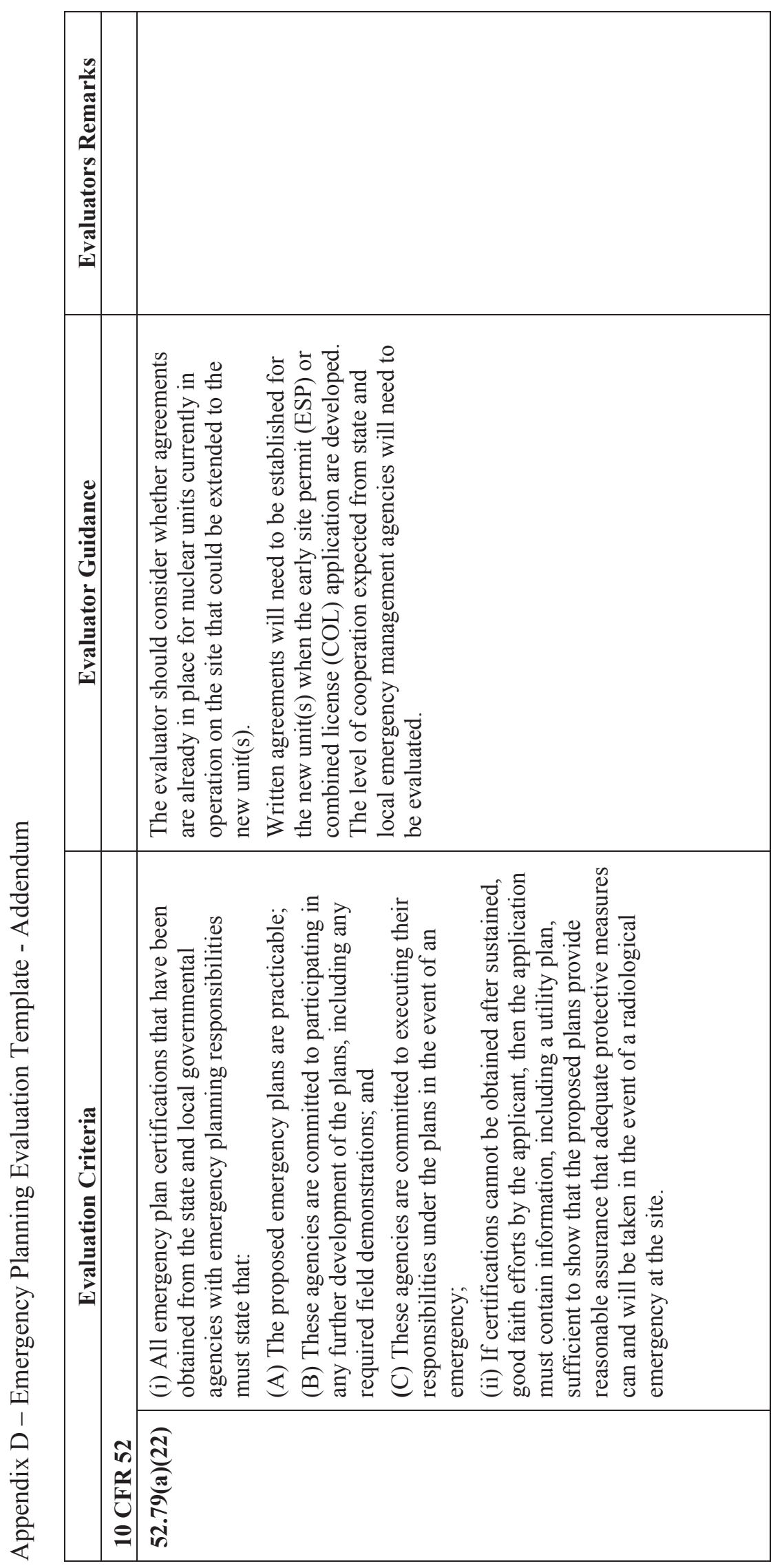

$\frac{9}{d}$ 


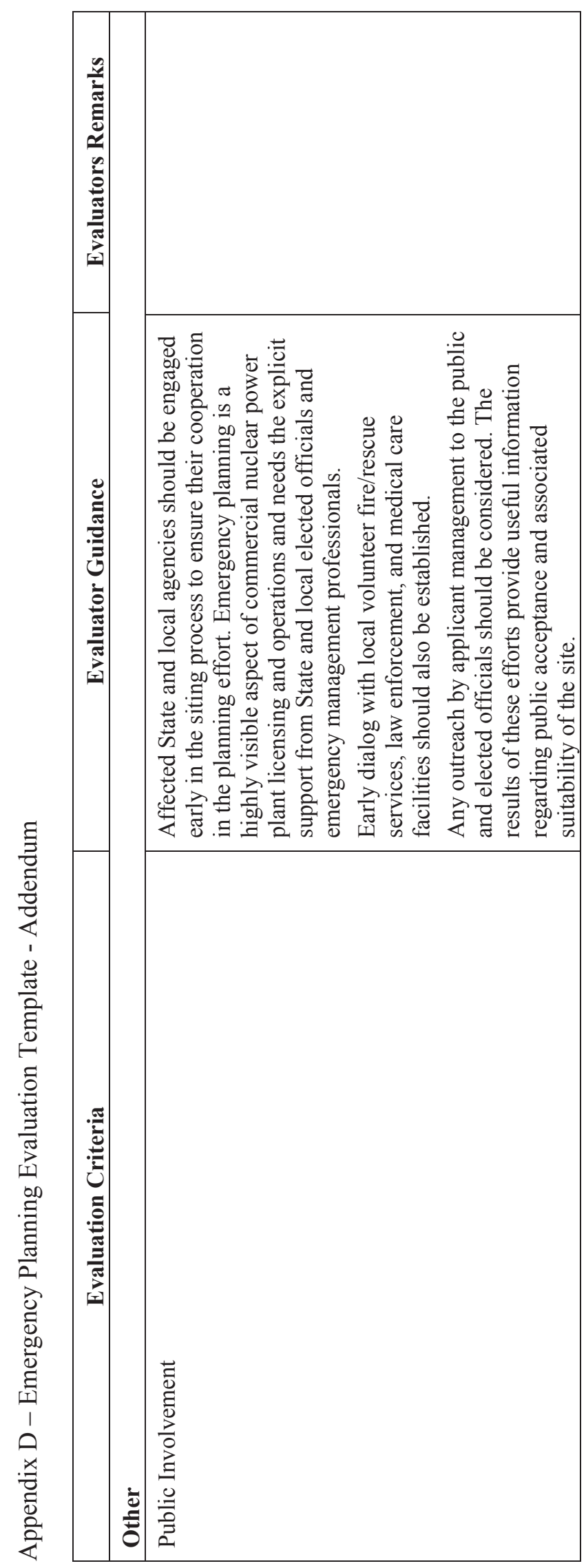

$\stackrel{m}{0}$ 